Florida International University FIU Digital Commons

FIU Electronic Theses and Dissertations

University Graduate School

6-29-2018

\title{
Gender, Party, and Political Communication in the 114th Congress
}

Maria Gabryszewska

Florida International University, mgabr009@fiu.edu

DOI: $10.25148 /$ etd.FIDC006893

Follow this and additional works at: https://digitalcommons.fiu.edu/etd

Part of the American Politics Commons

\section{Recommended Citation}

Gabryszewska, Maria, "Gender, Party, and Political Communication in the 114th Congress" (2018). FIU Electronic Theses and Dissertations. 3744.

https://digitalcommons.fiu.edu/etd/3744

This work is brought to you for free and open access by the University Graduate School at FIU Digital Commons. It has been accepted for inclusion in FIU Electronic Theses and Dissertations by an authorized administrator of FIU Digital Commons. For more information, please contact dcc@fiu.edu. 


\section{FLORIDA INTERNATIONAL UNIVERSITY}

Miami, Florida

\section{GENDER, PARTY, AND POLITICAL COMMUNICATION IN THE $114^{\text {th }}$ CONGRESS}

A dissertation submitted in partial fulfillment of

the requirements for the degree of

DOCTOR OF PHILOSOPHY

in

POLITICAL SCIENCE

by

Maria I. Gabryszewska

2018 
To: Dean John F. Stack, Jr.

Steven J. Green School of International \& Public Affairs

This dissertation, written by Maria I. Gabryszewska, and entitled Gender, Party, and Political Communication in the $114^{\text {th }}$ Congress, having been approved in respect to style and intellectual content, is referred to you for judgment.

We have read this dissertation and recommend that it be approved.

Todd Makse

Kyle Mattes

Nicole Kashian

Kevin Evans, Major Professor

Date of Defense: June 29, 2018

The dissertation of Maria I. Gabryszewska is approved.

Dean John F. Stack, Jr. Steven J. Green School of International \& Public Affairs

Andrés G. Gil

Vice President for Research and Economic Development and Dean of the University Graduate School

Florida International University, 2018 
(C) Copyright 2018 by Maria I. Gabryszewska

All rights reserved. 


\section{DEDICATION}

I dedicate this dissertation to my family. Dla moich rodziców, and my siblings Stan and Emily: thank you for all that you do; I would not be who I am without you. Your love and support encourages me to follow my heart and achieve my goals.

To the friends who became family, your care and joy always has and will continue to nurture my spirit. Thank you.

Lastly, to my sweetheart Luis - thank you for keeping me grounded, cared for, and loved. All that coffee you prepared for me has led up to this moment! 


\section{ACKNOWLEDGMENTS}

I wish to thank all the members of my committee, including those who have passed, for their immense support throughout the dissertation process. Dr. Rebecca Salokar helped me acclimate to life in graduate school, going beyond the role of mentor to ensure I felt welcome. Dr. Kevin Hill was a jovial presence, his quick wit and helpful comments aiding my learning process through coursework and the dissertation. They will be missed.

A huge thank you goes to Dr. Kevin Evans for his continued encouragement. His wholehearted effort stepping into the role of major professor inspired me to keep at it, both with my dissertation and throughout the job search process. The countless hours Dr. Evans has spent giving nuanced feedback and guidance pushed me to excel, and I cannot thank him enough for it. While the circumstances under which Dr. Todd Makse and Dr. Kyle Mattes joined my committee were heartbreaking, I have truly appreciated how they stepped forward to aid my completion of the dissertation, and successfully navigate the academic job search. I also thank Dr. Nicole Kashian for joining my committee and helping me to the finish line. FIU is truly fortunate to have all of you as professors.

To my colleagues and friends, I thank you for your time and talents. Your wisdom and humor truly made graduate school a memorable, life-changing experience - just ask Zenel.

To Bibek, Biva, and Prakash - thank you for making our little house a home. 


\title{
ABSTRACT OF THE DISSERTATION \\ GENDER, PARTY, AND POLITICAL COMMUNICATION IN THE \\ $114^{\text {th }}$ CONGRESS
}

\author{
by \\ Maria I. Gabryszewska \\ Florida International University, 2018 \\ Miami, Florida \\ Professor Kevin Evans, Major Professor
}

This dissertation investigates the interaction of gender and party in the political communication of members of Congress (MCs). The study focuses on the tweets of all MCs in the House of Representatives during two weeks of the $114^{\text {th }}$ Congress $(9,374$ tweets from $431 \mathrm{MCs})$. I conduct an in-depth content analysis of these tweets to extract important message characteristics related to issue areas, electoral behaviors, and constituency targeting.

I find that MCs emphasize their partisan ties when they tweet about women's or men's issues, but Democratic congresswomen and Republican congressmen go further to address feminine and masculine issue areas respectively. In their electoral behaviors, congresswomen posted more advertising tweets than congressmen, especially Republican congresswomen. Republican congresswomen took individual credit for legislation at high rates and shared very little, while Democratic congresswomen shared credit almost as much as they took individual credit. Furthermore, while both Democratic and Republican congresswomen see themselves as "surrogate representatives" (Carroll 2000) of the women beyond the boundaries of their districts, Democratic congresswomen target national 
constituencies significantly more often than their colleagues. These results provide evidence that gender is not enough to understand how MCs communicate - the key lies at the nexus of gender and partisanship. 


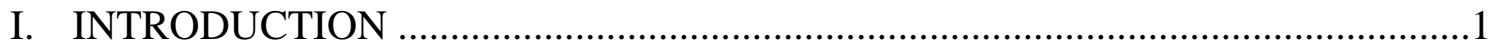

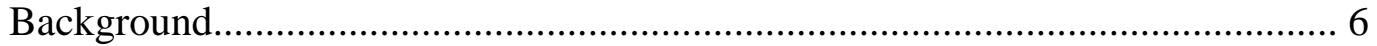

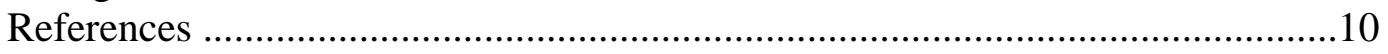

II. GENDERED ISSUE AREAS IN CONGRESSIONAL TWEETS ...................... 20

Literature Review ……………….................................................. 22

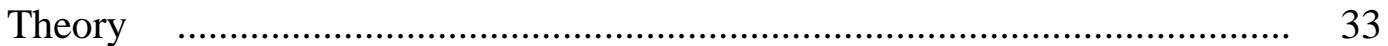

Data and Methods ............................................................................... 38

Quantitative Results of Gendered Issue Areas in Congressional

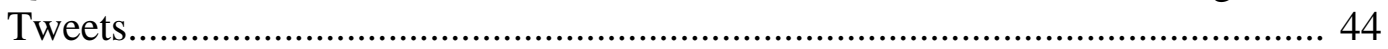

Qualitative Analysis of Gendered Issue Areas in Congressional

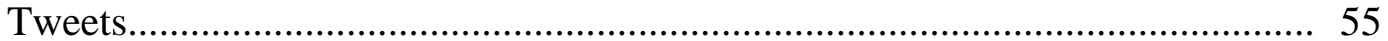

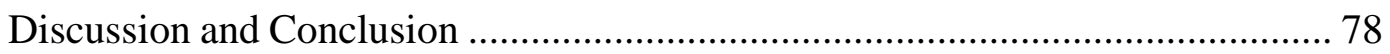

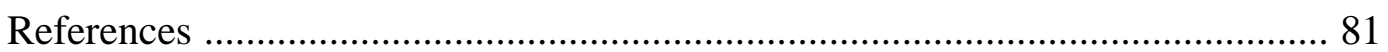

III. GENDERED MAYHEWIAN BEHAVIOR AND CREDIT CLAIMING

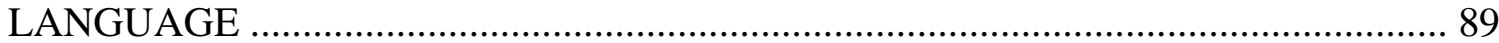

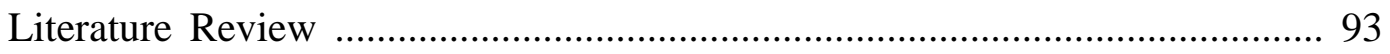

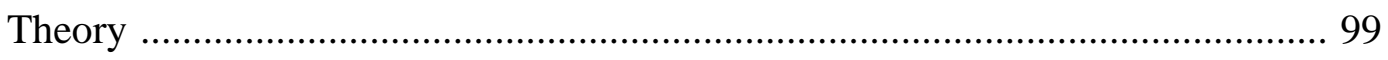

Data and Methods ............................................................................... 105

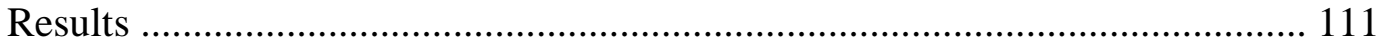

A Deeper Examination of Credit-Claiming Tweets ........................................... 129

Discussion and Conclusion ...................................................................... 146

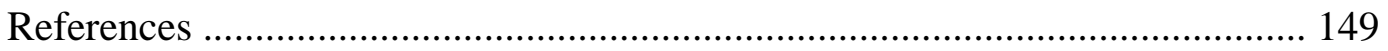

IV. GENDERED POLITICAL COMMUNICATION AND SURROGATE REPRESENTATION IN CONGRESSIONAL TWEETS ......................................... 154

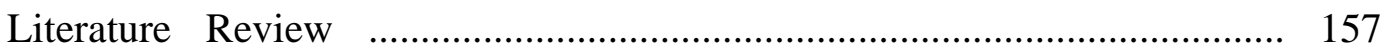

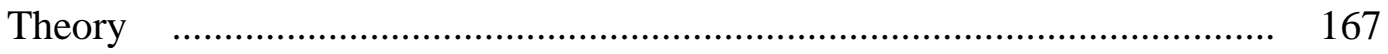

Data and Methods …n..................................................................... 170

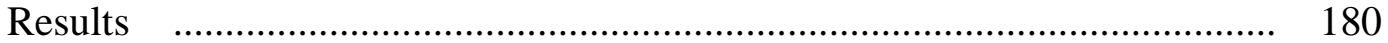

Discussion and Conclusion .............................................................. 184

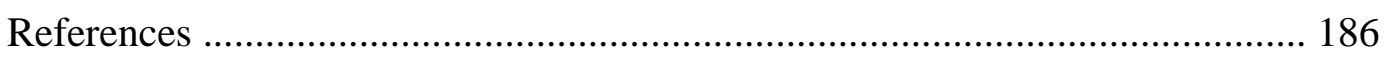

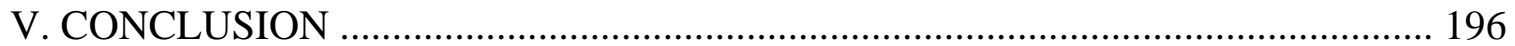

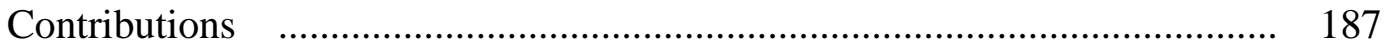

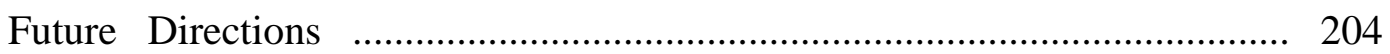

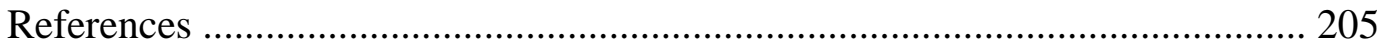

VITA 


\section{LIST OF TABLES}

TABLE

PAGE

1. Chapter 2, Table 1: "Women's Issue" Mentions in Congressional Tweets.................47

2. Chapter 2, Table 2: "Men's Issue" Mentions in Congressional Tweets......................48

3. Chapter 2, Table 3: Congressional Tweets Mentioning "Women's Issues" ..............53

4. Chapter 2, Table 3: Congressional Tweets Mentioning “Men's Issues” ....................54

5. Chapter 3, Table 1: Coded Mayhewian Tweets by Congressmember's Gender.......112

6. Chapter 3, Table 2: Mayhewian Tweets by Congressmembers' Gender and Party

7. Chapter 3, Table 3: The Impact of Gender and Party on the Number of Advertising Tweets and Retweets

8. Chapter 3, Table 4: The Impact of Gender and Party on the Number of Position-Taking Tweets and Retweets.

9. Chapter 3, Table 5: The Impact of Gender and Party on the Number of Credit Claiming Tweets and Retweets.

10. Chapter 3, Table 6: Differences in Mayhewian Tweet Behavior Compared to Lawless (2012) Study

11. Chapter 3, Table 7: Congressmembers Dissemination of Information on Twitter... 125

12. Chapter 3, Table 8: Congressional Tweets about Appearances

13. Chapter 3, Table 9: Credit Claiming Gendered Language

14. Chapter 4, Table 1: Sample Characteristics of Twitter Using Representatives $114^{\text {th }}$ Congress.

15. Chapter 4, Table 2: Influence of Gender on the Number of District-Target Tweets 181

16. Chapter 4, Table 3: Influence of Gender on the Number of National-Target Tweets 


\section{LIST OF FIGURES}

FIGURE

PAGE

1. Chapter 3, Figure 1: Word Cloud of Credit Claiming Tweets..................................130

2. Chapter 4, Figure 1: Gendered Home Style with added Surrogate Representation

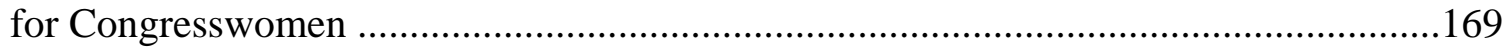

3. Chapter 4, Figure 2: Total Tweets for all Representatives on Twitter.........................176

4. Chapter 4, Figure 3: Total Tweets by Gender of Representatives .............................177

5. Chapter 4, Figure 4: Total Tweets by Gender and Party ID ..................................178

6. Chapter 4, Figure 5: National Targeted Tweets .....................................................179 


\section{CHAPTER I: INTRODUCTION}

"Glossy mailers and the six o'clock news are no longer how members of Congress reach their constituents. Our constituents want us to speak to them where they are, and that's online, so I am happy to oblige. However, you're competing with a lot of other noise online, so we have to be creative and avoid clichés to break through. Going this path is cheaper, more immediate, involves more two-way communication, and, in the end, is more meaningful to the debate."

-Rep. Mark Takano (D-CA) (Suebsaeng 2013)

Politicians are driven by electoral incentives to shape public opinion about themselves, their party, and their performance in office. While the American public may overwhelmingly disapprove of the way Congress as a whole is handling its job (reaching a record 9\% approval in 2014), ${ }^{1}$ the fact is that members of Congress (MCs) still enjoy high reelection rates - in 2016, 97\% remained in the House of Representatives, $90 \%$ in the Senate $^{2}$. Politicians do their best to maintain a favorable image with their constituencies, using district casework, gaining district funding, working on party maintenance, and strategically explaining their vote choices (see Crisp et al. 2004, Buck and Cain 1990, Fenno 1978, Mayhew 1974) to deter potential candidates (Carson, Engstrom, and Roberts 2007). Since congresswomen have the perception that their gender additionally factors

${ }^{1}$ Gallup poll. http://www.gallup.com/poll/1600/congress-public.aspx

${ }^{2}$ Incumbency advantage tends to be observed in advanced democracies such as the UK (Carey and Shugart 1995) or Ireland (Redmond and Regan 2015), while research on developing democracies finds the incumbency effect may hurt reelection chances (Eggers et al. 2014). Emerging democracies may observe this effect when a strong legislator exists - strong legislatures produce electorally strong incumbents (Opalo 2014). Scholars such as Lenz (2012) challenge the assumption that voters are the ones guiding the reigns, positing that politicians steer voters to their position stances; they choose their preferred candidates and adapt their positions to what either the candidate or party says. 
against them (which comes from a documented reality - see Streb et al. 2008), they devote more time and energy to secure more funding for their district (Anzia and Berry 2011), deliver more speeches on the House floor than their male colleagues (Pearson and Dancey 2011), have higher participation on floor debates regarding women's issues (Walsh 2002; Swers and Caiazza 2000; Tamerius 1995), sponsor more bills (Pearson 2013; Anzia and Berry 2011), and their policy positions more closely align with their district (Lazarus and Steigerwalt 2018). With the widespread use of social media by Congress, congresswomen were found to be more likely to adopt and use Twitter more frequently (Evans et al. 2014; Beevolve 2012). There is reason to believe, then, that congresswomen may also have different political communication patterns.

The main research puzzle I address is whether there is a gendered as well as partisan element to the way congressmen and congresswomen utilize Twitter to disseminate political information. Twitter has only become more and more central to the communication activities of MCs (Gainous and Wagner 2014) with nearly universal adoption (Golbeck, Grimes, and Rogers 2010). Therefore, to get leverage on this research puzzle, I conducted a content analysis of all tweets sent by MCs in the House of Representatives during two separate weeks in the $114^{\text {th }}$ Congress (May 1-7, 2015 and May 1-7, 2016; $\mathrm{n}=9,374$ tweets from 431 members of Congress). Using a mixed methods approach, I used both quantitative and qualitative methods to show whether there is a difference in the issue areas broached, language used, and appeals to constituencies due to constraints and considerations Republican and Democratic congresswomen contend with, in comparison to their male colleagues. I look at subject themes, language, target audiences, 
as well as conduct t-tests, tally percentages and counts of tweets, as well as run negative binomial regression models.

Does the interaction of gender and party shed more light on $\mathrm{MC}$ communication than a more singular focus on just gender or just party? Throughout this dissertation, I show it can help advance our basic theoretical frameworks and understanding of political communication in some ways. DW-nominate scores in conjunction with gender impact broaching women's issue areas, congresswomen more heavily use advertising tweets more than congressmen, and Democratic congresswomen go above and beyond to target a national constituency. However, some results of the NBRM models ran contrary to expectations, such as congressmen - in particular conservative congressmen - credit claiming more than congresswomen, or congresswomen not targeting the district more than congressmen that point to some interesting findings. Indicators such as marginal seats or belonging to party leadership ended up mattering more with respect to tweeting more about men's issues, even though Republican congressmen had the percentage of their total tweets devoted to these issues. The use of both quantitative as well as qualitative methods allowed for further exploration of why these findings occurred.

The dissertation is organized as three stand-alone article manuscripts - as such, there is some overlap and repetitiveness in the literature reviews, data, and methods. Therefore, I will just briefly cover each chapter and its findings.

Chapter 2 asks whether congresswomen will focus on "women's issues" due to perceived issue competency (Falk and Kenski 2006; Lawless 2004; Herrnson and Stokes 2003; Sanbonmatsu 2002); with congressmen doing the same due to their perceived "masculine issue" competency (Frederick 2011; Swers 2005; Thomas and Welch 2001). 
What the results show is that Democratic and Republican congresswomen do tweet more than their male counterparts about "women's issues," Republican congresswomen do so to emphasize their partisan loyalty. While the percent of men's issue tweets was highest for Republican congressmen, it was not found to be significant in the NBRM model, meaning most MCs address these issues at similar levels. Issue activation on the Twittersphere plays a role in how MCs emphasize their partisan ties and accomplishments.

In chapter 3, I draw from Mayhew's $(1974,49)$ theory to analyze whether there is a gendered dimension to MCs' constant engagement in activities related to reelection, specifically tweet and retweet percentages. I extended Lawless's (2012) study which analyzed Mayhewian tweet behavior to consider the interaction of both gender and party in reelection activities - advertising, position taking, credit claiming - but coding each category as mutually exclusive to distinguish how much credit claiming versus position taking is actually occurring. The analysis revealed that both gender and party played a role in Mayhewian tweet content, with Republican congresswomen advertising the most and claiming credit the least. Democratic congresswomen posted the fewest advertising tweets, and Republican congressmen the highest percentage of credit claiming tweets.

Additionally, in chapter 3, I conducted an in-depth content analysis of creditclaiming tweets to reveal the role of gender as well as partisanship in how credit is individually claimed or shared with others, which has been studied in credit claiming newsletters (Dolan and Kropf 2004), but not in tweets. The results show that while Republican congresswomen did individually credit claim at high rates and very low within credit sharing, Democratic congresswomen claimed shared credit almost as much as they 
took individual credit, giving mixed conclusions again based on a result of the interaction of party and gender.

Chapter 4 takes Fenno's (1978) concept of targeting constituencies and analyzes whether the surrogate representation congresswomen say they feel (Carroll 1985) applies to targeting the national level more than congressmen. The results provide some evidence that Democratic congresswomen are more likely to target their tweets at the national level, while gender and party do not seem to influence the number of tweets targeted at the district level. While Republican congresswomen say they want to represent women broadly, they have partisan pressures to deal with and therefore stick to traditional types of targeting behaviors. Democratic congresswomen are not similarly constrained. At the district level there is no significant difference in targeting practices by either gender or party. Therefore, Democratic congresswomen go above and beyond reelection-minded home style tweets to target at the national level - an interesting update to Fenno's classic work.

Chapter 5 is the conclusion, where the findings are contextualized. Ultimately, the research is important because this study serves to add to the extant dialogue of what issues areas congresswomen to tend focus in office, serves as an update to an older study of gendered Mayhewian behavior (Lawless 2012), as well as adds the new element of gender to Fenno's established theory of Home Style. Since politicians are motivated to shape public perceptions, documenting a gendered and partisan gap in the way MCs utilize Twitter to reach their constituencies has ramifications beyond the American politics arena. Furthermore, the analysis of retweets adds to the small amount of studies that include RT analysis in their work (Evans 2016; Straus et al. 2014). 
In an age of internet politics where tweets have a real-world impact in public perception of candidates, documenting the differences in tweet styles can help the citizenry have a better grasp of the different ways they are being targeted, so that they are able to make more informed decisions and act accordingly at the polls.

\section{Background}

Early literature on gendered communication focused on "interpersonal and organizational contexts" (Edwards 2009, xiii); however, recent literature has started to critically examine discourse in politics. Variance in the literature signifies a lack of consensus regarding whether women are on the same playing field when it comes to running, or their accomplishments (or perception of such) when in office. Some researchers found evidence of voter bias against women as they ran for office (Herrick and Mendez 2014; Fulton 2013; Fox and Smith 1998; Huddy and Terkildsen 1993), while others found no voter bias against women (Fox 2014; Brooks 2013; Dolan 2013, 2004, 2003; Lawless and Fox 2008). Another group of scholars wrote about the barriers and incentives for women to run, such as a favorable electoral system, elite support, and cultural support for women in high raking positions (Lawless and Fox 2010; Norris 1997; Paxton 2006), while other strands of the literature looked at the impact of these women through their focus on policy content, and the traction of women's issue bills (see: Wittmer and Bouché 2013). 
Some research (Brown 2014, Hawkesworth 2003) posits there is a difference in race-gendering ${ }^{3}$ that renders credit claiming more difficult for women and even more so for women of color. Other research finds voters make broad assumptions - voters perceive women MCs as more liberal regardless of party, which can hurt female Republican candidates who want to be portrayed as conservative, and Democratic candidates may be viewed as "betraying" their party by working across party lines (see Pearson 2013, 68, for an overview of the literature).

While some scholars find party labels more important than candidate's gender, the particular impact that voters play on women's representation is still unclear. Part of the answer to this research puzzle is coverage of women who run. Absent a partisan cue, voters will look at individual characteristics such as race or sex (Kam 2007), with minority women facing more negative and less frequent media coverage than all other MCs (Gershon 2012). Fulton posits that held equal, women candidates face a 3 percent vote disadvantage at the macro and micro-level (2013; 2012).Furthermore, individuals search for different elements of male versus female candidates: seeking out more competence-related information and information about "compassion issues" (Ditonto, Hamilton, and Redlawsk 2014). The media plays a large role in framing a candidate, and so a focus on certain qualities such as leadership or personality with a positive or negative frame will influence the way citizens analyze and scrutinize. A negative frame may, in turn, color the entire perception of a

\footnotetext{
${ }^{3}$ Race-gendering is a political process that silences, stereotypes, enforces invisibility, excludes, and challenges the epistemic authority of congresswomen of color (Hawkesworth 2003, 529).
} 
candidate, which can become a double-edged sword; "critiques of her ability also contribute to markedly lower ratings of her likability" (Bligh, et al. 2011, 587).

A theory that the gender literature tends to use to describe this phenomenon of sex differences is a "gendered communication style" (Meeks 2016). This style is one that has been described as acts or tendencies evoking a "feminine" or "masculine" style - e.g. selfdisclosure viewed as feminine (Davisson 2009) while being impersonal and analytical viewed as masculine (Campbell 1989). Public speech has traditionally been viewed as 'masculine' (Brody 1993), and even following the greater participation of women in that realm, it continues to still be viewed as such (Cameron 2006). The usage of the language of war and sports is prevalent in campaign coverage, and aggressiveness by candidates is framed positively - qualities more associated with masculinity (Carroll and Fox 2014). Research on language and gender has gone through marked differences. Lakoff's (1975) seminal work on "women's language” described it as containing 'empty' adjectives, vocalizing statements as questions, polite measures, speaking less frequently and other measures that suggest uncertainty and lack of authority (48). This conclusion was followed by two oft-cited works finding men interrupted women more frequently (West and Zimmerman 1983) and women provided more interactional support than men (Fishman 1978). There has been a disciplinary move away from correlational sociolinguistics as scholars believe it oversimplifies and is antiquated.

On issues that fit the definition of “women's issues" such as sexual discrimination, equal pay, childcare, and education, it is clear that both sexes have incentives to ensure work is being done in these policy areas. While women legislators do set a distinct agenda concerning women's issues in the legislature, and are more likely to vote for “women's 
issues bills" than their male colleagues even when you control for constituency, party, personal characteristics, and ideology (Swers 1998), Tamerius (1995) writes that these women balance their gender issues with their other obligations and influences as legislators (96). Congresswomen can be perceived as pursuing a women's issue agenda by introducing more women's issue bills than men legislators (Bratton and Haynie 1999; Thomas 1994). Women also elect to sit on committees that focus on these policy areas (Dolan and Ford 1997; Thomas 1994). As such, the literature suggests that there will be some nuance between the sexes on issue areas discussed.

While Republican women say they want to represent women broadly, they have partisan pressures to deal with. "Women's issues" tend to fall under Democratic purview due to perceptions of issue ownership (Evans 2005, Wolbrecht 2000); therefore, with increased levels of partisanship in both chambers and Republicans prizing ideological purity (Grossman and Hopkins 2016), Republican women may distance themselves from targeting women for primary concerns, as Republican voters and activists are more likely than their Democratic counterparts to prize "symbolic demonstrations of ideological purity and to pressure their party leaders to reject moderation and compromise" (Grossman and Hopkins 2016, 23).

How then are women MCs poised to address issues such as misperception? One way is to utilize social media to cultivate their image. While social media is a concept under constant evolution, it is generally defined as "a group of internet-based applications that build on the ideological and technological foundations of web 2.0 and that allow the creation and exchange of user-generated content" (Kaplan and Haenlein 2010, 61). This evolution makes it difficult for scholars to analyze just what is occurring, but recent 
research acknowledges the potential of media to influence the political behavior of both constituencies and political leaders. As of 2014, the number of internet users in the United States was 279.8 million; $86.75 \%$ of its population has internet access (Statista 2018). Still, while the number increases, the reality is that only a subset of the population will use it for the purposes of direct political engagement. There is not only a divide between digital and nondigital users, but also between those actually interested in using social media for politics versus simply for entertainment or staying in touch with friends (Katz, Barris, and Jain 2013). Policy actors have had to adapt to changes in how news is made and disseminated (Jeffares 2014).

To this end, a congresswoman may focus on specific issue areas, utilize certain language to claim credit for the work that she does in office, and directly interact or target her constituents to correct these misconceptions. On Twitter, the 140 character limit constrains messages to a palatable, sharable bite that can easily be favorited, retweeted, and/or commented on. This is an advantage for citizens, who prefer simple statements to detailed policy plans (Kahn and Kenney 2002).

\section{References}

Alexander, Deborah and Kristi Anderson. 1993. "Gender as a Factor in the Attributions of Leadership Traits." Political Research Quarterly. 46: 527-545.

Althaus, S. L. 2003. Collective preferences in democratic politics: Opinion surveys and the will of the people. New York: Cambridge University Press.

Ammah-Tagoe, A. 2009. "Who’s winning the Twitter wars?” Newsweek. September 8.

Anderson, Karin V. 2011. "'Rhymes with Blunt': Pornification and U.S. Political Culture." Rhetoric and Public Affairs. 14(2): 327-368.

Anzia, Sarah and Christopher Berry. 2011. "The Jackie (and Jill) Robinson Effect: Why 
Do Congresswomen Outperform Congressmen?". American Journal of Political Science. 55(3): 478-493.

Bartels, Larry M. 2003. "Democracy with attitudes." In M. MacKuen \& G. Rabinowitz (Eds.), Electoral democracy. Ann Arbor: University of Michigan Press, 48-82.

Bartels, Larry M. 1996. "Uninformed Votes: Information Effects in Presidential Elections." American Journal of Political Science 40(1): 194-230.

Becker, Jeffrey A. 2014. Ambition in America: Political power and the collapse of citizenship. Lexington: University Press of Kentucky.

Beevolve. 2012. "An Exhaustive Study of Twitter Users Across the World." http://www.beevolve.com/Twitter-statistics/

Blight, Michelle C, Michèle M. Schlehofer; Bettina J. Casad; Amber M. Gaffney. 2011. "Competent Enough, But Would You Vote for Her? Gender Stereotypes and Media Influences on Perceptions of Women Politicians."

Bratton, Kathleen, and Kerry Haynie. 1999. "Agenda Setting and Legislative Success in State Legislatures: The Effects of Gender and Race." Journal of Politics 61(3): $658-79$.

Brody, M. 1993. Manly Writing: Gender, Rhetoric, and the Rise of Composition. Carbondale and Edwardsville: Southern Illinois Press.

Brooks, Deborah Jordan. 2013. He runs, she runs: Why Gender Stereotypes do not Harm Women Candidates. Princeton: Princeton University Press.

Brown, Nadia E. 2014. "Political Participation of Women of Color: An Intersectional Analysis." Journal of Women, Politics \& Policy. 35:315-348.

Bryce, James. 1893. The American Commonwealth. New York: Macmillan.

Buck, J. Vincent and Bruce E. Cain. 1990. "British MPs in Their Constituencies." Legislative Studies Quarterly 15(1): 127-143.

Cameron, D. 2006. "Theorising the Female Voice in Public Contexts." In J. Baxter (ed.), Speaking Out: The Female Voice in Public Contexts. Basingstoke: Palgrave Macmillan, 3-20.

Cameron, D. 2005. "Language, gender and sexuality: Current issues and new directions." Applied Linguistics. 26(4): 482-502.

Campbell, K. 1989. Man cannot speak for her. New York, NY: Greenwood Press.

Davisson, A. 2009. “'I'm in!': Hillary Clinton's 2008 Democratic primary campaign on YouTube.” Journal of Visual Literacy 28: 70-91. 
Campbell, A., Converse, P., Miller, W. E., and Stokes, D. 1960. The American Voter. New York: Wiley.

Carey, John M and Matthew Soberg Shugart. 1995. "Incentives to cultivate a personal vote: A rank ordering of electoral formulas.” Electoral Studies. 14(4):417-439.

Carroll, Susan J, and Richard L. Fox. 2014. Gender and Elections: Shaping the Future of American politics. New York: Cambridge University Press.

Carroll, Susan J. 2000. "Representing Women: Congresswomen's Perceptions of Their Representation." Presentation at "Women Transforming Congress: Gender Analyses of Institutional Life," Carl Albert Congressional Research and Studies Center, University of Oklahoma, April 13-15.

Carson, Jamie L., Erik J. Engstrom, and Jason M. Roberts. 2007. "Candidate Quality, the Personal Vote, and the Incumbency Advantage in Congress." The American Political Science Review. 101(2): 289-301.

Cox, Gary W., and Jonathan N. Katz. 1996. "Why Did the Incumbency Advantage in U.S. House Elections Grow?" American Journal of Political Science 40(2): 478-497.

Chang, Chingching \& Jacqueline Hitchon. 1997. "Mass Media Impact on Voter Response to Women Candidates: Theoretical Development." Communication Theory. 7(1): $29-52$.

Dahl, Robert A. 1989. Democracy and Its Critics. New Haven: Yale University Press.

Converse, P.E.. 1964. "The Nature of Belief Systems in Mass Publics.” In D. E. Apter (Ed.), Ideology and Discontent (pp. 206-261). New York: Free Press.

Davis, A. 2010. Political Communications and Social Theory. London: Routledge.

Dodson, Debra L. 2006. The Impact of Women in Congress. New York: Oxford University Press.

Dolan, Julie and Jonathan S. Kropf. 2004. "Credit Claiming from the U.S. House: Gendered Communications Styles?" The International Journal of Press/Politics. 9(1): 41-59.

Dolan, Kathleen A. 2013. "Gender Stereotypes, Candidate Evaluations, and Voting for Women Candidates: What Really Matters?" Political Research Quarterly. 1-12.

Dolan, Kathleen A., Sanbonmatsu, K. 2009. "Gender stereotypes and attitudes toward gender balance in government." American Politics Research. 37(3): 409-428.

Dolan, Kathleen A. 2003. Voting for women: How the Public Evaluates Women Candidates. Boulder: Westview Press. 
Dolan, Kathleen, and Lynne Ford. 1997. "Change and Continuity among Women State Legislators: Evidence From Three Decades.” Political Research Quarterly 50(1): 137-51.

Ditonto, Tessa M.; Allison J. Hamilton; David P. Redlawsk. 2014. “Gender Stereotypes, Information Search, and Voting Behavior in Political Campaigns." Political Behavior. 36: 335-358.

Eagly, Alice H. and Steven J. Karau. 2002. "Role Congruity Theory of Prejudice Toward Female Leaders.” Psychological Review. 109: 573-598.

Edwards, Janis L. 2009. Gender and political communication in America: Rhetoric, Representation, and Display. Lanham: Lexington Books.

Eggers, Andrew C., Anthony Fowler, Jens Hainmueller, Andrew B. Hall, and James M. Snyder, Jr. 2014. "On the Validity of the Regression Discontinuity Design for Estimating Electoral Effects: New Evidence from Over 40,000 Close Races." American Journal of Political Science. 59(1): 259-274.

Entman, Robert M. 1993. "Framing: Towards Clarification of a Fractured Paradigm." Journal of Communication 43(4): 51-58.

Fisher, Patrick. 2014. Demographic gaps in American political behavior. Boulder: Westview Press.

Fishman, P. 1978. "Interaction: The work women do.” Social Problems. 25: 397-406.

Fox, Richard L. and Jennifer M. Ramos. 2012. iPolitics: Citizens, elections, and governing in the new media era. New york: Cambridge University Press.

Fox, Richard L. and Eric R. A. N. Smith. 1998. "The Role of Candidate Sex in Voter Decision-Making.” Political Psychology. 19: 405-419.

Fridkin, Kim L. and Patrick J. Kenney. 2014. The Changing Face of Representation: The Gender of U.S. Senators and Constituent Communciations. Ann Arbor: University of Michigan Press.

Fulton, Sarah A. 2014. "When Gender Matters: Macro-dynamics and Micro-mechanisms." Political Behavior. 36: 605-630.

Fulton, Sarah A. 2012. "Running Backwards and in high heels: The gendered equality gap and incumbent electoral success." Political Research Quality. 65(2): 303-314.

Gainous, Jason and Kevin M. Wagner. 2014. Tweeting to Power: The Social Media Revolution in American Politics. New York: Oxford University Press.

Gelber, Alexis. 2011. "Digital Divas: Women, Politics and the Social Network." Joan 
Shorenstein Center on the Press, Politics and Public Policy Discussion Paper Series. Harvard University John F. Kennedy School of Government.

Gershon, Sarah. 2012. "When Race, Gender, and the Media Intersect.: Campaign News Coverage of Minority Congresswomen." Journal of Women, Politics and Policy. 33(2): 105-125.

Gertzog, Irwin N. 2004. Women and Power on Capitol Hill: Reconstructing the Congressional Women's Caucus. Boulder: Lynne Rienner Publishers.

Gertzog, Irwin N. 1995. Congressional women: their recruitment, integration, and behavior. Westpor: Praeger.

Goodyear-Grant, Elizabeth. 2013. Gendered news: Media coverage and electoral politics in Canada. Vancouver: UBC Press.

Gray, Mark M., Kittilson, Miki Caul, and Wayne Sandholtz. "Women and Globalization: A Study of 180 Countries, 1975-2000. International Organization Foundation. 60(2): 293-33.

Hawkesworth, Mary. 2003. "Congressional Enactments of Race-Gender: Toward a Theory of Raced-Gendered Institutions." The American Political Science Review. 97(4): 529-550.

Hong, Sounman. 2013. "Who benefits from Twitter? Social media and political competition in the U.S. House of Representatives." Government Information Quarterly. 30: 464-472.

Hong, Sounman and Daniel Nadler. 2012. "Which candidates do the public discuss online in an election campaign?: The use of social media by 2012 presidential candidates and its impact on candidate salience." Government Information Quarterly 29: 455461.

Huddy, Leonie and Nadya Terkildsen. 1993. "The Consequences of Gender Stereotypes for Women Candidates at Different Levels and Types of Office." Political Research Quarterly. 46: 503-525.

Huddy, Leonie and Nayda Terkildsen. 1993. "Gender Stereotypes and the Perception of Male and Female Candidates." American Journal of Political Science. 37: 119-147.

Inglehart, Ronald, and Pippa Norris. 2003. Rising Tide: Gender Equality and Cultural Change Around the World. New York: Cambridge University Press.

Jacobson, Gary C. 1987. "The Marginals Never Vanished: Incumbency and Competition in Elections to the U.S. House of Representative, 1952-82." American Journal of Political Science 31: 126-141. 
Jeffares, Stephen. 2014. Interpreting hashtag politics: Policy ideas in an era of social media. New York: Palgrave Macmillan.

Jacobson (1987) seems to bolster Mayhew's claim that candidates have become more personalistic, and their drive due to risk and uncertainty leads them to take measures to gain power and influence in their electorate. This is done in particular to dissuade any strong competition.

Johnson-Cartee, Karen S. \& Gary A. Copeland. 2004. Strategic Political Communication: Rethinking Social Influence, Persuasion, and Propaganda. Rowman \& Littlefield Publishers, Inc. New York.

Kaid, Lynda Lee. 2004. Handbook of political communication research. Mahwah: Lawrence Eribaum Associates.

Kahn, Kim F. 1992. "Does Being Male Help? An Investigation of the Effects of Candidate Gender and Campaign Coverage on Evaluations of US Senate Candidates." Journal of Politics 54(2): 497-517.

Kam, C. D. 2007. "Implicit attitudes, explicit choices: When subliminal priming predicts candidate preference." Political Behavior. 29: 343-367.

Kaplan, A. M. and Haenlein, M. 2010. "Users of the world, unite! The challenges and opportunities of social media." Business Horizons. 53(1): 59-68.

Karpf, David. 2012. The MoveOn Effect: The unexpected transformation of American political advocacy. New York: Oxford University Press.

Kathlene, L. 1994. "Power and ingluence in state legislative policymaking: the interaction of gender and position in committee hearing debates." American Political Science Review 88(3): 560-76.

Kathlene L., Clarke S.E., Fox B.A. 1991. "Ways Women Politicians are Making a Difference." In Gender and Policymaking Studies of Women in Office, ed. DL Dodson, pp. 31-38. New Brunswick, NJ: Cent. Am. Woman Politics.

Katz, James E., Michael Barris, and Anshul Jain. 2013. The social media president: Barack Obama and the politics of digital engagement. New York: Palgrave Macmillan.

Kidd, Quentin. 2011. Civic participation in America. New York: Palgrave Macmillan.

Kies, Raphaël. 2010. Promises and limits of Web-deliberation. New York: Palgrave Macmillan.

Kindler, Donald R., and Thomas R. Palfrey. 1993. "On Behalf of an Experimental Political Science.” In Experimental Foundations of Political Science, ed. Kinder and Palfrey, Experimental Foundations of Political Science, Ann Arbor: University of Michigan 
Press.

Kuklinski, J.H., \& Quirk, P. J. 2000. "Reconsidering the rational public: cognition, heuristics, and mass opinion.” In A. Lupia, M. D. McCubbins \& S. L. Popkin (Eds.) Elements of reason: Understanding and expanding the limits of political rationality. London: Cambridge University Press.

Lakoff, Robin. 1975. “Language and Woman's Place.” Language and Society, 2(1): 45-80.

Lassen, D. S. \& Brown, A. R. 2011. “Twitter: the electoral connection?” Social Science Computer Review. 29(4): 419-436.

Lawrence, Regina G. and Melody Rose. 2009. Hillary Clinton's Run for the White House: Media, Gender Strtegy, and Campaign Politics. Boulder: Lynne Rienner.

Lee, Jayeon. 2013. “'You Know how tough I am?;' Discourse analysis of US Midwestern congresswomen's self-presentation." Discourse \& Communication. 7(3): 1-19.

Lenz, Gabriel. 2012. Follow the Leader?: How Voters Respond to Politicians'Policies and Performance. Chicago: University of Chicago Press.

Lippmann, Walter. 1922. Public Opinion. New York: Macmillan.

Lockhart, Michele and Kathleen Mollick. 2013. Political women: language and leadership. Lanham: Lexington Books.

Luskin, R. C. 2002. "From denial to extenuation (and finally beyond): Political sophistication and citizen performance." In J. H. Kuklinski (Ed.), Thinking about Political Psychology (pp. 281-301). New York: Cambridge University Press.

Mansbridge, Jane. 2005. 'Quota Problems: Combating the Dangers of Essentialism.' Politics and Gender 1(4): 621-38.

Martin, James. 2014. Politics and rhetoric: a critical introduction. Milton Park: Routledge.

Matland, Richard E. and Kathleen A. Montgomery. 2003. Women's Access to Political Power in Post-Communist Europe. New York: Oxford University Press.

Mayhew, David R. 1974. Congress: The Electoral Connection. Yale University Press.

Norris, Pippa. ed. 1997. Passages to Power: Legislative Recruitment in Advanced Democracies. Cambridge, UK: Cambridge University Press.

O’Connor, B., Balasubramanyan, R., Routledge, B.R., and Smith, N.A. 2010. "From 
tweets to polls: Linking text sentiment to public opinion time series." Reitrieved from:

http://www.cs.cmu.edu/ nasmith/papers/oconnor+balasubramanyan+routledge+s mith.icwsm10.pdf

Opalo, Kennedy O. 2014. "Institutions and Legislative Incumbency Advantage: A Regression Discontinuity Analysis of Legislative Elections in Africa.” Available at SSRN: https://ssrn.com/abstract=2495927.

Parmelee, John H. and Shannon L. Bichard. 2012. Politics and the Twitter revolution: How tweets influence the relationship between political leaders and the public. Lanham: Lexington Books.

Passini, F. T., \& Norman, W. T. 1976. “A universal conception of personality structure.” Journal of Personality and Social Psychology. 4:44-49.

Paxton, Pamela 1997. Women in national legislatures: a cross-national analysis. Social Science Research 26 :442-64.

Paxton, Pamela, and Melanie M. 2007. Women, Politics, and Power: A Global Perspective. Thousand Oaks, CA: Pine Forge.

Paxton, Pamela, Kunovich, Sheri, and Melanie M. Hughes. 2007. "Gender in Politics." Annual Review of Sociology 33: 263-270.

Pearson, Kathryn. 2013. "Congresswomen's Pursuit of Power in a Partisan Environment." In Congress Reconsidered, ed. Lawrence C. Dodd and Bruce I. Oppenheimer. Washington DC. Sage CQ Press.

Pearson, Kathryn and Logan Dancey. 2011. "Elevating Women's Voice in Congress: Speech Participation in the House of Representatives." Political Research Quarterly. 64: 910-923.

Ramirez Francisco O., Soysal Yasemin, and Suzanne Shanahan. 1997. "The changing logic of political citizenship: cross-national acquisition of women's suffrage rights, 1890 to 1990." American Sociological Review. 62(5): 735-45.

Ridout, Travis N. 2013. New directions in media and politics. New York: Routledge, Taylor \& Francis Group.

Rhode, Deborah L. 2014. What Women Want: An Agenda for the Women's Movement. New York: Oxford University Press.

Rosenthal, C.S. 1998. When Women Lead: Integrative Leadership in State Legislatures. New York: Oxford Univ. Press.

Ross, Karen and Tobias Bürger. 2014. "Face to face(book): Social media, political 
campaigning and the unbearable lightness of being there." Political Science. 66(1): 46-62.

Ruggerio, Alena A. Media Depictions of Brides, Wives, and Mothers. Maryland: Lexington Books.

Sanbonmatsu, Kira. 2004. "Political Knowledge and Gender Stereotypes." American Politics Research. 31(6): 575-594.

Sanbonmatsu, Kira. 2002. "Gender Stereotypes and Vote Choice." American Journal of Political Science. 46(1): 20-34.

Schneider, Monica C. 2014. "The Effects of Gender-Bending on Candidate Evaluations." Journal of Women, Politics \& Policy. 35: 55-77.

Schumpeter, Joseph A. 1942. Capitalism, Socialism and Democracy. $3^{\text {rd }}$ Edition. New York: Harper \& Row.

Shockels, Theodore F., Nichola D. Gutgold, and Diana B. Carlin. 2012. Gender and the American presidency: Nine presidential women and the barriers they faced.

Suebsaeng, Asawin. 2013. "Most Congressmen are Boring. This one is funny - On Purpose." http://www.motherjones.com/politics/2013/09/rep-mark-takano-bestdemocrat-social-media-twitter-tumblr

Statista. 2018. "Number of internet users in the United States from 2000 to 2016 (in millions)." https://www.statista.com/statistics/276445/number-of-internet-usersin-the-united-states/

Street, J. 2003. "The Celebrity Politician: Political Style and Popular Culture." in D. Pels and and J. Corner (eds), Media and the Restyling of Politics: Consumerism, Celebrity, and Cynicism. London: Sage, 85-91.

Tamerius, Karin. 1995. "Sex, Gender and Leadership in the Representation of Women.' In Gender Power, Leadership and Governance, eds. Georgia Duerst-Lahti and Rita Mae Kelly. Ann Arbor: University of Michigan Press, 93-112.

Taylor, S. E., \& and Falcone, H. 1982. "Cognitive bases of stereotyping: The relationship between categorization and prejudice." Personality and Social Psychology Bulletin. 8: 426-432.

Temple, Mick. "The Media and the Message." Journal of Political Marketing. 12: 147-165.

Tesser, A. 1978. "Self-generated attitude change." Advances in Experimental Social Psychology. 11:289-338.

Thomas, Sue and Clyde Wilcox. Women and elective office: Past, present, and future. New 
York: Oxford University Press.

Thomas, Sue. 1994. How Women Legislate. New York: Oxford University Press.

True, Jacqui, and Michael Minstrom. 2001. "Transnational networks and policy diffusion: the case of gender mainstreaming." International Studies Quarterly. 45(1): 27-57.

Vaccari, Cristian and Rasmus Kleis Nielsen. 2013. "What Drives Politicians' Online Popularity? An Analysis of the 2010 U.S. Midterm Elections." Journal of Information Technology \& Politics. 10: 208-222.

West, C. and Zimmerman, D. 1983. "Small insults: A study of interruptions in cross-sex conversations between unacquainted persons." In Thorne, B., Kramarae, C. and Henley, N. (eds) Language, Gender and Society. Rowley, MA: Newbury House. 103-17.

Wittmer, Dana E. and Vanessa Bouché. 2013. "The Limits of Gendered Leadership: Policy Implications of Female Leadership on 'Women's Issues"'. Politics \& Gender, 9: 245-275. 


\section{CHAPTER II. GENDERED ISSUE AREAS IN CONGRESSIONAL TWEETS}

There is an expectation based on literature that congresswomen will focus on “women's issues" like gender equity, day-care programs, minimum wage increases, reproductive rights, and welfare when looking at their speeches, bills sponsored, or what they vote upon - issues seen as under "ownership" of the Democratic Party. Therefore, this chapter analyzes whether gendered partisanship drives congresswomen and men to focus on women's versus men's issue areas in their political communication on Twitter. Hand-coded content analysis was undertaken for the Twitter feeds of all $114^{\text {th }}$ Congress Representatives during May 1-7, 2015 and May 1-7, 2016. Republican women have to contend with the ideological purity of their party (Grossman and Hopkins 2016), therefore do engage with women's issues to emphasize how they align with their party's position (Dabelko and Herrnson 1997). While Democratic congresswomen and Republican congressmen had the highest percent of their tweet totals regard women's and men's issues respectively, the NBRM model showed mixed results regarding how well they served as indicators. Additionally, in the exploratory qualitative portion, conservative congressmen were found to be the highest credit claimers.

Keywords Congress, issue areas, social media, Twitter, gendered communication

Debates about representation often pit substantive (policy-based) representation against descriptive (characteristic-based) representation. Yet, Pitkin's (1967) classic work on the topic argues that substantive representation is enhanced by descriptive representation. More recent scholarship finds evidence of this phenomenon for both women and minorities in Congress (e.g. Swers 2002; Mansbridge 1999; Phillips 1995) and 
at the state level (Osborn 2012; Caiazza 2004; Berkman and O’Connor 1993; Dolan and Ford 1995; Thomas 1994). Scholars find that female representatives are more likely to care about, sponsor, and vote for "women's issue" bills, broadly defined as those whose "policy consequences are likely to have a more immediate and direct impact on significantly larger numbers of women than of men" (Carroll 1985, 15); (also see: Swers 2005; Frederick 2011; Thomas and Welch 2001). These women's issues include education, gender equity, daycare programs, minimum wage increases, reproductive rights, and welfare. While the framing of political issues as "women's issues" may seem to perpetuate the idea that these policies do not impact men, these issues - from education to welfare - impact both women and men.

Congresswomen are perceived by constituencies as having additional competency for these women's issues (Falk and Kenski 2006; Lawless 2004; Herrnson and Stokes 2003; Sanbonmatsu 2002; Kahn 1996; Huddy and Terkildsen 1993), but partisan pressures may keep Republican congresswomen from fully engaging with women's issues since they are perceived to be under the broad umbrella of Democratic issue ownership (Evans 2005, Wolbrecht 2000). Instead, Republican women may emphasize men's issues that coincide with Republican strengths (Winter 2010; Petrocik 1996). Republicans prize ideological purity (Grossman and Hopkins 2016) and with increased levels of partisanship that make it challenging to advocate on behalf of women's issues for Republican women (Swers 2013), they may distance themselves from women's issues, or do so only to emphasize how they align with their party's position (Dabelko and Herrnson 1997).

I will explore these themes throughout this chapter and ask whether gender and partisanship influence how members of Congress (MCs) emphasize women's or men's 
issues in their online political communication. Using a mixed-methods approach to analyze a sample of tweets sent by MCs in the $114^{\text {th }}$ House, I conduct an in-depth content analysis of the issue areas broached in these messages and run several statistical models to distinguish the patterns I uncover from potential confounding factors. The results provide some evidence that gender is not enough to understand how MCs communicate about women's issues; the key to a deeper understanding lies at the intersection of gender and partisanship. Democratic and Republican congresswomen tweet more than their male counterparts about "women's issues," with Republican congresswomen doing so to emphasize their partisan loyalty. Democratic congresswomen and Republican congressmen go above and beyond to address women's and men's issue areas respectively. Since congresswomen strategize about gender in their campaigns (Dittmar 2015; Fox 1997; Kahn 1996), adding the element of how gender and partisanship interact to influence political communication of MCs provides nuance to the literature on congress, gender, and political communication in the online sphere, as the current literature focuses on gender and partisanship separately.

\section{Literature Review}

Women's Issues

Since there is still a substantial gap in the ratio of congresswomen to men, many congresswomen signal that they feel a surrogate relationship for women outside the bounds of their constituencies (Carroll 2000, 2). Senator Barbara Boxer (D-CA) describes this duty:

"There are still so few women in Congress...So you really do have to represent much more than your own state although my state is huge... Women all over the country really do follow what you do and rely on you to speak out for them on the 
issues of women's health care, reproductive choice, conditions of families, domestic priorities, environment...equal pay for equal work...I even had that in the House of Representatives, which was incredible because I just came from a small district. So, it is a pretty big burden. And I remember when I came [to the Senate], Barbara Mikulski said, 'Oh, my god, thank god, someone I can share this with,' because she carried the load for so long as the only Democratic woman in the Senate" (Carroll 2002, 53).

Surrogate representation is particularly important for historically marginalized groups, such as women and racial minorities (Mansbridge 2003, 1999), where these groups may not have representation in their own district. Research shows that the addition of women and racial minority members of Congress has expanded the U.S. legislative agenda to better address the interests of women and racial minorities in domestic policy (Wallace 2014; Tate 2003; Swers 2002; Wolbrecht 2002). Representative Louise Slaughter (D-NY) touches on this type of representation, explicitly stating that she feels an obligation to all women in the country. Since most constituents have a man representing their district, Slaughter feels that one of the most important things to her is to make sure "all those women have equal opportunity and equal access to what we have...I think we have an obligation...to make sure that the other women in the county aren't left behind" (Rosenthal 2002, 54).

The experience of Republican congresswomen tended to be initial resistance - as was the case of Democratic congresswomen elected in the 1990's - but with time came a willingness and responsibility of representing women's issues as they felt they were unaddressed or worse: "[I had been] shocked to my toenails to realize...the indifference of the men in Congress and...the callousness of them to some of these issues" (Marge Roukema (R-NJ) (Rosenthal 2002, 55). Roukema describes this evolution from initially 
not wanting to be stereotyped as a "woman legislator" and avoiding the stereotypical categories, instead wanting to be engaging in policy issues such as banking and finance. ${ }^{4}$ She came to realize that if she was not going to address family concerns such as "jobs or children or equity...then they weren't going to be attended to. So I quickly shed those biases that I had, and said, 'Well, nobody else is going to do it; I'm going to do it' (Rosenthal 2002 55).

In the early public policy literature, the content of policy outputs was assumed to be a product of the "self-interest" of policy actors, tempered by the nature of conflicts and the compromises they make during policy formation (Howlett 2009, 51). In that sense, the claim that women policymakers would advocate for "women's issues" could be argued as furthering self-interest. Backing policies that concern slightly over half of the population seems politically sound in a rational, self-interested, and electorally-motivated sense, as women also constitute the majority of voters in the U.S. system. ${ }^{5}$ Since for women's issues, congresswomen are viewed as being more competent (Kahn 1996; Huddy and Terkildsen 1993), it may be in their interest to emphasize their productivity or perspectives on these issues to appeal to their various constituencies, especially among women voters.

While there has been a documented decrease in negative social attitudes and stereotypes concerning women candidates (Dolan 2004), they still persist. Public opinion

\footnotetext{
${ }^{4}$ For female candidates that run, their motivation for running tended to be for more policy oriented reasons; men were socialized to have abstract policy goals, while women "view politics as an opportunity to forward a cause and fight for an issue" (Fox 1997, 28).

${ }^{5}$ Since 1964, women have voted in higher rates than men in every presidential election (CAWP 2017).
} 
surveys find that women are still perceived as better suited to address education and health care while men seen as competent on defense and foreign affairs - termed as "issue competency" or a "domain stereotype" (Falk and Kenski 2006; Lawless 2004; Herrnson and Stokes 2003; Sanbonmatsu 2002; Kahn 1996; Huddy and Terkildsen 1993). Therefore, if issues such as healthcare are salient at the moment, congresswomen can capitalize on this supposed advantage. Dolan (2010) also found both positive and negative stereotypes about women candidates held for actual voters, but that party and incumbency are more important than gender.

Policies deemed as "women's issues" or "compassion issues" generally include gender equity, day-care programs, minimum wage increases, reproductive rights, and welfare policies (Carroll and Fox 2014). Contrary to that assumption, "women's issues" such as healthcare, education, sexual discrimination, equal pay, and childcare clearly impact both sexes, and thus all MCs should have the incentive to ensure work is being done in these policy areas. Overall, the focus for literature on women in Congress was whether women would be broaching women's issue bills as their numbers increased in the legislature (Barnello and Bratton 2007; Bratton 2002; Bratton and Haynie 1999; Dodson and Carroll 1991; Reingold 2000; Thomas 1994, 1991).

Dolan (1998) found that in 1992, the widely acclaimed "Year of the Woman," congresswomen were more likely than congressmen to vote for "women's interests" bills. This result may point to a critical mass of legislators. For example, Kanter (1997) finds as the proportion of women increases in the legislature, they are more willing to pursue policy preferences that have gendered connotation. Thomas (1994) also shows that women impact policy outputs when the number of women in a given legislature reaches a certain threshold. 
These women legislators set a distinct agenda concerning women's issues in the legislature. Yet, Tamerius $(1995,96)$ suggests that they balance their gender issues with their other obligations and influences as legislators. While foreign policy tends to be perceived by the electorate as a masculine domain, Angevine (2017) finds that congresswomen in Congress are more likely to introduce legislation on behalf of women worldwide, acting as global surrogates - regardless of race, committee membership, or political party.

Since congresswomen do have this interest regarding women's issues, does this extend to their committee membership preferences? While some research states that the assignment of women to female-biased committees is reflective of their own preference of women rather than the attitudes of leadership making committee assignments (Carroll 1989), more recent work argues that the leadership tends to assign congresswomen to these committees at higher rates than they would have chosen otherwise (Heath, Schwindt-Bayer and Taylor-Robinson 2005). On that note, Volden, Wiseman, and Wittmer (2016) find that the purported women MC's bias of congresswomen towards proposing policies regarding women's issues can be attributed to the actual committee process rather than women's selfselection alone.

Among many different dimensions of representation, we also see this pressure to represent the marginalized group, beyond the boundaries of the district. For issues of ethnicity, a sense of "linked fate" for Blacks in the U.S. due to a history of discrimination and institutionalized racism leads expectations for Black legislators to pursue issues that positively affect their group (Minta 2009; Gamble 2007). We also see this support occurring in low information elections - racial affinity is a factor in wards without incumbents (Gregor et al. 2017). However, these connections do not seem to be as 
prevalent among Latinos. While there is some group consciousness among Latinos (Sanchez 2006), they do not tend to identify themselves as a bloc (Schildkraut 2016), though more so as a group than Asian Americans (Junn and Masuoka 2008).

In a similar vein as the research on race and ethnicity, Haider-Markel (2010) finds that an increased LGBT presence coincides with the number of pro-LGBT bills introduced and passed - a pattern that differs both across and within states. These pro-LGBT bills often make up a small percentage of the bills a legislator chooses to spend time and effort in pursuing (Haider-Markel 2010, 152). In another study, Haider-Markel (2007) reveals an increase in LGBT state legislators leads to greater substantive representation; there was a positive net policy for the LGBT community in this representation, and thus the aim should be for a greater presence in politics. Here we see the effect of substantive representation at play.

\section{Gendered Partisanship}

With the expectation in the "women's issues" literature pointing to congresswomen supporting issues relating to gender regardless of party, there is also some literature finding that congresswomen exhibit more communal behavior versus the "assertive and agentic" behavior of their male counterparts (Gelb and Palley 1996; Alexander and Anderson 1993; Huddy and Terkildsen 1993), sometimes by working across party lines with other women (Dodson 2006; Gertzog 2004). That said, with an increased level of partisanship within both parties, some bipartisan cooperation still exists among women, but partisan identity has increasingly become more important (Pearson 2013). 
While historically both the Democratic and Republican Party seemed to look similar regarding women's issues such as the Equal Rights Amendment (ERA), equal pay, and abortion, by the 1980s, the two parties started to diverge. While Republicans initially led the charge to incorporate the ERA into the Constitution in the 1940s, in 1980 the party reversed its position and withdrew its support for the amendment while Democrats backed candidates supporting the initiative (Wolbrecht 2000). Republicans then moved to embrace a traditional view of women and femininity which has stuck with the party ever since (Domke and Coe 2008; Sanbonmatsu 2004). The parties' divergence also coincided with two trends. First, women were entering the work force and thus changes were occurring regarding their social, political, and economic roles (Sharrow et al. 2016). Second, polarization of both political parties extended to their positions on sex and gender. Democrats tended to emphasize a liberal, progressive position on race, labor, and the economy, as well as abortion, social welfare, education, and more (Wolbrecht 2000).

In addition, some literature finds that Democrats (the party and voters) are directly more supportive of women candidates than Republicans (Kitchens and Swers 2016; King and Matland 2003), including at the state level (Elder 2012). Since Republicans view female candidates as more liberal than their male counterparts, unless a party signal differentiates the two, they will more likely back the male candidate (King and Matland 2003). Republican women therefore face additional barriers even after they choose to run for office, pointing to a gap in elite support that does not exist for Democratic women (Bucchianeri 2017). Still, some recent studies suggest that even if voters have gendered biases, they will ultimately defer to their party label rather than candidate's sex when 
deciding who to ultimately choose at the polls (Dolan 2014; Hayes 2011; Anderson, Lewis, and Baird 2011; Falk and Kenski 2006; Matland and King 2002).

While Banwart (2010) and Sanbonmatsu and Dolan's (2009) show that women have an advantage on education and healthcare and men have an advantage on crime, military, and economic issues, in the legislation that they put forth, Meeks (2016) concludes that Democratic women propose a wider array of masculine and feminine issues, while Republican women sponsor bills across a host of other issues. Republicans and Democrats tend to focus on party-owned issues, though analyzing the tweets of Democrats and Republicans who lost tended to stress owned content compared to unowned content, with winning Democrats seen as more likely to trespass (Meeks 2015). This could be due to the perception of Republican-owned traits - tied to issues of national security - being more important to address (Hayes 2011; Smith et al., 2007). In the Senate, Schaffner (2005) found Democratic women more likely to campaign on education, health care, and childcare than Democratic men. In the House, Democratic women were more likely to campaign on social issues and abortion than Democratic men; Republican women were more likely than Republican men to campaign on abortion (Dabelko and Herrnson 1997). Thus, congresswomen still must contend with the issues of gender as they campaign and advertise, but these must also come with the interaction of party at play.

Ultimately, congresswomen strategize about gender in their campaigns (Dittmar 2015; Fox 1997; Kahn 1996). If female candidates are perceived to have different policy preferences than their male counterparts (Swers 2002), they may choose to overemphasize how closely they align with their party's platform to distinguish themselves within and outside their party. Therefore, congresswomen must consider their base when emphasizing 
their masculine or feminine traits (Bauer 2017; Burns, Eberhardt, Merolla 2013). At the end of the day, congresswomen are running as strategic politicians; using the issues of the day and adopting their partisan perspectives to respond to these issues (Dolan and Lynch 2017). This extends beyond issue areas to masculine or feminine qualities congresswomen emphasizing toughness and aggressiveness, or downplaying ability to be compassionate, in comparison with congressmen who may feel compelled to appear sympathetic, kind, and accessible (Huddy and Terkildsen 1993, 120). Lee's (2013) study of Midwestern congresswomen's self-presentation on their official online biographies showed women stressing the masculine aspects of their personalities while male House members did not.

Continuing the discussion of women's strategic self-presentation, due to congresswomen's own perceived vulnerability, Lazarus and Steigerwalt (2018) coin the term gendered vulnerability to describe the phenomenon where congresswomen perceive they must devote more of their time than their male colleagues to courting and winning their constituents' favor. Therefore, congresswomen devote more time and energy to secure more funding for their district, introduce more bills and resolutions, and their policy positions more closely align with their district (Lazarus and Steigerwalt 2018). Studies have also found that congresswomen deliver more speeches on the House floor than their male colleagues (Pearson and Dancey 2011), have higher participation on floor debates regarding women's issues (Walsh 2002; Swers and Caiazza 2000; Tamerius 1995), sponsor more bills (Pearson 2013; Anzia and Berry 2011), and secure about nine percent more spending from federal discretionary programs at about $\$ 49$ million per year (Anzia and Berry 2011). How partisanship factors into this gendered vulnerability is looking outside 
of the district. While Republican congresswomen feel the weight of surrogacy for women, they also feel the reelection pressures of their party who prize ideological purity (Grossman and Hopkins 2016); since "women's issues" tend to fall under Democratic purview due to perceptions of issue ownership (Evans 2005, Wolbrecht 2000; Petrocik 1996), they do not follow through to target women as a group beyond the parameters of their district.

All in all, while the literature on gender and politics has been able to draw some tentative conclusions regarding women's behavior during elections and in the legislature, more analysis needs to be done regarding their behavior online - how they market themselves, what issues they focus on, and what language they choose to use.

\section{Congressional Behavior on Social Media}

Due to the low cost of online information transmission for political campaigns combined with the sheer magnitude of social media use among their constituencies, MCs take advantage of this opportunity and market themselves online. Indeed, $68 \%$ of all Americans use some form of social media, with $21 \%$ on Twitter (Pew Research 2016). Furthermore, two-thirds of Americans report that they get at least some of their news on social media, with one in five doing so often (Pew Research Center 2017). While the average citizen may not be necessarily following their MC on Twitter, they may come across MCs' tweets as they use hashtags to become visible within their district, state, or nationally.

The widespread use of social media by MCs allows researchers easy access to how MCs communicate to their constituencies and engage in representation. For instance, some MCs go beyond in-person meetings or even phone calls to utilize Twitter and Facebook to 
conduct "town hall" meetings. Minozzi et al. (2015) discovered evidence that constituents were persuaded on the issues the MC brought up during online town halls, including more positively viewing their legislator simply by meeting with and engaging their representative through this online medium. Mergel (2012) found that while MCs tweet about appearances in their home district and policy issues they care deeply about, responding to tweets to carry a conversation (using @ for replies) is rare among MCs, even when one $\mathrm{MC}$ mentions another MC in a tweet. Additionally, early studies of tweet content showed that MCs were predominantly focusing their efforts on just advertising - largely linking to press releases or publicizing their official actions, like committee hearings (Glassman et al., 2009). Glassman et al. (2009) found 43 percent of in-session tweets in 2009 were press-related tweets with little original content. Another study categorized 53 percent of MC tweets as "informational” content (Golbeck et al., 2010).

Within the online sphere, a few studies analyzed the gendered differences in the utilization of the medium. Some studies claim that men have more "friends" or "followers" than women, with others concluding the opposite (Kuss and Griffiths 2011). At the citizen level, Cha (2010) shows that age was inversely related to frequency of social media use and that women were more active users and spent more time on social media sites than men. Furthermore, Evans (2016) uncovers that female candidates were more likely to tweet than their male counterparts in the House election of 2012, but those differences disappear in non-election periods. Therefore, to get a better picture of tweeting behavior, data from a non-election period that does not have this skew based on gender would show how the usual tweeting behavior of Congress is like. 
On the campaign website for congressional candidates in 2000 and 2002, Dolan (2005) reveals few significant differences in the issues on which women and men campaign, and most of those could be explained by party, not sex. Similarly, another study by Naven and Zilber (2001) examined the official websites of a sample of members of MCs, and confirms little difference, with a majority of both congresswomen and men focusing on “women's issues." In her book chapter, Lawless (2012) found that Republicans were

producing the most content as the out-group. In an analysis of mudslinging on Twitter during the 2014 election, Senate incumbents and winners tended to send more attack tweets, while the House results were the exact opposite (Evans et al. 2017). Also, congresswomen sent more attack tweets than their male counterparts in both chambers. While there are a few interesting strides made, a clear picture of congressional gender differences in social network usage is still very much in progress in the literature.

\section{Theory}

Most literature on congresswomen emphasizes gender, but not partisan, differences in behavior and legislation. This chapter will explore the impact of both gender and partisanship on the issue areas broached in the tweets of MCs.

First, since congresswomen are perceived as better suited to address education and health care, while men are seen as competent on defense and foreign affairs (Falk and Kenski 2006; Lawless 2004; Herrnson and Stokes 2003; Sanbonmatsu 2002; Kahn 1996; Huddy and Terkildsen 1993), I will test whether congresswomen use this strategic advantage to broach women's issues. With congresswomen in the House more likely than congressmen to vote for "women's interests" bills (Dolan 1998), a higher likelihood to 
pursue policy preferences that have gendered connotation with a greater female presentence in the legislature (Kanter 1997), testing whether women engage these areas online will push the literature towards a greater understanding of what congresswomen choose to emphasize in their political communication. Based on this literature, the expectation is that congresswomen will take advantage of the electorate's perception that they should address women's issues since they are best suited to do so, as well as their own feelings about acting as surrogate representatives (Carroll 1985). This suggests the following testable hypothesis:

H1: Democratic and Republican congresswomen will tweet more than Democratic or Republican congressmen about "women's issues."

Republican women may consider the fact that they may gain an advantage for crossing partisan lines and emphasizing feminine issues (Herrnston et al. 2003; Dolan 1998; Paolino 1995), but this is tempered by partisan factors. In the Senate, Schaffner (2005) found Democratic women more likely to campaign on education, health care, and childcare than Democratic men. In the House, Democratic women were more likely to campaign on social issues and abortion than Democratic men, and Republican women were more likely than Republican men to campaign on abortion (Dabelko and Herrnson 1997). Therefore, Republican congresswomen may choose to engage in women's issues in an effort to establish party loyalty.

Swers (2013) also shows how rising partisanship in Congress has been more favorable for Democratic women to advocate on behalf of women's interests and more 
challenging for Republican women. Increased partisanship has made the differences in ideology between Republican and Democratic women larger than their male colleagues (Frederick 2009, 197). Since women's issues have become part of the partisan divide, Democratic women attack the Republican agenda as harmful to women's interests, and Republican women feel compelled to defend their party's record rather than reach for bipartisan compromise (Swers 2016). Due to the reelection pressures of their party who prize ideological purity (Grossman and Hopkins 2016), and since these women's issues are perceived as less important to the Republican Party and general public, the literature seems to point to the fact that Republican women will not engage in this issue-based crossover to the extent that Democratic women will.

In tweets, Meeks (2015) finds that Republicans and Democrats tended to focus on party-owned issues. Since congresswomen consider their base when emphasizing their masculine or feminine traits (Bauer 2017; Burns, Eberhardt, Merolla 2013), in an increasingly partisan environment, it naturally follows that they would consider which issue areas to emphasize to prove their party loyalty. At the end of the day, congresswomen are running as strategic politicians - using the issues of the day and adopting their partisan perspectives to respond to these issues (Dolan and Lynch 2017). A synthesis of these scholarly works suggests the following testable hypothesis:

H2: Republican women will discuss social issues and women's issues more than Republican men. 
Congresswomen are perceived by constituencies as having additional competency for women's issues by virtue of their gender (Falk and Kenski 2006; Lawless 2004; Herrnson and Stokes 2003; Sanbonmatsu 2002; Kahn 1996; Huddy and Terkildsen 1993). This gender advantage, combined with women's issues being viewed as under Democratic ownership (Evans 2005, Wolbrecht 2000; Petrocik 1996), means Democratic women should have the greatest advantage to engage in this issue area. The incentive is there for Democratic women to take advantage of the gender as well as party advantage, more so than their male Democratic colleagues, or Republican congresswomen. Therefore, the path of the literature suggests the following hypothesis:

H3: Democratic congresswomen will emphasize "women's issues" more than all other party-gender combinations in Congress.

Lastly, while the congressional gender literature tends on focus on "women's issues," like whether congresswomen support them more than their male colleagues (Dolan 2008; Swers 1998), few studies analyze the dynamics of partisanship and gender as they interact with broaching "men's issues". Male politicians tend to be linked to issues such as economy, foreign affairs, as well as national defense and the military, which is how men's issues tend to be defined (Carroll \& Schreiber 1997). The scholarship generally focuses on linguistic elements of feminine versus masculine speech, like Midwestern congresswomen stressing the masculine aspects of their personalities while male counterparts did not (Lee 2013) or congresswomen discussing female issues more often than men (Fridkin and 
Woodall 2005; Dolan and Kropf 2004; Gulati 2004). Dolan and Kropf (2004) show men claim credit for "male issues" while women claim credit for "female issues".

To get at the interaction of gender and partisanship, Evans (2016) analyzes tweets during and after the 2012 elections, concluding congresswomen spend more time devoted to "female issues" than male representatives, but they also send more tweets about "male issues" than men. While not statistically significant, Evans did find evidence that Republicans sent more tweets regarding "male issues" in the summer months. Considering this was the only study analyzing coverage of women's versus men's issue areas in congressional tweets, this chapter will add to the scarce literature that looks at the interaction of gender and party in congressional communication. In legislative activity within the Senate, Swers (2016) finds Republican women constrained since women's issues are not central to the message of the Republican Party, and thus they tend not to spend political capital on policies such as health policies, while Democratic women are expected to, since the policy reputation of the Democratic Party aligns with their preferences. Therefore, the literature seems to indicate an impetus when party goals and preferences align to go after particular issue areas. Considering men's issues coincide with Republican ownership of issue areas like foreign policy or national security (Wolbrecht 2000; Petrocik 1996), the expectation for the next hypothesis is as follows:

H4: Republican men will emphasize "men's issues" more than all other genderparty combinations in Congress. 


\section{Data and Methods}

The choice of Twitter as the means of communication for candidates is due to its efficient, inexpensive, and immediate nature (Gainous and Wagner 2014), and as such is widely used by members of the House (Golbeck, Grimes, and Rogers 2010). Since MCs must stay within the parameters of 140 characters per tweet, it distills their policy statements to simple tweets that citizens prefer compared to detailed plans (Kahn and Kenney 2002). Therefore, by analyzing tweets, we can see not only congressional campaign strategies, but also their efforts to connect with constituents, including at a surrogate level for women. Therefore, the use of Twitter was due to its widespread use, concise nature owing to its character limit, as well as a need to fill a gap in the political communication literature, as few studies (apart from Evans 2016) analyze gender and partisanship as it impacts congressional tweets. Since House members are always concerned with re-election, the primary motivator for a selection of a week in May coincided with two weeks that would activate both Democratic and Republican issue areas, which allows for a look at the phenomenon of gendered partisanship.

During the week of May 1-7, 2015, according to the NY Times headlines, the top news of the week was: passage of a cost-cutting budget plan in Congress, mulling the fate of the Iran nuclear agreement deal, considering whether the N.S.A. should be collecting data about Americans, and dealing with allegations of police overreach. During May 1-7, 2016, Congress was preoccupied with: the Flint water crisis, North Carolina's controversial transgender bathroom law, and another combat death in Iraq. Within the week in May in 2016, Republicans and Democrats were in the midst of running potential presidential candidates, but of the nearly 10,000 total tweets, just a handful mentioned potential 
candidates. Most importantly, the period under study coincided with both Mental Health Awareness Week as well as Small Business Week, which allows for a close view of how specific legislators broach each topic (if they do so at all). It is also convenient that both of these symbolic weeks focus on issues areas that are typically associated with gender and party lines.

To choose how to go about coding the tweets, I first ran a pilot study where I took a small sample of 10 congresswomen and 10 congressmen and their tweets over the course of two weeks to establish a codebook and get a feel for the data I would be looking at. It became clear that some tweets were written in a manner that would not facilitate easy computer coding (e.g. no comment but a link to a picture in the district, one-word statements framed by an explanation of what it meant in surrounding tweets). Since the validity of automatically applied measures comes into question within computer-aided text analysis (CATA) as it does not account for human nuance (Neuendorf 2017, 39) and I wanted to be able to get rich qualitative data, I decided to use hand-coding for the entire House over a small timeframe. The House has a small percentage of congresswomen compared to congressmen and getting a slice of what all men and women in the House have to say for one week across two years allows for a look at what electorally motivated behaviors they display during a "regular" period. That said, the limitations for a smaller timeframe include not considering MCs who tweet less frequently - the number of tweets can range from a few per year up to 20 a day. However, to account for women and men's issue activation, a week was chosen that would spur tweets from both categories of tweets.

To test intercoder reliability, a coder was trained by reviewing the codebook and independently applying it to a random sample of tweets $(n=500)$, meeting the minimum 
requirement based on Kaid and Wadsworth (1989) suggestion of 5-7\% of the total sample size. A coding comparison query was run in NVIVO to determine the Kappa coefficient. If there is complete agreement then the Kappa coefficient $(K)=1$, while if there is no agreement among the raters (other than what would be expected by chance) then the Kappa coefficient $(\mathrm{K}) \leq 0$. The Kappa values exceeded appropriate acceptance levels, as the overall weighted Kappa for the entire coded random sample was 0.79 .6 The Kappa coefficient for women's issues was 0.77 and for men's issues was 0.85 , meeting the standards of excellent agreement based on the guide to interpretation provided by NVIVO, as delineated by Fleiss et al. (2003).

To examine these hypotheses, a mixed-methods approach was used on the Twitter feeds of all House congresswomen and men for the weeks of May 1-7, 2015 and May 1-7, 2016 to facilitate an analysis of tweets based on gender, party, and issue areas. Since handcoded analysis was undertaken for this study, I teased out the nuance of the women's and men's issue area categories. I used quantitative analysis to unpack the statistical relationships between women's issues, gender, and party. Since my main dependent variables are a simple count of tweets at the member-level for women's and men's issues, I use a negative binomial regression model (NBRM) for the statistical analysis. Considering differences in the overall number of congresswomen and men in the House and member-level variation in the number of tweets sent during the study's timeframe, a

\footnotetext{
${ }^{6} \mathrm{~A} \mathrm{~K}$ value of over 0.75 indicates excellent agreement, $0.40-0.75$ is fair to good agreement, and below 0.40 is poor agreement. See here: http://helpnv11mac.qsrinternational.com/desktop/procedures/run_a_coding_comparison_query.htm\#MiniT OCBookMark7
} 
negative binomial regression is more appropriate than a linear regression model because it can be used for over-dispersed count data (Long 1997). The NBRM is commonly used for general over-dispersed counts within the congressional literature (see: Peterson 2014; Swers 2007; Anderson et al. 2003). The data collected for this project contains similar characteristics. The NBRM is also widely used in scholarly work with research designs that mirror my own (how various member-level characteristics influence a simple count of some type of MC behavior). For example, the NBRM is utilized in studies that focus on how the racial or ethnic characteristics of MCs impact representation (Grose 2011; Wilson 2010), how gender influences vote revelation strategy (Cormack 2016), and how gender affects congressional tweets (Evans et al. 2017; Evans 2016; Evans and Clark 2015).

The DVs were coded by explicit or implicit reference to women's or men's issues. Explicit mention would be any reference to the issue in question, such as Medicare for a healthcare tweet within women's issues, such as Rep. Suzan DelBene (D, WA-1) tweet: “I support the \#RaiseTheWage Act so Americans working a 40-hour week aren't living below the poverty line. \#12by2020 http://t.co/L2AUKEpbaq." Implicit reference would be either text or a picture that indirectly references that subject area; for instance, a picture about increasing the share for veteran's affairs in the budget would count for men's issues. An example of a men's issue tweet is as follows: "Let's get Washington out of the way, so \#smallbiz can grow. Check out my Main Street jobs plan >\&gt; https://t.co/2npV6vfN05 \#SmallBizWeek2016” - Rep. Tim Walberg (R-MI).

The main independent variables of interest are gender (dichotomous, $1=$ congresswoman), party (dichotomous, 1 = Democrat), and the interaction between gender and party. These variables will be crucial for getting leverage on Hypothesis 1 and 
Hypothesis 2-whether congresswomen focus more on women's issues while congressmen focus more on men's issues, with Democrat congresswomen and Republican congressmen engaging in women's and men's issues the most, respectively.

The statistical models also account for a number of control variables that potentially impact the level of women's issue versus men's issue tweets. Given that a MC's committee assignment can guide policy activity (Norton 2002; Hall 1996) and influence the volume and content of their political communication, I include a dichotomous variable for membership in a constituency or re-election minded committee ${ }^{7}$ (as opposed to informational committees, as defined by Young and Heitschusen 2003, and Frisch and Kelly 2004). Membership on these kinds of committees may influence the focus on women's versus men's issue areas. Another measure that would influence electoral behavior more generally is ideology; there may be an incentive for more liberal MCs to focus on women's issues, or more conservative MCs on typically masculine issue areas like national security. As a result, I also incorporate a MC's DW-Nominate score ${ }^{8}$ as a control. The party leadership is a more nationally visible role than an average legislator and there is reason to believe they might be focusing more on nationally-minded issues or more strictly adhere to their party agenda; therefore, I include a dichotomous party leader

\footnotetext{
${ }^{7}$ Descriptive data for what committees the House members were in was gathered from Charles Stewart III and Jonathan Woon's Congressional Committees dataset in voteview.com, while the theoretical justifications for which committees qualified as a constituency committee came from a combination of Frisch and Kelly (2004) as well as Young and Heitschusen (2003)'s classifications of district motivated committees as opposed to informational committees. The reelection minded constituency committee was comprised of a bin of Agriculture, Armed Services, Natural Resources, Science, Small Business, Transportation, and Veterans Affairs committees.

${ }^{8}$ Voteview.com archive.
} 
variable. ${ }^{9}$ Additionally, I integrate the most recent two-party electoral margin (percent) in each MC's district. The communication strategies of those running on tight margins may look different from those running in relatively safe districts. This serves as an important control because Republican women tend to be elected from more marginal districts (Evans 2005). ${ }^{10}$

Second, I provide a rich qualitative analysis of how gender and party impact the tweets of MCs on a women's issue (healthcare) and a men's issue (business). Women's issues were those defined by the literature, particularly informed by Evans $(2016)^{11}$ and the Congressional Caucus for Women's Issues (whose membership consists of all women in both the House and Senate) who have delineated their accomplishments for "women's issues" as healthcare, education, civil rights, and child support enforcement. ${ }^{12}$ Thus, gendered or women's issues were coded as abortion, education, healthcare, minimum wage, race, social welfare, and mentions of women. Men's issues were informed by issue area literature (Wolbrecht 2000; Petrocik 1996), and thus were coded as business, national security, foreign policy, guns, military, business/economic matters (including regulation, jobs, and taxes) and budgeting. For the qualitative section, I chose healthcare and business as my focus for the impact of gender and partisanship, as the week chosen coincides with

\footnotetext{
${ }^{9}$ Leadership was counted from Speaker of the House to House Minority Whip.

${ }^{10}$ Daily Kos Elections dataset.

${ }^{11}$ See Evans (2016) Appendix 1; pg. 672 for list of "female" versus "male" issues.
} 
Mental Health Week, as well as Small Business Week, which causes an activation of women versus men's issue areas.

The dataset includes $431 \mathrm{MCs}, 354$ are congressmen, and 77 are congresswomen. The average age is 60 . Furthermore, the average length of service is approximately 9 years.

\section{Results}

Quantitative Analysis of Gendered Issue Areas in Congressional Tweets "Women's Issues"

To test the first hypothesis of whether congresswomen broach women's issues at higher rates than congressmen, Table 1 compares the mentions of women's issues by gender and party as a percentage of the tweet totals for each category. Past research shows that congresswomen tweet more than congressmen on women's issues while congressmen spend more time on men's issues (Fox 1997; Kahn 1993). In addition, studies reveal that congresswomen tweet at similar levels as congressmen on "Men's issues" (Evans et al. 2015), but also tweet about women's issues more extensively (Evans and Clark 2015). To account for the disparity among the groups based on the total number of tweets per category, I compare percentages rather than raw counts.

Table 1 provides some support for the underlying logic of H1 (Democratic and Republican congresswomen will tweet more than Democratic or Republican congressmen about "women's issues"), but it only holds for Democratic congresswomen. As a group, Democratic congresswomen mentioned women's issues at the highest rate $(44 \%$ of their tweets). Democratic congressmen came in second, mentioning women's issues in $24 \%$ of their tweets. While Republican congresswomen (21\%) did not mention women's issues 
more than Democratic congressmen (24\%), they did outperform Republican congressmen (11\%). This suggests that both gender and partisanship are playing a strong, and tangled, role in these relationships. Furthermore, looking at the highest percentage of women's issues content for each category, healthcare was the top mentioned women's issue area by all members of Congress, across both gender and party lines. As we saw in the tweet text within the qualitative content analysis, congressmembers broached healthcare with different frames and focus, in accordance with partisan expectations - Republicans focused more on Obamacare repeal, the business aspect of healthcare, and assuaging fears of cutting back on Medicare, while Democrats were broaching healthcare to urge more federal funding.

In Table 2, mentions of "masculine" issue areas are also compared by gender and party as a percentage of tweet totals. As expected, Republican congressmen mentioned "men's issues" at the highest rate when compared to other groups (39\% of their total tweets), lending support to hypothesis 4 . The other three groups are all tightly packed together in the mid-20s (Democratic congresswomen, 26\%; Republican congresswomen, 25\%; and Democratic congressmen, 24\%). One possible explanation for the high level of "masculine issue" tweets by Democratic congresswomen is the presence of Small Business Week in the timeframe under study. As discussed in the previous section, Democratic women took full advantage of the occasion to showcase their presence in the district - often using multiple tweets and events throughout the week. In comparison, general tweeting behavior of Republican congresswomen tended to contain a lot of advertising (devoid of policy content), instead showcasing district events, or news in the district, state, or nation. 
${ }^{13}$ If we look at the highest mention men's issue for each group, Democrat congresswomen mention small business the most, Republican congresswomen are tied at $5 \%$ for mentions of veterans and small business, Democrat congressmen mention foreign policy and small business the most, and at 11\%, Republican men mention small business the most out of all the other groups. Based on the text of the tweets, the high rate of mentioning veterans for Republican congresswomen is due to connecting it to healthcare, a traditionally Democratic/women's issue area. Democrat congressmen mention foreign policy at such high rates due to some mega-tweeters detailing their trips abroad during this time period and connecting it to our national policies regarding Israel, Iran, and free trade policies.

${ }^{13}$ A further explanation is in chapter three, which analyzes content posted by congressmembers by advertising, position taking, and credit claiming behaviors. Republican women are the highest advertisers $-88 \%$ of their total content posted. 
TABLE 1

"Women's Issue" Mentions in Congressional Tweets

\begin{tabular}{|c|c|c|c|c|c|c|c|c|}
\hline & \multicolumn{2}{|c|}{ Democratic Women } & \multicolumn{2}{|c|}{ Republican Women } & \multicolumn{2}{|c|}{ Democratic Men } & \multicolumn{2}{|c|}{ Republican Men } \\
\hline & $\begin{array}{c}\# \text { of } \\
\text { Tweets }\end{array}$ & $\begin{array}{c}\% \text { of Total } \\
\text { Tweets }\end{array}$ & $\begin{array}{c}\text { \# of } \\
\text { Tweets }\end{array}$ & $\begin{array}{c}\% \text { of Total } \\
\text { Tweets }\end{array}$ & $\begin{array}{c}\text { \# of } \\
\text { Tweets }\end{array}$ & $\begin{array}{l}\% \text { of Total } \\
\text { Tweets }\end{array}$ & $\begin{array}{c}\# \text { of } \\
\text { Tweets }\end{array}$ & $\begin{array}{c}\% \text { of Total } \\
\text { Tweets }\end{array}$ \\
\hline abortion & 9 & $0.56 \%$ & 5 & $0.93 \%$ & 3 & $0.10 \%$ & 19 & $0.45 \%$ \\
\hline education & 174 & $11 \%$ & 29 & $5 \%$ & 0 & $0 \%$ & 0 & $0 \%$ \\
\hline environment & 24 & $1 \%$ & 4 & $1 \%$ & 84 & $3 \%$ & 79 & $2 \%$ \\
\hline healthcare & 217 & $13 \%$ & 66 & $12 \%$ & 312 & $10 \%$ & 326 & $8 \%$ \\
\hline LGBT & 29 & $2 \%$ & 1 & $0.19 \%$ & 44 & $1 \%$ & 1 & $0.02 \%$ \\
\hline minimum wage & 0 & $0 \%$ & 0 & $0 \%$ & 48 & $2 \%$ & 1 & $0.02 \%$ \\
\hline race & 93 & $6 \%$ & 0 & $0 \%$ & 116 & $4 \%$ & 13 & $0.31 \%$ \\
\hline social welfare & 77 & $5 \%$ & 2 & $0.37 \%$ & 94 & $3 \%$ & 29 & $0.69 \%$ \\
\hline women & 76 & $5 \%$ & 8 & $1.48 \%$ & 30 & $1 \%$ & 12 & $0.29 \%$ \\
\hline equal pay & 17 & $1 \%$ & 0 & $0 \%$ & 0 & $0 \%$ & 0 & $0 \%$ \\
\hline Total & 716 & $44 \%$ & 115 & $21 \%$ & 731 & $24 \%$ & 480 & $11 \%$ \\
\hline
\end{tabular}

Notes: Total \% tweets includes Retweets. Total Tweet totals for each category are: Democrat Women $=1616$; Republican Women $=540$; Democratic Men $=3041$; and Republican Men $=4177$. Total N=9374. 
TABLE 2

"Men's Issue" Mentions in Congressional Tweets

\begin{tabular}{|c|c|c|c|c|c|c|c|c|}
\hline & \multicolumn{2}{|c|}{ Democratic Women } & \multicolumn{2}{|c|}{ Republican Women } & \multicolumn{2}{|c|}{ Democratic Men } & \multicolumn{2}{|c|}{ Republican Men } \\
\hline & $\begin{array}{c}\text { \# of } \\
\text { Tweets }\end{array}$ & $\begin{array}{c}\% \text { of Total } \\
\text { Tweets }\end{array}$ & $\begin{array}{c}\text { \# of } \\
\text { Tweets }\end{array}$ & $\begin{array}{c}\% \text { of Total } \\
\text { Tweets }\end{array}$ & $\begin{array}{c}\text { \# of } \\
\text { Tweets }\end{array}$ & $\begin{array}{c}\% \text { of Total } \\
\text { Tweets }\end{array}$ & $\begin{array}{c}\text { \# of } \\
\text { Tweets }\end{array}$ & $\begin{array}{c}\% \text { of Total } \\
\text { Tweets }\end{array}$ \\
\hline budget & 22 & $1 \%$ & 4 & $1 \%$ & 39 & $1 \%$ & 79 & $2 \%$ \\
\hline jobs & 35 & $2 \%$ & 4 & $1 \%$ & 35 & $1 \%$ & 76 & $2 \%$ \\
\hline economy & 35 & $2 \%$ & 3 & $1 \%$ & 34 & $1 \%$ & 62 & $1 \%$ \\
\hline foreign policy & 63 & $4 \%$ & 24 & $4 \%$ & 138 & $5 \%$ & 235 & $6 \%$ \\
\hline guns & 11 & $1 \%$ & 0 & $0 \%$ & 18 & $1 \%$ & 10 & $0.24 \%$ \\
\hline infrastructure & 18 & $1 \%$ & 2 & $0.37 \%$ & 57 & $2 \%$ & 16 & $0.38 \%$ \\
\hline military & 37 & $2 \%$ & 32 & $6 \%$ & 83 & $3 \%$ & 283 & $7 \%$ \\
\hline national security & 6 & $0.37 \%$ & 2 & $0.37 \%$ & 41 & $1 \%$ & 112 & $3 \%$ \\
\hline regulation & 4 & $0.25 \%$ & 6 & $1 \%$ & 6 & $0.20 \%$ & 58 & $1 \%$ \\
\hline small business & 140 & $9 \%$ & 27 & $5 \%$ & 167 & $5 \%$ & 449 & $11 \%$ \\
\hline taxes & 1 & $0.06 \%$ & 5 & $1 \%$ & 10 & $0 \%$ & 67 & $2 \%$ \\
\hline veterans & 49 & $3 \%$ & 27 & $5 \%$ & 92 & $3 \%$ & 180 & $4 \%$ \\
\hline Total & 421 & $26 \%$ & 136 & $25 \%$ & 720 & $24 \%$ & 1627 & $39 \%$ \\
\hline
\end{tabular}

Notes: Total \% tweets includes Retweets. Total Tweet totals for each category are: Democrat Women =1616; Republican Women = 540; Democratic Men = 3041; and Republican Men = 4177. Total N=9374. 
Are the differences revealed in Table 1 statistically significant? After running a two-sample t-test with equal variances, the results show that Democratic congresswomen are more than twice as likely to mention women's issues compared to congressmen $(\mathrm{t}=-6.04, \mathrm{p}<0.05)$. Democratic congressmen are also more likely to mention women's issues when compared to Republican congressmen ( $\mathrm{t}=-3.8, \mathrm{p}<0.05)$. The relationship is the opposite for Republican congressmen; they are significantly less likely to mention women's issues in their tweets compared to Democrat congresswomen $(t=7.4, p<0.05)$. Republican congresswomen also appear to be less likely to mention women's issues compared to Democratic congressmen ( $t=1)$, but this difference is not statistically significant.

In Table 2, a two-sample $t$ test was also run for mention of masculine issues by gender and party affiliation. Masculine issues were expected to be significant, particularly for Republican men. At a $\mathrm{p}$ value of .05 , a positive statistical significance was found for Republican men ( $\mathrm{t}=-2.2)$, and Democratic men ( $\mathrm{t}=2.4)$ for being less likely to tweet about it. Statistical significance was not found for Republican women $(t=-0.36)$ or Democratic women $(t=0.18)$. Taking the results of Tables 1 and 2 in conjunction with the t-tests, we see some support for hypothesis 2 and 3 - Republican women do mention women's issues more than their Republican colleagues, but not at the high level that Democratic women do. Democrat men tweet more about women's issues than do Republican women, so we do not see full support for hypothesis 1.

When thinking about other factors that may impact Congressional tweeting about feminine versus masculine issues, the text of tweets pointed to holding a party leadership position, or committee membership playing a role in a focus on tweet 
content. Party leadership tended to take advantage of issue activation during these weeks to emphasize how their party is making a different during small business week for the GOP, and mental health week for Democrats. Literature also pointed to the issue of gendered vulnerability, particularly since women tend to be running in contested districts. Table 3 and 4 show the results of a regression used to test the interaction of these variables for masculine and feminine issues respectively. These controls include a dichotomous variable of membership in a constituency or re-election minded committee $^{14}$, DW-Nominate score ${ }^{15}$, a dichotomous party leader variable ${ }^{16}$, and their electoral margin percent ${ }^{17}$.

When thinking about other factors that may impact congressional tweeting about feminine versus masculine issues, the text of tweets pointed to holding a party leadership position, or committee membership playing a role in a focus on tweet content. Party leadership tended to take advantage of issue activation during these weeks to emphasize how their party is making a different during small business week for the GOP, and mental health week for Democrats. Literature also pointed to the issue

\footnotetext{
${ }^{14}$ Descriptive data for what committees the House members were in was gathered from Charles Stewart III and Jonathan Woon's Congressional Committees dataset in voteview.com, while the theoretical justifications for which committees qualified as a constituency committee came from a combination of Frisch and Kelly (2004) as well as Young and Heitschusen (2003)'s classifications of district motivated committees as opposed to informational committees. The re-election minded constituency committee was comprised of a bin of Agriculture, Armed Services, Natural Resources, Science, Small Business, Transportation, and Veterans Affairs committees.

${ }^{15}$ Voteview.com archive.

${ }^{16}$ Leadership was counted from Speaker of the House to House Minority Whip.

${ }^{17}$ Daily Kos Elections dataset.
} 
of gendered vulnerability (Lazarus and Steigerwalt 2018; Evans 2005), particularly since women, especially republican women, tend to run in contested districts.

In order to better understand the relationships and control for other possible confounding factors, I ran a negative binomial regression for women's issues, including a model with and without a gender and party interaction variable. The results in Table 3 indicate that an MC's gender has a weak correlation in mentioning women's issues, but the strongest predictor is DW-Nominate score. Thus, we are seeing the phenomenon of not just any Democrat emphasizing women's issues, but liberal Democrats in particular emphasizing women's issues. Considering many Democrats took advantage of the tweet storm that occurred with Mental Health Week to push the Democratic agenda more broadly, this provides some insight into why liberalism may have affected the incidence of women's issue tweets. Thus, the results indicate gender as a weak predictor, but the strongest indicator is liberalism on the DW-nominate scale. Gender may be a weak predictor due to a threshold issue - MacDonald and O'Brien (2011) find that women provide higher levels of substantive representation on social welfare issues than their male colleagues, but only when women populate the House at relatively high percentages (480).

In Table 4, we find two party margin and party leadership as the significant predictors of whether tweets will focus on masculine issues. In conducting textual analysis, many tweets regarding small business week were tweeted from Republican and Democratic leadership and retweeted by party members, with Republicans being more likely to retweet leadership and party accounts. Furthermore, while it was clear that Republican men focused on masculine issue areas for a higher percentage of their 
total tweets as found in Table 2, the regression does not take into tweet totals put into perspective of what percent it would be of their total tweets.

The results of these regressions should be contextualized with Tables 1 and 2, which find that Democratic women do disproportionately focus on women's issues just as Republican men focus on masculine issues, even if the latter was not found statistically significant. For men's issues, two party margin was found to be significant. Focusing on more men's issue areas may be due to the fact that they are perceived by the electorate to be more important to address (Hayes 2011; Smith et al. 2007). Just what these issue area tweets look like will be further analyzed in the following qualitative section. 
TABLE 3

Congressional Tweets Mentioning "Women's Issues"

\begin{tabular}{|c|c|c|c|c|}
\hline & $\begin{array}{l}\text { Model } 1 \\
\text { Coef. } \\
\text { (S.E.) }\end{array}$ & & $\begin{array}{l}\text { Model } 2 \\
\text { Coef. } \\
\text { (S.E.) } \\
\end{array}$ & \\
\hline \multirow[t]{2}{*}{ Gender } & 0.20 & & 0.12 & \\
\hline & $(0.134)$ & & $(0.251)$ & \\
\hline \multirow[t]{2}{*}{ Democrat } & -0.56 & & -0.58 & $\dagger$ \\
\hline & $(0.347)$ & & $(0.349)$ & \\
\hline \multirow[t]{2}{*}{ DW-Nominate (1st Dimension) } & -1.66 & $* *$ & -1.65 & $* *$ \\
\hline & $(0.388)$ & & $(0.388)$ & \\
\hline \multirow[t]{2}{*}{ Gender x Democrat } & & & 0.11 & \\
\hline & & & $(-0.296)$ & \\
\hline \multirow[t]{2}{*}{ Two Party Margin } & -0.09 & & -0.09 & \\
\hline & $(0.160)$ & & -0.160 & \\
\hline \multirow[t]{2}{*}{ Party Leader } & 0.64 & & 0.626 & \\
\hline & $(0.579)$ & & $(-0.580)$ & \\
\hline \multirow[t]{2}{*}{ Constituency Committee } & -0.05 & & -0.05 & \\
\hline & $(0.102)$ & & $(-0.102)$ & \\
\hline \multirow[t]{2}{*}{ Constant } & 2.19 & $* *$ & 2.19 & $* *$ \\
\hline & $(0.214)$ & & -0.22 & \\
\hline$N$ & 431 & & 431 & \\
\hline $\mathrm{R}^{\wedge} 2$ & 0.0379 & & 0.0380 & \\
\hline
\end{tabular}

$\dagger \mathrm{p}<.1 ; * \mathrm{p}<.05 ; * * \mathrm{p}<.01$ 


\section{TABLE 4}

Congressional Tweets Mentioning "Men's Issues"

\begin{tabular}{|c|c|c|c|c|}
\hline & $\begin{array}{c}\text { Model } 1 \\
\text { Coef. } \\
\text { (S.E.) }\end{array}$ & & $\begin{array}{c}\text { Model } 2 \\
\text { Coef. } \\
\text { (S.E.) }\end{array}$ & \\
\hline \multirow[t]{2}{*}{ Gender } & 0.14 & & -0.09 & \\
\hline & $(0.146)$ & & $(0.260)$ & \\
\hline \multirow[t]{2}{*}{ Democrat } & 0.14 & & 0.07 & \\
\hline & $(0.350)$ & & $(0.358)$ & \\
\hline \multirow[t]{2}{*}{ DW-Nominate (1st Dimension) } & 0.43 & & 0.40 & \\
\hline & $(0.395)$ & & $(0.397)$ & \\
\hline \multirow[t]{2}{*}{ Gender x Democrat } & & & 0.33 & \\
\hline & & & $(0.310)$ & \\
\hline \multirow[t]{2}{*}{ Two Party Margin } & -0.41 & $* *$ & -0.41 & $* *$ \\
\hline & $(0.172)$ & & $(0.172)$ & \\
\hline \multirow[t]{2}{*}{ Party Leader } & 1.50 & $* *$ & 1.47 & $* *$ \\
\hline & $(0.592)$ & & $(0.592)$ & \\
\hline \multirow[t]{2}{*}{ Constituency Committee } & -0.14 & & -0.141 & \\
\hline & $(0.106)$ & & $(0.106)$ & \\
\hline \multirow[t]{2}{*}{ Constant } & 1.94 & $* *$ & 1.97 & $* *$ \\
\hline & $(0.222)$ & & $(0.225)$ & \\
\hline$N$ & 431 & & 431 & \\
\hline $\mathrm{R}^{\wedge} 2$ & 0.0093 & & 0.0097 & \\
\hline
\end{tabular}




\section{Qualitative Analysis of Gendered Issue Areas in Congressional Tweets}

"Women's Issue": Healthcare (Mental Health Week)

In the quantitative portion, the NBRM model indicated that gender was a weak predictor and the strongest predictor is liberalism for broaching women's issues. While both Republicans and Democrats touched on this gendered issue area, there was a tangible difference in the way that they focused on these issues. Democrats, specifically liberal congresswomen, tweeted acknowledgement of Mental Health Month in order to destigmatize the illness, and urged action on a multitude of issues on the Democratic agenda - shaming Speaker Ryan for not pressing the budget vote, Zika funding, curtailing the opioid epidemic, as well as Flint Water Crisis. Some Republican women made mention of women's issues to emphasize their pro-life position, following Dabelko and Herrnson's (1997) finding that Republican women will emphasize their position on social issues and abortion more than men. Also, Republican women focused on veteran healthcare - a way of linking a traditional Republican category (veterans) to healthcare, traditionally a Democratic category. Republican men tended to focus on reassuring constituents they were not cutting Medicare and lauding personal achievements passing district-minded healthcare measures.

\section{Democratic Congresswomen}

Across the board, Democratic women were vocal about healthcare issues, including a whole platform on social welfare issues specifically affecting women in addition to the party effort to have a consistent message on mental health 
destigmatization. Democratic women also included some credit claiming on healthcare related bills.

For example, regarding healthcare as a women's issue, the following tweets illustrate the various types of content that you may find for Democrats, from health coverage for military personnel, to mental health reform, to providing child care benefits:

- Rep. Suzan DelBene (D-WA): “ICYMI:@EverettHerald on my bill to ensure health coverage for @USNationalGuard members who help in state disasters. https://t.co/eKNC1w2XFy" (May 3, 2016 at 9:17:08 PM)

- Rep. Virginia Garcia (D-OR): "We need \#paidfamilyleave; new moms shouldn't have to survive on hospital graham crackers. \#PoliticsIRL https://t.co/fwxv3TdqTi” (May 2, 2016 at 8:40:09 PM)

- Rep. Diana DeGette (D-CO): “As communities across US face heartbreak of opioid addiction every day, the time is now for comprehensive mental health reform \#MHM2016.” (May 2, 2016 at 6:23:57 PM)

- Rep. Donna Edwards (D-MD) "When \#WomenSucceed, America succeeds = \#PayEquity \#ChildCare \#FairPay \#PaidLeave \#RaiseMinimumWage.

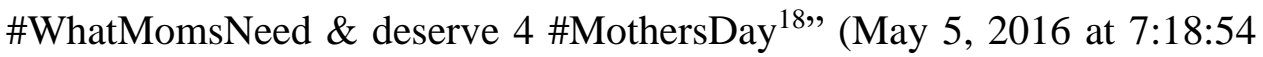
$\mathrm{PM})$

As mentioned in one of the tweets above, some Representatives took advantage of the occurrence of Mental Health Week/Month to tie it to their own legislative

\footnotetext{
${ }^{18}$ Mother's Day falls on the second Sunday in May - after the timeframe of this study.
} 
agendas, or that of the party. Some like Rep. Susan Brooks (D-IN) tied it to efforts in her district, directly soliciting her constituents: "May is \#MentalHealthMonth. Join @FishersIN in learning more about mental illness \& treatment. \#StigmaFreeFishers https://t.co/ZBjQDuiNKu" (May 6, 2016 at 2:05:30 PM). By tying a national level issue area to the district, Brooks is making this Democratic issue area relevant to her constituents, who may or may not be Democrats.

Other congresswomen used Mental Health Week to more broadly link to healthcare and the Democratic agenda, and were therefore widely retweeted by both Democratic men and women:

- Rep. Debbie Dingell (D-MI): “Unacceptable House recessed w/o \#budget vote, action on \#Zika, opioid epidemic, OR \#FlintWaterCrisis. Time to work together for American ppl” (May 2, 2016 at 12:35:57 PM).

Dingell was part of the tweet storm ${ }^{19}$ for Mental Health Week, but also took advantage of being widely retweeted to also draw attention a few other issues: her disapproval of the House recessing without voting on the budget, no action on funding for the CDC to take care of the Zika issue, no Congressional traction on the Flint water poisoning crisis, or movement to rectify the opioid epidemic.

Like Dingell, most Democratic women either posted or retweeted jabs at Speaker Ryan to try and shame him into bringing the House back into session and to place various health related measures on the agenda:

\footnotetext{
${ }^{19}$ Twitter lingo for many tweets being sent out
} 
- Rep. Kathy Cantor (D, FL): “RT @RepLujanGrisham: .@SpeakerRyan continues to keep House in recess w/ \#Zika threat, opioid epidemic, \#FlintWaterCrisis \& budget debacle p..." (May 6, 2016 at 1:42:10 PM)

- Rep. Chellie Pingree (D-ME): “Dems agree: Time to act, @ SpeakerRyan! // HuffPo: Most Americans Think Gov Could Do More To Stop Opioid Epidemic $\rightarrow$ http" (May 4, 2016 at 2:29:47 PM)

Only a handful of Democratic women tweeted about abortion. The text of these tweets either surrounded approval of RHNDA, which would prevent organizations such as religious or faith-based employers from making employment decisions based on reproductive health-care choices, or a defense of Planned Parenthood. Generally, the content of these tweets emphasized privacy in treating reproductive healthcare as a private health matter, with some like Rep. Gwen Moore even adding the hashtag \#IStandWithPlannedParenthood.

One example of such a tweet came from Rep. Donna Edwards (D, MD):

“Women's personal medical decisions aren't their bosses' business. I stand with the city and people of Washington, DC and oppose HJ Res 43." (May 1, 2015 at 2:04:43 $\mathrm{AM})$

Tweets like these provide some evidence for H3. While the NBRM model showed a weak indicator for gender and strong indicator for liberalism, here we see that Democratic congresswomen do take advantage of their issue ownership from gender as well as partisanship to take a stand for women's issue areas - in particular health care, since it was activated with Mental Health week. They take advantage of 
the attention of Mental Health week to draw attention to other issues on the Democratic agenda too.

\section{Democratic Men}

Compared to Democratic women, Democratic men tended not to dwell on gendered issue areas to the large extent their female colleagues did. That said, the more liberal Democratic congressmen did engage with Mental Health week, and therefore contributed to the finding in the NBRM model that the strongest predictor for tweeting about women's issues was liberal DW-nominate score. The overall trend for male Democratic congressmembers was to focus on the Democratic agenda, which included retweeting senior party members (men and women) to indicate their position regarding Mental Health Week, the opioid crisis, and efforts to curtail Zika. There were fewer personal tweets about individual congressmembers ties to healthcare, and more signal boosting of others in the party who had already tweeted about the topic. This retweet from Congressman Don Beyer (D-VA) provides an example of what these typically looked like:

- “RT @HouseDemocrats: It's simple: every American in need should have access to quality, affordable mental health care \#MHM2016" (May 2, 2016 at 6:27:51 PM)

This retweet from the House Democrat twitter account shows how the party is using issue area activation to emphasize their position on affordable, accessible health care. Similarly, Rep. Joe Courtney (D, CT) draws the attention of the House Democrats twitter account for them to retweet his post (which they did) regarding the opioid and 
drug epidemic. Like other Democrats, Courtney called on Speaker Ryan to make a solution or at least discussion of the opioid epidemic part of the Congressional agenda.

- “@HouseDemocrats have called on @SpeakerRyan to address the growing opioid \& heroin epidemic. Our letter: https://t.co/9zlPtCp13L \#DoYourJob" (May 5, 2016 at 12:30:15 PM)

Generally, leadership in the party widely retweeted Democratic women's tweets and senior Democratic men in the House coined their own tweets for healthcare topics:

- Rep. Elijah Cummings (D-MD): “The American people are right. Congress can \& must do more to fight the \#opioidepidemic. @ SpeakerRyan must act now. https://t.co/RXYlxHQlYV"

- Rep. Denny Heck (D-WA): "During \#MHM2016 lets commit to ending a stigma that has left too many suffering from mental illness feeling abandoned and alone.” (May 2, 2016 at 6:11:08 PM)

The outliers for the group were Rep. Joe Kennedy III (D-MA) and Rep. Paul Tonko (D-NY). Kennedy hosted a Mental Health Week (MHM) roundtable in his district (calling to mind Susan Brooks' tweet that was directed at the district as well) and also did a tweet stream relating to Mental Health Week. Tonko also tweeted multiple times on MHM and destigmatization, on issues pertaining to women like healthcare and education, and took part in the \#WhatMomsNeed tweetstorm that emphasized paid sick days, child care, quality health care, and more.

A notable tweet and corresponding picture came from Rep. Eric Swalwell (DCA): 
- "Mom worked hard raising me \& my bros. For \#MothersDay, consider \#WhatMomsNeed: fair wages, child care, health care. https://t.co/H5SYD2MRJ2” ( May 5, 2016 at 7:17:24 PM)

Swalwell made his political position clear with the personal touch of a photo of his mother and him as a baby - an effort to personalize his policy stances.

In sum, while there were a few male Democratic congressmen in leadership that coined their own tweets to make note of mental health week, most Democratic men either did not dwell on the topic or retweeted others, in particular Democratic women. Therefore Democratic women had higher rates of women's issue activation as expected by hypothesis 1 while Democratic men felt comfortable using issue activation of healthcare to further Democratic issue areas, though not at the high rates that their Democratic female colleagues did, as predicted in hypothesis 3 .

\section{Republican Women}

Again, in the NBRM model we saw that gender was a weak predictor of engaging in women's issues. Looking at the text of the tweets, we see that Republican women engaged in women's issues to showcase how they stand with their party's platform regarding healthcare topics. Representative Diane Black's (R-TN) tweets during the two weeks were indicative of how Republican women tended to tweet. Touching on one of the topical issues of the week, Transgender individuals' rights, including whether they should be able to use the bathroom they were most comfortable with, Rep. Black retweeted a Fox News link about how Planned Parenthood helps transgender patients with sex changes. Reposting the link, Rep. Black tweets: 
- "This is not health care and it should not be subsidized by taxpayer dollars. One more reason to \#DefundPP. https://t.co/1BS03t4jxL" (May 6, 2016 at 8:54:53PM).

Here we are seeing an instance where women's issues - LGBT rights as well as healthcare - is broached by Republican woman to emphasize how her stance aligns with the party.

A few congresswomen and men used to be nurses or doctors prior to serving in the legislature. On issue areas pertaining to healthcare, that may give additional credibility to their statements. Representative Diane Black (R-TN) whose tweet was mentioned about defunding Planned Parenthood, has a tie to healthcare - May 6 is National Nurses Day, and Rep. Black was a former nurse:

- "Happy \#NationalNursesDay! Honoring my fellow nurses today \& reflecting on my 40+ years in the industry that $\mathrm{I}$ love. https://t.co/tTwoxpnKMw" (May 6, 2016 at 2:01:55PM)

Rep. Renee Ellmers (R, NC) also used to be a nurse, and it is interesting to note that nearly all of her healthcare tweets dealt with veteran healthcare - a "masculine" or partisan tie to a traditionally feminine issue area. For example, she tweeted:

- "Read about special visitors to my office \& my bill to preserve access to prosthetic limbs for \#veterans \&amp; \#seniors: https://t.co/10PrjCZaOW" (May 2, 2016 at 6:50:12 PM)

These types of tweets linking a Republican owned issue area like veterans or the military to the Democrat owned issue of healthcare allows Republican congresswomen to emphasize the partisan element of an otherwise "women's issue," 
lending support to hypothesis 2 - emphasis on a women's issue area to underline their partisan loyalty and attachment.

Another instance of this was another of Rep. Black's tweets, this time on the issue of abortion:

- "Today the House took a stand for \#religiousfreedom \& voted to stop DC's coercive \#RHNDA law. Read my full statement: http://t.co/QH813rJW2t,"

Here we see Black taking credit for a vote where she voted against a women's issue, in line with Republican expectations. Black also claimed credit by retweeting the Susan B Anthony List's twitter, an organization that mobilizes Pro-Life women in politics:

- “RT@SBAList: THANK YOU @RepDianeBlack for leading the charge on H. J. Res. 43 to protect \#prolife \& religious orgs from DC's discriminatory...”@RepDianeBlack (R, TN) May 1, 2015 at 2:06:11AM.

Black's colleague Marsha Blackburn (R-TN) also retweets SBAList, expressing displeasure over Planned Parenthood:

- "RT@SBAList: .@MarshaBlackburn to Cate Dyer: Turn Over @StemExpress Documents https://t.co/hmVBCgmkK4 \#ProLife \#PPSellsBabyParts" - @MarshaBlackburn (R, TN) May 6, 2016 at 2:01:55PM.

Blackburn also tweeted her approval of the passage of H.J. Resolution 43 that Black was advocating for, emphasizing religious freedom and disapproval of RHNDA.

Thus, among Republican women we see a hard line against abortion as well as mandating an employer to provide contraceptives, consistent with the Republican party 
platform. Furthermore, if there are mention of healthcare initiatives, they tend to coincide with military or veterans' benefits. Compared to the ideological pressure that Republican women have due to their gender, very few Democratic women tweeted during these weeks about abortion. Here we can give some support to Hypothesis 2 Republican congresswomen do discuss social policy to emphasize their party loyalty in comparison to Republican congressmen, though it they do not do so more than liberal congresswomen, in alignment with Hypothesis 3 .

\section{Republican Congressmen}

Following partisan cues, Republican men tended not to tweet about healthcare or mental health week. Following the predictors of the NBRM model, Republican congresswomen have the least likelihood to broach women's issues, and the percentage of women's tweets compared to their total confirmed that. When healthcare was mentioned, it was either individual legislator's efforts in some element of healthcare or a top-down retweet of the GOP leadership's efforts towards healthcare, or insisting that they were not going to be cutting Medicare or hurting seniors. Only Representatives located in Florida mentioned wanting Zika funding, like Rep. Carlos Curbelo (R-FL):

- "My bill, Zika Eradication \& Good Gov Act, would ensure adequate funds are made available \&amp; taxpayers are protected https://t.co/CyLyCv6Ps5"

- Rep. Carlos Curbelo May 4, 2016 at 12:49:04 AM.

Representative Gus Bilirakis was an outlier within the Republican group of men, as he had a personal tie to healthcare - his family was affected by Parkinson's. Therefore, Bilirakis makes many references to the issue of healthcare, within and 
outside the district during the week in 2016 and 2015. For example, Congressman Bilirakis (R-FL12) tweets:

- "ICYMI: My bill will help the 600 medical device companies in FL: https://t.co/tt9mRV8ahi” (May 4, 2016 at 3:50:14 PM)

- “My constituents, including my family, have been impacted by Parkinson's. @ECcures brings hope to patients: https://t.co/95nIP7aBhP” (May 1, 2015 at 8:35:06 PM)

Here we see the phenomenon of having a personal tie to an issue area breaking through partisan lines, giving Bilirakis a measure of credibility, including the ability to credit claim by receiving the Legislator of the Year award from Florida Medical Manufacturers Consortium:

- "Monday I was honored to receive the Legislator of the Year award from @FloridaMedTech \#Path2Cures http://t.co/7oVAzPWQz4” (May 6, 2015 at 7:45:04 PM)

However, it is worth noting the tie between healthcare and business in receiving this award - the consortium advertises itself on Twitter as a "statewide association of medtech firms, which exists to unite, promote and grow our medical device industry." Even within the "feminine" healthcare element context, we see elements of business the "masculine" issue area. Furthermore, although Bilirakis did mention healthcare in 37 of his 65 total tweets, including a district-level event to address Zika - "Grateful to have @ONDCP's @ Botticelli44 here in \#FL12 to address the drug abuse \& addiction epidemic. https://t.co/n6097RWkOZ” (May 3, 2016 at 8:30:52 PM) - he did not make mention of mental health week during either week. 
Representative Charles Boustany (R, LA) as a former doctor, also had a tie to healthcare as a topic. Therefore, Boustany brought his expertise to bolster his efforts and credibility when speaking of Medicare, including credit claiming when the Ways and Means GOP twitter gave him a shout out for efforts to help seniors:

- “As a Dr, we can't put important drugs out of reach for seniors. That's why I'm leading effort to stop cutting \#Medicare reimbursements." (May 2, 2016 at 7:34:04 PM)

- "Cutting \#Medicare reimbursements will especially harm rural patients \& physicians. We should be looking to improve rural health, not harm." ( May 2, 2016 at 7:42:05 PM)

- “RT@WaysandMeansGOP: W\&M Reps @RepTomPrice \&amp; @RepBoustany are taking action to protect our seniors https://t.co/YzAF97bY8S https://t.co/dOG...”'(May 2, 2016 at 8:23:19 PM)

As another example, Rep. Frank Guinta (R-NH) also reassured his constituency in person that he will not be cutting Medicare during a townhall hosted in his district the eighth one he held by that point in May.

Since Republicans tend to do well in rural districts, we see some MCs like Rep. Cresent Hardy (R-NV) pushing for a Republican backed piece of legislation - the Rural Health Act:

- "Our rural communities are certainly resilient, but too often forgotten $b / c$ of that. We need \#RuralHEALTH Act \#NV04 https://t.co/SnH6Mi9wvt" (May 6, 2016 at 5:26:34 PM) 
Overall, we see a great deal of credit claiming for receiving awards tied to healthcare, assurances that Medicare will not be cut for seniors, and the occasional negative tweet about Obamacare, like Rep. Kevin Cramer (R-ND)'s:

"Taxpayers deserve better than the \#Obamacare bureaucracy that will deceive Congress and avoid the law. https://t.co/Hzci33kfJx" (May 6, 2016 at 8:26:01 PM)

Only one Republican congressman, Rep. Todd Young (R-IN) made reference to abortion, and this was in the context of other initiatives:

- "My priorities are simple: preserve the 2nd amendment, protect the unborn, repeal Obamacare, and reform the tax code. https://t.co/t98htIaPQg”- Rep. Todd Young (R, IN) May 3, 2016 at 7:15:02 PM.

Compared to Republican congresswomen, the emphasis on feminine or women's issues was not as prevalent. As expected by hypothesis two, Republican congressmen as a whole did not feel the need to engage in these issues to distinguish their position as much as Republican congresswomen.

\section{"Masculine” Issue: Business - Small Business Week}

Small Business Week was a popular tweet topic. Although the total tweet count was less than healthcare; a more diverse group of MCs participated. Members of Congress really used this opportunity to show off in the district: photos of MCs visiting district businesses were all over the House Twittersphere. In fact, mentions of small business are positively correlated with both district visits as well as photos posted of 
members of Congress for both weeks. ${ }^{20}$ Therefore, the results from the NBRM model showed that members from both sides of the aisle, regardless of gender, were engaging in men's issue tweets. While the percentage of tweets showed evidence for hypothesis 4, the NBRM model did not show significance for Republican congressmen emphasizing men's issues more than any other group. While Republican men and women were most likely to tweet about small businesses, what was distinctive between them was that Republican congressmen went beyond just advertising their visits to emphasize their personal legislative achievements in conjunction with celebrating Small Business week. Most of Republican congresswomen's tweets were advertising, highlighting their visits to the districts and the achievements of small businesses in their region, as opposed to their own legislative achievements. The NBRM model indicated that being part of the party leadership and having a marginal seat also impacted broaching men's issue areas. Considering the national importance of those issues classified as "men's issues," it follows that members of both parties would engage in broaching them.

\section{Republican Congressmen}

Even though the NBRM model did not show evidence for Republicans or congressmen (or the interaction of both) to be a predictor for engaging in men's issues, Table 2 did show that of the different party and gender combinations, Republican men did have the highest percent of their total tweets devoted to men's issues. Since

\footnotetext{
${ }^{20}$ For the tweet count, the only statistically significant finding was that Democratic men were less likely to tweet about small businesses.
} 
Republican congressmen are perceived by the electorate as best equipped to handle economic policies which happen to coincide with Republican strengths (Winter 2010; Petrocik 1996), as theorized by hypothesis 4, small business week should prove their time to shine. We see efforts to credit claim on the wave of the SmallBiz hashtag, like Rep. Brad Ashford (R-NE):

- "I'm committed to helping growing \#SmallBiz. My HIRED Act encourages laid off workers to \#DreamSmallBiz. https://t.co/jZ0zfZybFW" - (May 7, 2016 at 2:15:04 PM)

In addition to credit claiming on legislation he put forth, Rep. Ashford also has the qualification of being a previous small business owner that he uses to promise his district that he has their interests in mind. This is similar to how congresswomen and men with a healthcare background used their experiences to show their districts that they have the credibility to advocate for healthcare issues, regardless of partisanship. What we see throughout Republican congressmen's tweets are lots of district visits, credit claiming for voting and legislating behavior, highlighting the GOP's efforts to aid small businesses, and general facts about the role of small businesses in the American economy.

The tweets of the average Republican congressman during this period looks much like Rep. Gus Bilirakis's (R, FL):

- "This week we celebrate the small businesses that make our communities great. Be sure to spread the word \& \#shopsmall \#SmallBizWeek2016" (May 4, 2016 at 6:55:14 PM) 
Tweets included the small business week hashtag to grab national attention, urging constituents to support small businesses in their district, and more often than not, showcasing a picture or describing visiting a small business within their district. Also a prevalent theme was that of reducing regulation, as highlighted by Rep. Tim Walberg (R-MI):

- "Let's get Washington out of the way, so \#smallbiz can grow. Check out my Main Street jobs plan >\&gt; https:/t.co/2npV6vfN05 \#SmallBizWeek2016" (May 7, 2016 at 3:38:04 PM)

Republicans were able to link and emphasize Republican issue ownership with Small Business week, and thus highlighted achievements that would show their expertise in party "owned" matters like regulation.

So, Republican men were very much visible in the district, posting one or more photos of these visits. Rep Frank Guinta's tweet really encompasses the spirit of Republican men who emphasized their presence in the district during this week; he staged a photo to :

- "[PHOTOS] Worked behind the counter at downtown Manchester's Casario's today as part of \#NationalSmallBusinessWeek --> http://t.co/4knc5VuqHL" -(May 5, 2015 at 6:03:43 PM)

What is interesting to note, is the rural tie that again appeared in tweets, like Rep. Robert Aderholt's (R-AL):

- "Small businesses, which also includes family farms, are the backbone of America's economy. \#smallbusinessweek http://t.co/Oaces4qMwX" - Rep. Robert Aderholt (R, AL) May 4, 2015 at 10:05:15 PM. 
Small business is being tied to economy in a way that highlights the district and region by a focus on family farms. Republican women also touched on rural themes in their tweets, which follows considering their intense focus on the district.

Claiming credit for legislation was more visible for Republican men than Republican woman. For instance, Rep. Michael Burgess (R-TX) takes advantage of the small business hashtag to highlight his achievement:

- "My TROL Act defends small businesses from bad-faith patent demand letters http://t.co/7t9naN7SVe \#DreamSmallBiz \#smallbusinessweek" (May 5, 2015 at 4:59:00 PM)

In a distinctive credit claim, Rep Steve Chabot retweets GOPEspanol:

- “RT@GOPEspanol: El congresista@RepSteveChabot habla sobre la importancia de pequeños negocios en el mensaje semanal Republicano: https://t...”-@RepSteveChabot May 7, 2016 at 1:26:38 PM.

In the tweet, Rep Chabot highlights his role as House Small Business Committee chair, in Spanish. We have seen an effort among Republican legislators over the years to cater to the Hispanic bloc of voters, and so the news that Chabot is delivering the weekly Republican address was imparted both in an English and Spanish tweet. (He retweeted both). Also distinctive was Rep Chabot's mass retweeting of the GOP leadership tweets, particularly regarding small business week.

Ultimately, while there was no significance in the NBRM model, there is some evidence in the text of the tweets and in Table 2 supporting hypothesis four which states Republican congressmen should broach men's issues more than any other gender and 
party combination. This group very much did take advantage of small business week, a traditionally “men's issue," and a Republican owned issue area.

\section{Republican Congresswomen}

Republican congresswomen mentioned small business week in levels similar to their male counterparts, which explains why the NBRM model did not find significance for gender to be a predictor for broaching men's issues. Republican congresswomen highlighted their efforts to cater to their districts and support small businesses in person were similar to most MCs during this period. Occasionally, they might add some element of the feminine by their choice of where in the district to frequent, as was the case one year for Rep Diane Black (R, TN):

- "In honor of \#SmallBizWeek, had to stop at Cathy's Flowers \& Gifts in \#Lafayette - a \#TN06 favorite! \#ShopSmall https://t.co/naqJ4A2gmz" May 4, 2016 at 9:53:24 PM.

Noticeably, Rep Black put the qualifier of it being a district favorite, lest it seem solely informed by her feminine attributes, perhaps. Also, in the tweets surrounding that district visit, Rep Black emphasizes National Day of Prayer, bemoans political correctness, and as discussed in the section on healthcare, calls for the defunding of Planned Parenthood - all very much in line with masculine, partisan tendencies of the Republican Party.

Another interesting aspect of these tweets is how some representatives chose to celebrate small business week by highlighting the contributions of constituents, rather than highlighting any sort of partisan attachment or personal achievements like 
Republican congressmen tended to do. While Rep Marsha Blackburn (R, TN) elected to credit claim for issues of healthcare, she chose to delegate praise to others for this business issue area:

- "Congrats to Dr. Ed Glaser of Sole Supports, Inc., for being named @SBAgov's TN Small Business Person of the Year. http://t.co/JIRfvtsapH" (May 5, 2015 at 3:38:43 PM.)

Rep. Blackburn also sent another tweet saying how proud she was of the small businesses that were within her district.

The difference between Republican congressmen and congresswomen's tweets within the week boiled down to credit claiming behavior. Both advertised, but Republican men took it further by really emphasizing position taking and credit claiming in addition to simple advertising behaviors. While broader gender communications literature leads the expectation that women will use more credit sharing language when taking credit in a work setting (e.g. Haynes et al. 2013) and female legislators may engage in more collaboration (Rosenthal 1998), a more recent study analyzing credit claiming in newsletter finds credit claiming for women may be higher than men due to electoral insecurity (Dolan and Kropf 2004), and Lawless (2012) finds women credit claim at similar levels to men, though the findings were disaggregated from a picture on how partisanship affects that relationship.

Ultimately, we see Republican congresswomen will engage in the issue area that falls under their party's purview, but not to the extent that their male counterparts do. 


\section{Democratic Congressmen}

Of all the groups, Democratic men were least likely to emphasize small businesses. Thus, most tweets were some type of iteration reminding their district to shop small, or a district tour of a small business. President Obama was also doing a small business week conference call during the week, and some Democratic representatives, including some congressmen like Jim Himes (D-CT), Tony Cardenas (D-CA), Sam Farr (D-CA) urged their constituents to listen in.

Most Democratic congressmen retweeted Congresswoman Nydia Velazquez's (D-NY) tweet - who happens to serve on the small business committee:

- “RT@NydiaVelazquez: This National Small Business Week we salute American entrepreneurs who create 3 out of 4 new jobs. Let's help them succ...” - @RepGaramendi (D, CA) (May 6, 2015 at 8:40:24 PM)

This retweet was often followed by a tweet showcasing the conterssman's presence in the district, and a call for constituents to visit local businesses. One example is Rep Juan Vargas (D-CA):

- “Visited@FirstImperialCU's newly renovated \#ElCentro branch. I enjoyed meeting the team and touring their offices! http://t.co/IoySsaf1bF” May 6, 2015 at $7: 16: 38 \mathrm{PM}$.

While Rep Vargas made no direct mention of small business week within that tweet ${ }^{21}$ it came right after retweeting Rep Velazquez's small business week tweet

\footnotetext{
${ }^{21}$ This is a great example for the value of hand-coding tweets rather than relying on a fully automated system. Most automated processes would not have identified this tweet as related to Small Business Week because it likely would have ignored the surrounding context of the retweet.
} 
saluting entrepreneurs. Whether directly or indirectly mentioning small business, Democrat men generally tended to at least visit the district during that period, touring a small business.

A distinctive tweet came from Rep Don Beyer (D-VA):

- "Happy \#SmallBizWeek to you, \#VA08! I am a proud owner of a small business and an advocate for women in business - https://t.co/Cg7vFNiNjY" May 7, 2016 at 5:38:50 PM.

In penning that tweet, Rep. Beyer turned a masculine and partisan issue area neutral by juxtaposing his own experience as a small business owner with his efforts to aid women in business.

Ultimately, Democratic men tended to engage in retweeting behavior or simple advertising behavior to highlight Small Business week. They did not focus on Small Business Week to highlight their policy perspectives or achievements like Republican congressmen or Democratic congresswomen.

\section{Democratic Congresswomen}

Since Democratic congresswomen have to prove to the electorate that they are equipped to handle all types of policy areas (Dolan 2004), it is unsurprising that they take advantage of Small Business Week to not only showcase their concern for small businesses, but also visibly cater to the electorate that they are concerned about due to their perceived gendered vulnerability (Lazarus and Steigerwalt 2018). Therefore, we see many tweets consisting of MCs posing in their districts in a small business, bringing up concerns that businesses have, or giving tips about how to start businesses in their 
district - showing utility through what their office can provide to aid constituents. Due to this effort by Democrat congresswomen, the NBRM model did not find men more significantly likely to broach men's issues, even though Republican congressmen did have the highest percentage of these men's issue tweets as found in Table 2.

Congresswoman Adams (D-NC) emphasizes her committee assignments to highlight her ability to help small businesses back home:

- "As a member of the \#smallbiz Cmte \& Ranking member for \#smallbiz Subcmte on Oversight, will be working to help our small businesses thrive" -@RepAdams May 7, 2015 at 9:44:25 PM.

Here we see a Democratic congresswoman serving on multiple committees concerning a typically "masculine" and Republican issue area - small business (Dolan 2004). Since she has these qualifications, Adams emphasized her multiple visits to the district in many tweets; she hosted a symposium on small business, and distinctively included in her visit a "woman-owned business in Highpoint" (May 5, 2015 at 10:39:21 PM). This tweet in particular highlights a connection to women, business, as well as a showcase of her constant presence in the district. For Rep Adams, these tweets come in between a multitude of other issues - education, district town halls, criminal justice reform. Thus, we see a highlighting of her qualifications that do not traditionally fall under the Democratic umbrella, as she continues tweeting about other partisan and nonpartisan events.

Other than district visits, Democrat congresswomen also do not shy away from tweets that simply call into attention to the economic importance of small business. 
This includes drawing attention to how gender and race interacts with the small business phenomenon:

- Rep. Joyce Beatty (D-OH): "Small businesses are the backbone to our economy: account for 2/3's of all new \#jobs. https://t.co/tPWbAylhGi \#SmallBizWorks \#SBW2016” (May 2, 2016 at 2:24:43 PM)

- Rep. Judy Chu (D-CA): “The gov't has NEVER met its goal of awarding just $5 \%$ of all contracts to women-owned small businesses. We can do better! \#SmallBizWeek" (May 7, 2015 at 5:30:10 PM)

- Rep. Yvette Clarke (D-NY) "Businesses in underserved communities pay 22\% more interest for loans. I Support @RepMaloney’s bill for affordable credit. \#SmallBizWeek” (May 5, 2016 at 12:45:44 AM)

In these tweets, we see Democratic congresswomen inserting concerns associated with the Democratic platform into traditionally men's or Republican territory, framing the issue in a way similar to what Republican congresswomen did with veterans' healthcare.

In addition to highlighting economic issues, we also see Democratic congresswomen taking advantage of Small Business Week to tout their legislative accomplishments. Rep Cheri Bustos (D-IL) and Tammy Duckworth (D-IL) took advantage of the small business week to highlight their legislation:

- Rep. Cheri Bustos (D, IL): “At Monoxivent in Rock Island to discuss my new legislation to help small businesses export to new markets \#tagtheQC https://t.co/RheibTPph1" -May 5, 2016 at 5:01:51 PM. 
- Rep. Tammy Duckworth (D, IL): “It's \#NatlSmallBizWeek! I introduced H.R. 2221 to help our \#Vets in business: http://t.co/hoQot99cbC http://t.co/czcbXDrZgM"-May 7, 2015 at 6:40:00 PM.

Generally, we see this credit claiming behavior predominantly among Republican men for Small Business Week. In particular, Congresswoman Duckworth's military experience may make it easier to claim credit for issue areas associated with masculinity

The most distinctive behavior for business week amongst Democratic congresswomen was ultimately district visits, congratulating the small business within their districts, or drawing attention to some elements of small business that had racial or gender elements - a way of gendering the traditionally masculine issue similar to how Republican women focused on healthcare through the lens of veterans or their opposition to abortion. While at a high rate, this masculine issue area still was not broached by more Democratic congresswomen than Republican congressmen, so while the NBRM model did not show it, there is some small support for hypothesis four.

\section{Discussion and Conclusion}

Based on the content analysis as well as models run with negative binomial regression, there is some evidence that both Republicans and Democrats emphasize their partisan ties when it comes to issues that coincide with what constituencies deem feminine or masculine issues, but liberal congresswomen go above and beyond to address women's issues, while party leaders as well as those with marginal seats address masculine issue areas. 
Ultimately, there is evidence for hypothesis 1 and 2 - Democratic and Republican congresswomen tweet more than their male counterparts about "women's issues." Republican congresswomen do so to emphasize their partisan loyalty. For Mental Health Awareness Week, healthcare does become the priority for Democratic congresswomen, who tie it to broader healthcare and maternity/family concerns, and use tweet streams to emphasize the Democratic agenda more broadly, which is why we see statistical significance in the NBRM model for more liberal members tweeting about women's issues. Republican women use women's issues to reinforce their partisan ties, such as their support for pro-life initiatives or focusing on veteran's healthcare. Therefore, there is less support for hypothesis 3, which claims Republican women will not emphasize issues traditionally viewed as "owned" by Democrats. Republican women simply tied these Democrat-owned issue areas to Republican strengths, such as veterans, or emphasized their partisan ties on the subject. Republican men did mention healthcare during this week, but did not focus on Mental Health, instead focusing on other issues such as Medicare, rural healthcare issues, or the opioid/Zika crisis - which coincides with whether those issues are affecting their states or districts directly.

Within small business week, Democrat congresswomen do not shy away from bringing up the issue area even though it does not traditionally fall under the partisan issue umbrella. They take the opportunity to showcase to their district that they do visit and care about small businesses (economic aspects). Republican men really take advantage of the opportunity to showcase their small business experience, broad GOP efforts (in particular retweeting the GOP leadership), what they've voted on, and 
legislation that they are working on that tie into the week. Of all of the gender and partisan interactions, Republican congressmen have the highest rate of tweeting about men's issues, consistent with the expectations of hypothesis four, but this was not found significant in the NBRM model. The model shows that two party margin and being part of the party leadership were better indicators of tweeting about men's issues. While Republican women do tweet about men's issues, the content of their tweets tend to be heavily focused on advertising measures rather than lauding their accomplishments in the issue areas. Of all the groups, it was Democrat congressmen who tended to just send a cursory "shop local!" tweet reminding their constituents to support local businesses; they engaged less with men's issues than did Republican congresswomen.

Through both content analysis and statistical analysis, we can tentatively conclude that both gender and partisanship factor into the calculations of what congressmembers post on Twitter, though the NBRM model does show an effect of broaching men's issues more often when an MC has a marginal seats as well as being within party leadership. Regarding issue areas, this chapter takes a step towards understanding how issue activation on the Twittersphere plays a role in how members of Congress emphasize their partisan ties and accomplishments. Further work can take a look at a longer spectrum of time to understand general tweeting behavior when issue areas are not activated, particularly as it coincides with the nexus of gender and partisanship. The next chapters will delve into types of tweets posted, as well as analyzing the audience MCs have in mind as they coin these tweets. 


\section{References}

Anderson, Mary R., Christopher J. Lewis, and Chardie L. Baird. 2011. "Punishment or Reward? An Experiment on the Effects of Sex and Gender Issues on Candidate Choice." Journal of Women, Politics \& Policy 32(2): 136-57.

Anderson, William D., Janet M. Box-Steffensmeier and Valeria Sinclair-Chapman. 2003. "The Keys to Legislative Success in the U.S. House of Representatives." Legislative Studies Quarterly. 28(3): 357-386.

Angevine, Sara. 2017. "Representing All Women: An Analysis of Congress, Foreign Policy, and the Boundaries of Women's Surrogate Representation." Political Research Quarterly. 70(1) 98-110.

Banwart, Mary Christine. 2010. "Gender and Candidate Communication: Effects of Stereotypes in the 2008 Election." American Behavioral Scientist. 54(3): 265283.

Barnello, Michelle A., and Kathleen Bratton. 2007. "Bridging the Gap in Bill Sponsorship.” Legislative Studies Quarterly 32(3): 449-474.

Bauer, Nichole M. "Untangling the Relationship between Partisanship, Gender Stereotypes, and Support for Female Candidates." Journal of Women, Politics, \& Policy. 39(1): 1-25.

Berkman, Michael B., and Robert E. O'Connor. 1993. "Do Women Legislators Matter? Female Legislators and State Abortion Policy." American Politics Quarterly 21 (1): $102-24$.

Bratton Kathleen. 2002. "The Effect of Legislative Diversity on Agenda Setting Evidence from Six State Legislatures.” American Politics Research 30(2): 111142.

Bratton, Kathleen, and Kerry L. Haynie. 1999. "Agenda Setting and Legislative Success in State Legislatures: The Effects of Gender and Race." Journal of Politics 61(3): 658-679.

Bucchianeri, Peter. 2017. "Is Running Enough? Reconsidering the Conventional Wisdom about Women Candidates." Political Behavior. 1-32.

Burns, S., Eberhardt, L., Merolla, J. 2013. "What Is the Difference Between a Hockey Mom and a Pit Bull? Presentations of Palin and Gender Stereotypes in the 2008 Presidential Election," Political Research Quarterly 66(3): 687-701.

Caiazza, Amy. 2004. "Does Women's Representation in Elected Office Lead to Women-Friendly Policy? Analysis of State-Level Data." Women \& Politics 26(1): 35-70. 
Carroll, Susan J. 2002. "Representing Women: Congresswomen's Perceptions of Their Representational Role." In Women Transforming Congress, edited by Cindy Simon Rosenthal. Norman: University of Oklahoma Press.

Carroll, Susan J. 2000. "Representing Women: Congresswomen's Perceptions of Their Representation." Presentation at "Women Transforming Congress: Gender Analyses of Institutional Life," Carl Albert Congressional Research and Studies Center, University of Oklahoma, April 13-15.

Carroll, Susan. 1985. Women as Candidates in American Politics. Indiana University Press.

CAWP. 2017. "Gender Differences in Voter Turnout." Center for American Women and Politics, Eagleton Institute of Politics, Rutgers University.

Cha, Jiyoung. 2010. "Factors Affecting the Frequency and Amoutn of Social Networking Site Use; Motivations, Perceptions, and Privacy Concerns." First Monday (15)12: 1-18.

Cormack, Lindsey. 2016. "Gender and Vote Revelation Strategy in the United States Congress." Journal of Gender Studies. 25(6): 626-640.

Dabelko, Kirsten la Cour and Paul S. Herrnson. 1997. "Women's and Men's Campaigns for the U.S. House of Representatives," Political Research Quarterly 50: 121-135.

Dittmar, Kelly. 2015. Navigating Gendered Terrain: Stereotypes and Strategy in Political Campaigns. Philadelphia: Temple University Press.

Dodson, Debra L., and Susan J. Carroll. 1991. Reshaping the Agenda: Women in State Legislatures. New Brunswick: Eagleton Institute of Politics' Center for American Women and Politics.

Dolan, Kathleen and Timothy Lunch. 2017. "Do Candidates Run as Women and Men or Democrats and Republicans? The Impact of Party and Sex on Issue Campaigns." Journal of Women, Politics \& Policy. 38(4): 522-546.

Dolan, Kathleen. 2014. "Gender Stereotypes, Candidate Evaluations, and Voting for Women Candidates: What Really Matters?" Political Research Quarterly 67(1): 96-107.

Dolan, Kathleen and Kira Sanbonmatsu. 2008. "Gender Stereotypes and Attitudes Toward Gender Balance in Government." American Politics Research. 37(3): $409-428$.

Dolan, Katherine and J.S. Kropf. 2004. "Credit claiming from the U.S. House: gendered communication styles?" The Internatinoal Journal of Press/Politics. 9(1): 41-59. 
Dolan, Kathleen. 2004. Voting for Women: How the Public Evaluates Women Candidates. Boulder: Westview Press.

Dolan, Kathleen. 1998. "Voting for Women in the "Year of the Woman." American Journal of Political Science. 42: 272-293.

Dolan, Kathleen and Lynne E. Ford. 1995. "Women in the State Legislatures: Feminist Identity and Legislative Behaviors." American Politics Quarterly. 23(1): 96108.

Domke, David and Kevin Coe. 2008. The God Strategy: How Religion became a Political Weapon in America. New York: Oxford University Press.

Elder, Laurel. 2012. "The Partisan Gap Among Women State Legislators." Journal of Women, Politics \& Policy. 33(1): 65-85.

Evans, Heather K, Sean Smith, Alexis Gonzales, and Kayla Strouse. 2017. "Mudslinging on Twitter During the 2014 Election." Social Media + Society. April-June: 1-9.

Evans, H.K., Cordova, V., \& Sipole, S. 2014. "Twitter style: An analysis of how house candidates used Twitter in their 2012 campaigns." Political Science and Politics, 47(2): 454-462.

Evans, Jocelyn Jones. 2005. Women, Partisanship, and the Congress. New York: Palgrave Macmillan.

Falk, Erika and Kate Kenski. 2006. "Issue Saliency and Gender Stereotypes: Support for Women as Presidents in Times of War and Terrorism," Social Science Quarterly. 87(1): 1-18.

Fox, Richard. 1997. Gender Dynamics in Congressional Elections. Thousand Oaks: Sage.

Frederick, Brian. 2011. "Gender Turnover and Roll Call Voting in the US Senate." Jounnal of Women, Politics, \& Policy 32 (3): 193-210.

Frederick, Brian. 2009. “Are Female House Members Still more Liberal in a Polarized Era? The Conditional Nature of the Relationship Between Descriptive and Substantive Representation." Congress \& The Presidency 36: 181-202.

Fridkin, K. and G. Woodall. 2005. "Different portraits, different leaders? Gender differences in US Senators' presentation of self", in Thomas, S. and Wilcox, C. (Eds) Women and Elective Office: Past, Present, and Future, $2^{\text {nd }}$ ed., Oxford University Press, New York, NY pp. 126-144.

Fleiss, J. L., B. Levin, M. C. Paik, 2003. "Statistical Models for Rates and Proportions." In Wiley Series in Probability and Statistics, third eds. J. Wiley, Hoboken N.J. 
Greenwood, Shannon, Andrew Perrin, and Maeve Duggan. "Social Media Update 2016." Pew Research Center: Internet, Science \& Tech. November 11, 2016. Accessed November 01, 2017. http://www.pewinternet.org/2016/11/11/socialmedia-update-2016/.

Grose, Christian. 2011. Congress in Black and White: Race and Representation in Washington and at Home. Cambridge University Press.

Grossman, Matt and David Hopkins. 2016. Asymmetric Politics: Ideological Republicans and Group Interest Democrats. New York: Oxford University Press.

Gulati, G. 2004. "Members of Congress and presentation of self on the World Wide Web.” International Journal of Press/Politics. 9(1): 22-40.

Hauder-Markel, Donald P. 2010. Out and Running: Gay and Lesbian Candidates, Elections, and Policy Representation. Georgetown University Press.

Hayes, Danny. 2011. "When Gender and Party Collide: Stereotyping in Candidate Trait Attribution." Politics \& Gender 7(2): 133-165.

Herrnson, P., Lay, J., Stokes, A. 2003. Women running "as women": Candidate gender, campaign issues, and voter-targeting strategies. The Journal of Politics, 65, $244-255$.

Howlett, Michael. M. Ramesh, and Anthony Perl. 2009. Studying Public Policy: Policy Cycles \& Policy Subsystems. New York: Oxford University Press.

Huddy, Leonie and Nayda Terkildsen. 1993. "Gender Stereotypes and the Perception of Male and Female Candidates." American Journal of Political Science 37: $119-47$.

Junn, Jane, Natalie Masuoka. 2008. "Asian American Identity: Shared Racial Status and Political Context." Perspectives on Politics. 6(4): 729-740.

Kaid, L.L. and A.J. Wadsworth. 1989. "Content Analysis." In P. Emmert and L. L. Barker (eds) Measurement of Communication Behavior. (pp. 197-217). New York: Longman.

Kahn, Kim Fridkin, and Patrick J. Kenney. 2002. "The Slant of the News." American Political Science Review 96 (2): 381-94.

Kahn, Kim Fridkin. 1996. The Political Consequences of Being a Woman: How Stereotypes Influence the Conduct and Consequences of Political Campaigns. New York: Columbia University Press. 
Kahn, Kim Fridkin. 1993. "Gender differences in campaign messages: the political advertisements of men and women candidates for U.S. Senate." Political Research Quarterly. 46(3): 481-502.

Kanter, Rosabeth Moss. 1977. "Some Effects of Proportions on Group Life: Skewed Sex Ratios and Responses to Token Women." American Journal of Sociology, no. 82: $965-890$.

Kitchens, K. E. and Michele Swers. "Why Aren't There More Republican Women in Congress? Gender, Partisanship, and Fundraising Support in the 2010 and 2012 Elections." Politics \& Gender 12(4): 648-76.

Lawless, Jennifer L. 2004. "Women, War, and Winning Elections: Gender Stereotyping in the Post-September 11th Era." Political Research Quarterly 57(3):479-490.

Lazarus, Jeffrey and Amy Steigerwalt. 2018. "Gendered Vulnerability: How Women Work Harder to Stay in Office.” Ann Arbor: University of Michigan Press.

Lee, Jayeon. 2013. “'You know how tough I am?' Discourse analysis of US Midwestern congresswomen's self-presentation." Discourse \& Communication. 7(3): $1-9$.

MacDonald, K. and E. O'Brien. 2011. "Quasi-Experimental Design, Constituency, and Advancing Women's Interests: Reexamining the Influence of Gender on Substantive Representation." Political Research Quarterly 64(2): 472-486.

Mansbridge, Jane. 2003. "Rethinking Representation."American Political Science Review 97:515-28.

Mansbridge, Jane. 1999. "Should Blacks Represent Blacks and Women Represent Women? A Contingent 'Yes.'” The Journal of Politics 61 (3): 628-57.

Matland, Richard, and David King. 2002. "Women as Candidates in Congressional Elections." In Women Transforming Congress, Norman, OK: University of Oklahoma Press, 119-45.

McGregor, Michael R., Aaron Moore, Samantha Jackson, Karen Bird, and Laura B. Stephenson. "Why So Few Women and Minorities in Local Politics? Incumbency and Affinity Voting in Low Information Elections." Journal of Representative Democracy. 53(2): 135-152.

Meeks, Lindsey. 2016. "Examining Partisan Men and Women's Issue Emphases from Campaigns to Legislation." In Why Congress Needs Women: Bringing Sanity to the House and Senate. By Michele A. Paludi. Praeger: 
Meeks, Lindsey. 2016. “Aligning and trespassing: Candidates' Party-based issue and Trait ownership on Twitter." Journalism \& Mass Communication Quarterly. 93(4): 1050-1072.

Smith, Jessi L., David Paul and Rachel Paul. 2007. "No Place for a Woman: Evidence for Gender Bias in Evaluations of Presidential Candidates." Basic and Applied Social Psychology. 29(3): 225-233.

Minozzi, William, Michael A. Neblo, Kevin M. Esterling, and David M. J. Lazer. "Field experiment evidence of substantive, attributional, and behavioral persuasion by members of Congress in online town halls." National Academy Sciences.

Minta, Michael D. 2009. "Legislative Oversight and the Substantive Representation of Black and Latino Interests in Congress." Legislative Studies Quarterly. 34(2): 193-218.

Osborn, Tracy L. 2012. How Women Represent Women: Political Parties, Gender, and Representation in the State Legislatures. New York, NY: Oxford University Press.

Paolino, P 1995. "Group-salient issues and group representation: Support for women candidates in the 1992 Senate elections." American Journal of Political Science. 39: 294-313.

Petrocik, K. 1996. "Issue ownership in presidential elections, with a 1980 base study." American Journal of Political Science. 40: 825-850.

Pew Research. 2018. "Social Media Fact Sheet." http://www.pewinternet.org/factsheet/social-media/

Hayes, D. 2005. "Candidate qualities through a partisan lens: A theory of trait ownership." American Journal of Political Science. 49: 908-923.

Pitkin, Hanna Fenichel. 1967. The Concept of Representation. Berkeley: University of California Press.

Phillips, Anne. 1995. The Politics of Presence. New York, NY: Oxford University Press.

Reingold, Beth. 2000. Representing Women: Sex, Gender, and Legislative Behavior in Arizona and California. Chapel Hill, NC: University of North Carolina Press.

Sanbonmatsu, Kira. 2004. Democrats, Republicans, and the politics of Women's Place. Ann Arbor: University of Michigan Press.

Sanbonmatsu, Kira. 2002. "Gender Stereotypes and Vote Choice.” American Journal of Political Science. 46(1): 20-34. 
Sanchez, Gabriel R. 2006. "The Role of Group Consciousness in Latino Public Opinion. Political Research Quarterly. 59(3): 435-446.

Schaffner, Brian F. 2005. "Priming Gender: Campaigning on Women's Issues in U.S. Senate Elections." American Journal of Political Science 49: 803-817.

Schildkraut, Deborah J. 2016. "Latino Attitudes About Surrogate Representation in the United States.” Social Science Quarterly. 97(3): 714-728.

Sharrow, Elizabeth A., Dara Z. Strolovitch, Michael T. Heaney, Seth E. Masket, and Joanne M. Miller. 2016. "Gender Attitudes, Gendered Partisanship: Feminism and Support for Sarah Palin and Hillary Clinton among Party Activists." Journal of Women, Politics \& Policy. 37(4): 394-416.

Shearer, Elisa, and Jeffrey Gottfried. "News Use Across Social Media Platforms 2017." Pew Research Center's Journalism Project. September 07, 2017. Accessed November 01, 2017. http://www.journalism.org/2017/09/07/news-use-acrosssocial-media-platforms-2017/.

Swers, Michele L. 2016. "Pursuing Women's Interests in Partisan Times: Explaining Gender Differences In Legislative Activity on Health, Education, and Women's Health Issues." Journal of Women, Politics \& Policy. 37(3): 249-273.

Swers, Michele L. 2013. Women in the Club: Gender and Policy Making in the Senate. Chicago: University of Chicago Press.

Swers, Michele L. 2005. "Connecting Descriptive and Substantive Representation: An Analysis of Cosponsorship Activity.” Legislative Studies Quarterly 30 (3): 40733 .

Swers, Michele L. 2002. The Difference Women Make: The Policy Impact of Women in Congress. Chicago: The University of Chicago Press.

Swers, Michele L., A. Caiazza. 2000. "Transforming the political agenda? Gender differences in bill sponsorship on women's issues."

Tamerius, Karin. 1995. "Sex, Gender and Leadership in the Representation of Women." In Gender Power, Leadership and Governance, eds. Georgia DuerstLahti and Rita Mae Kelly. Ann Arbor: University of Michigan Press, 93-112.

Tate, Katherine. 2003. Black Faces in the Mirror: African Americans and Their Representatives in the U.S. Congress. Princeton: Princeton University Press.

Thomas, Sue, and Susan Welch. 2001. "The Impact of Women in States Legislatures: Numerical and Organizational Strength." In The Impact of Women in Public Office, ed. Susan Carroll. Bloomington: Indiana University Press.

Thomas, Sue. 1994. How Women Legislate. New York: Oxford University Press. 
Thomas, Sue. 1991. "The Impact of Women on State Legislative Policies." Journal of Politics 54(4): 958-976.

Walsh, Katherine Cramer. 2002. "Resonating To Be Heard: Gendered Debate On The Floor Of The House." In Women Transforming Congress. Norman: University of Oklahoma Press.

Wilson, Walter Clark. 2010. "Descriptive Representation and Latino Interest Bill Sponsorship in Congress." Social Science Quarterly 91(4): 1043-1062.

Winter, Nicholas J. G. 2010. "Masculine Republicans and Feminine Democrats: GEnde rand Americans' Explicit and Implicit Images of the Political Parties." Political Behavior 32: 587-618.

Wittmer, Dana E. and Vanessa Bouché. 2013. "The Limits of Gendered Leadership: Policy Implications of Female Leadership in "Women's Issues."

Wallace, Sophia J. 2014. "Representing Latinos Examining Descriptive and Substantive Representation in Congress." Political Research Quarterly 67 (4): 917-29.

Wolbrecht, Christina. 2002. "Female Legislators and the Women's Rights Agenda: From Feminine Mystique to Feminist Era." In Women Transforming Congress, edited by Cindy Simon Rosenthal, 170-239. Norman: University of Oklahoma Press.

Wolbrecht, Christina. 2000. The Politics of Women's Rights. Princeton, NJ: Princeton University. 


\section{CHAPTER III. GENDERED MAYHEWIAN BEHAVIOR AND CREDIT CLAIMING LANGUAGE}

When analyzing the behavior of members of Congress, it is common for scholars to assume that reelection concerns dominate. According to Mayhew's (1974) classic work on the subject, the reelection impulse leads members to advertise, credit claim, and position take. Lawless (2012) examines these behaviors on social media and finds differences based on characteristics like gender and party. However, the interaction between gender and party is not explored. Does gender and party influence Mayhewian behavior on Twitter? Focusing on the $114^{\text {th }}$ Congress, I extend and updated Lawless's (2012) study. The chapter reveals the influence of gender and party on the advertising, credit claiming, and position taking activities of members, finding it significant for some reelection motivated behaviors like advertising, but illuminating the greater impact of other indicators such as party leadership, membership on a constituent committee, or having a marginal seat for others. Furthermore, in-depth content analysis of credit-claiming tweets shows that congresswomen use credit sharing language more than congressmen, but that level differs by party.

Keywords social media, Congress, Twitter, gendered communication, credit claiming

"We tend to be more results-oriented and less concerned with getting the credit. The female approach is more conciliatory and less combative. We tend to use a more civil tone." - Kirstin Gillibrand (D, NY), NY Times, 2011 22

\footnotetext{
${ }^{22} \mathrm{http} / / / \mathrm{www}$. nytimes.com/2011/07/05/nyregion/gillibrand-wants-women-involved-inpolitics.html?_r=1
} 
In the discussion about the advantages of a greater female presence in politics, a host of literature points to the productivity of women - congresswomen deliver more speeches on the House floor than their male colleagues (Pearson and Dancey 2011), participate in more floor debates about women's issues (Walsh 2002; Swers and Caiazza 2000; Tamerius 1995), sponsor more bills (Pearson 2013; Anzia and Berry 2011) even when they are in the minority party (Volden, Wiseman, and Wittmer 2013), and secure about nine percent more spending from federal discretionary programs (Anzia and Berry 2011). If we follow the logic of Mayhew (1974), all members of Congress are primarily motivated by re-election and therefore should be showcasing these accomplishments. Mayhew (1974) asserts that this re-election impulse leads members of Congress to advertise, credit claim, and position take. Yet, recent scholarship shows that those behaviors may manifest themselves differently based on gender. For congresswomen, the literature finds that women may be more willing to share the credit and power as they work towards policy achievements (Rosenthal 1998), but since they are feeling electoral insecurity combined with their gender stereotypes, they are more likely to signal their electoral activities (Cormack 2016; Dolan and Kropf 2004). Given these findings, this chapter seeks to answer three related questions. First, do congresswomen advertise, credit claim, and position take differently than congressmen? Second, if there are differences, what do they look like? Third, if there are differences, are they simply attributable to gender or does party also play an important role? 
Other scholars have asked similar questions in the past and their work provides a solid foundation for this chapter to build upon. For example, Lawless (2012) was the first to test gendered expectations of Mayhewian behavior on Twitter. While Lawless (2012) finds tangible variance in advertising, position taking, and credit claiming tweets by gender, there is room to improve upon the study's design. First, the coding scheme did not categorize tweets into mutually-exclusive categories. This is problematic because it does not clearly distinguish between policy preferences and actual policy accomplishments. Second, the study considers gender and party separately, but does not consider the possibility of an interaction between those two important variables. This is potentially problematic because while all congresswomen perceive gendered vulnerability (Lazarus and Steigerwalt 2018), Republican women and Democratic women may contend with different kinds of pressures.

For instance, Republican congresswomen may consider the fact that they can gain an advantage for crossing partisan lines and emphasizing feminine issues (Herrnston et al. 2003; Dolan 1998; Paolino 1995), but due to the reelection pressures of the Republican party who prize ideological purity (Grossman and Hopkins 2016) they will not engage in issue-based crossover to the extent that Democratic women will for Republican owned issues. Thus, there may be differences in the way Democratic and Republican congresswomen display position taking behaviors too, including Republican women position taking less since they are less likely to engage in issuebased crossover. While credit claiming for women may be higher than men due to feelings of electoral insecurity, which research has demonstrated by examining the content of newsletters (Dolan and Kropf 2004). For these reasons, I argue that a close 
examination of the interaction between gender and party is crucial for developing a more complex understanding of the reelection behaviors of members of Congress.

To get leverage on these questions, I conducted a content analysis of all tweets sent by members of Congress in the House of Representatives during two separate weeks in the $114^{\text {th }}$ Congress (May 1-7, 2015 and May 1-7, 2016; n=9,374 tweets from 431 members of Congress). I extended Lawless's (2012) study to take into account the interaction of both gender and party in Mayhewian tweet behavior - advertising, position taking, credit claiming - but coding each category as mutually exclusive to distinguish how much credit claiming versus position taking is actually occurring. In addition, I conducted an in-depth content analysis of credit-claiming tweets to reveal the role of gender as well as partisanship in how credit is individually claimed or shared with others, a category not yet covered in literature on the Congressional social media sphere.

The analysis revealed that both gender and party played a role in Mayhewian tweet content, with Republican congresswomen advertising the most and claiming credit the least. Democratic congresswomen posted the fewest advertising tweets, and Republican congressmen the highest percentage of credit claiming tweets. In studying the language of credit claiming or sharing tweets, Democratic congressmen had the highest rates of individual credit claiming, followed by Republican congresswomen, and Democrat congresswomen and Republican congressmen tied at the same percent. For credit sharing language, Democratic congresswomen had the highest rate, with Republican congresswomen having the smallest percent. Lastly, retweets by congressmembers of special interests and party leaders uncovers that congresswomen, 
engage in less retweeting behavior than congressmen, particularly Republican women when it comes to credit claiming.

Since Congressional candidates ensure that they are devoting time online to Mayhewian pursuits of advertising, position taking, and credit claiming (Gainous and Wagner 2014; Gainous and Wagner 2011), this chapter's analysis of classic Mayhewian behavior on Twitter illustrates a gendered as well as partisan dimension in the attention given to each classic category. The impact of both gender and party shows that congresswomen have specific considerations when they engage in political communication, which is useful to Congressional scholars. Furthermore, this gendered language in credit claiming pulls confirms earlier literature which claimed congressmen engage in more credit claiming than women. This refutes more recent literature (Dolan and Kropf 2004) that posits congresswomen should be credit claiming at higher rates.

\section{Literature Review}

"I find an emphasis on the reelection goal attractive for a number of reasons...I think politics is best studied as a struggle among men to gain and maintain power and the consequence of that struggle...the reelection quest establishes an accountability relationship with an electorate, and any serious thinking about democratic theory has to give a central place to the question of accountability" (Mayhew 1974, 6). ${ }^{23}$

While scholars explain the motivations of members of Congress in slightly different ways, Mayhew's (1974) classic text, Congress: The Electoral Connection,

\footnotetext{
${ }^{23}$ Notable in Mayhew's quote is that politics best studied, "as a struggle among men to gain and maintain power" - no mention of women.
} 
and his description of MCs as single-minded seekers of reelection, continues to be central to our understanding of congressional behavior. Though the re-election rate continues to stay high, ${ }^{24}$ incumbents still perceive insecurity and thus "run scared" (King 1997); MC's must project a strength in the security of their seat to diminish the chances of intra and opposing party competition (Jacobson 1987). In an intimate portrait of Congressional behavior (with the caveat that he solely shadowed men), Fenno (1987) saw firsthand that the re-election interest is so encompassing that the majority of Congressional activity he saw fits within this Mayhewian scope. Are congresswomen not advertising their district visits, publicizing their stances on positions, or taking credit for policy achievements? Certainly so.

The early literature on congressional social media usage consistently found that MCs were using the communication tool similar to other forms of media (Golbeck et al. 2010). While the potential for the usage of social media was an opportunity for twoway communication, members of Congress used it primarily for informational messages rather than communicating with their followers (Golbeck et al. 2010). Part of that information distribution was giving information to followers about accomplishments, taking credit for pushing bills forward, or stopping their progress. This is consistent with Mayhewian advertising, position taking, and credit claiming behaviors. Glassman et al. (2010) found tweet content varies based on whether Congress is in session or recess; when in session, tweets focused on policies, with more

\footnotetext{
${ }^{24}$ In 2016, 97\% House Representatives got re-elected; 93\% in the Senate. Data from https://www.opensecrets.org/overview/reelect.php
} 
district directed tweets occurring during recess. Tweet amounts also vary; the minority party tends to use Twitter more often than the majority party (Lassen and Brown 2011).

Lawless's (2012) book chapter was the first attempt by a political scientist to use content analysis to investigate congressional behavior on both Twitter and Facebook. Lawless found that online political communication behaviors by members of Congress did fit the Mayhewian framework, and that as earlier literature found (e.g. Golbeck et al. 2010) members of Congress use social media as just another tool to engage in their reelection campaign efforts. Instead of taking advantage of the two-way dialogue format of Twitter or Facebook, MCs continued to use it as a one-way avenue for distributing information to their followers. Lawless found variance in tweeting or Facebook posts for Mayhewian categories by party and by gender, which is generally how the scholarship tends to focus on congressional political communication. The interesting nexus that needs further study is the interaction of both gender and party.

Two such studies by Meeks $(2016 ; 2015)$ look at legislation sponsorship and campaign tweets by party and gender. Meeks (2016) finds Democratic women propose a wider array of masculine and feminine issues, while Republican women sponsor bills across a host of other issues. Tied to her previous work, Meeks (2015) found that Republicans tended to focus on Republican-owned issues with Democrats doing the same. In analyzing the tweets of Democrats and Republicans who lost their campaigns, Meeks (2015) uncovered that these MCs tended to stress content not "owned" by their respective parties, while winning Democrats were more likely to trespass and talk about Republican categories. This could be due to the perception of Republican-owned traits 
- tied to issues of national security - being more important to address (Hayes 2011; Smith et al., 2007).

The scholarship on congresswomen's behavior on social media points to a variance in activity. Specifically, female candidates tweet more often, attack their opponents more often, engage in different types of tweeting than their male counterparts, and differ in their tweets before and after the election (Wagner et al. 2017; Evans, Ovalle and Green 2015; Evans, Cordova and Sipole 2014; Bystrom and Kaid 2002). Congresswomen and men also focus on different themes while campaigning and once they get into office (Fox 1997; Kahn 1996; Dodson 1995; Thomas 1994). This stems to politics traditionally being viewed as a masculine venture (Meeks 2012; Burns, Schlozman \& Verba 2001; Delli-Carpini \& Keeter 1996), and thus female candidates face additional pressures in their pursuit to office - they must possess stereotypical masculine traits, but not straying too far from stereotypes of female traits (e.g. toughness, competence, and confidence versus empathy, compassion, and modesty); therefore, congresswomen stress their qualifications and competence at higher levels than their male challengers in an attempt to fight and counteract these gender stereotypes (Lee 2013; Fox 1997; Burrell 1992). Women do tend to emphasize issues that voters stereotypically view them as more competent to address, such as health care, education, and family issues (Barnello and Bratton 2007; Gerrity et al. 2007; Thomas and Welch 2001; Dodson 2001; Carroll 2001; Welch 1985), though this is tempered by political context (Tolleson-Rinehart 2001) as well as partisanship and ideology (Evans 2005; Reingold 2000). 
Part of the reason there is a push for more visible representation through candidates that fit the descriptive characteristics of their district is findings that point to an increase in descriptive representation. Some literature goes so far as to posit that congresswomen perceive gendered vulnerability (Lazarus and Steigerwalt 2018) whereby their electoral vulnerability and persistent societal bias compared to their male colleagues convinces congresswomen to devote more of their time than their male colleagues to courting and winning their constituents' favor. Through political communication, a part of symbolic representation, women and minority representatives can draw attention to issues that impact their communities. They also create bridges and connections to general issues through the lens of gender, race, and ethnicity in higher rates compared to white congressmen (Gershon 2008). Since constituents taken as a whole have limited knowledge of their representatives, congressmembers can curate their perceptions through framing their press communications, particularly through press releases, which can be used by news media for low-cost stories (Grimmer 2013). If the frequency and not dollar amounts of credit claiming in press releases positively affect a constituent's perception of a congressmember (Grimmer 2012), it should not be surprising that legislators with very little tweet activity choose to focus on posting links to press releases detailing their behavior in concordance with typical Mayhewian behavior.

In the discourse analysis literature that has focused on feminine versus masculine language, studies point to language differences in credit sharing, as well as more fundamentally, what gendered language is, and what role it plays in society. The studies on gendered language have shifted and evolved over the years. While first 
characterizing men's language as standard and women's as other and lesser - the deficit model (Lakoff 1975), the literature then moved towards accepting the strength of feminine language as a different entity (Tannen 1990, 1986; Maltz and Borker 1982), which point to miscommunication between the sexes since each group are culturally socialized in a different way. The literature then moved towards constructivist interpretations, where gender is not an essential individual trait, but something that one does or performs (e.g. Shotter and Gergen 1994).

Recent research tends to focus on how norms impact the idea of gendered spaces, such as in public contexts where men tend to be more assertive (Tannen 1997; Gal 1991) and how women adopt masculine strategies to enter these male fields (Karpowitz and Mendelberg 2014; Yu 2014; Dodson 2006; Lovenduski 2005; McElhinny 1998; Webster 1990). Karpowitz and Mendelberg's (2014) findings stand in contrast to Pearson and Dancey's (2011) article finding women more often make speeches on the House floor, but the argument is that the gender composition and institutional rules make it difficult to truly translate those speeches to these congresswomen being heard and represented as a result of those speeches. More recently, Evans (2016) looks at Twitter behavior regarding women's issues and sees congresswomen do more often tweet about women's issues, but that their feed is not dominated only by these issues (not excluding "male issues".) Earlier work by Evans, Cordova, and Sipole (2014) also looks at candidates' "Twitter style.” The authors show that candidates focus on different characteristics (such as mobilization, personal elements, issue focus, interaction with users, attack style of opponents, and overall total 
of tweets) based on electoral competition, party, and gender (Evans, Cordova, and Sipole 2014).

Also of note, nearly all studies of congressional behavior on Twitter do not include retweets in their analysis, only tweets posted by members of Congress. Just two studies include RT analysis in their work, and both find congresswomen more likely to retweet than congressmen (Evans 2016; Straus et al. 2014). Straus et al. (2014) posit that it might be the case due to women appreciating the convenience of political information and using it more than men (Katz and Rice 2002, 148), but there was no clear explanation. Thus, it is clear there is much still to learn about the interaction of gender and social media as it relates to politics. This chapter will aim to further illuminate how gender may play a role in how a congresswoman crafts her online presence on Twitter to further her political goals.

\section{Theory}

In her study, Lawless (2012) teased out the demographics of avid social media users: Republicans were producing the most content, congressmen's tweets and Facebook posts were $25 \%$ more likely than congresswomen's to contain positiontaking language (the gap widening even further comparing white members of Congress to minority members), and Democrats were more likely than Republicans to include credit-claiming and advertising posts. While Lawless's (2012) coding scheme for the Mayhewian categories were not mutually exclusive, her chapter provides a springboard for this chapter (including categories of classification) and data to compare. 
A recent study by Cormack (2015) found perceived electoral insecurity coupled with gender stereotypes leads women to signal their policy competence and how they vote to their constituents, so there is reason to believe that Mayhewian behavior will similarly project online - in this instance a shift in more position-taking for women. Spurred by the finding that voters seek out more information about women candidates, in particular Republican women (Ditonto, Hamilton, and Redlawsk 2013), Wagner et al. (2017) found Republican women tweet more often than their male counterparts, including using more negative tweets to attack their opponent. Thus, the formal expectation is that while all MCs will use the Mayhewian framework of Advertising, Position-Taking, and Credit-Claiming, the ratios of these tweets will differ between men and women, shaped by ideology.

\section{Gender, Party, and Advertising}

While congresswomen and men are similar in their general campaigning style, women tweet more often (Bystrom and Kaid 2002). This may be tied to perceived electoral insecurity, as MCs in unsafe or challenged districts tend to tweet more often (Haber 2011; Amman 2010). This, in conjunction with congresswomen's own perceived electoral gendered vulnerability (Lazarus and Steigerwalt 2018) means women MC's will likely devote more of their time than their male colleagues to courting and winning their constituents' favor, since they feel the pressure of persistent gender bias throughout society. Therefore, the expectation is that congresswomen will be tweeting Mayhewian tweets - in particular advertising - more than their male counterparts, in an effort to reach their constituencies. 
H1: Congresswomen will advertise more than congressmen.

\section{Gender, Party, and Position Taking}

In an era of increased partisanship, position taking may be fairly straightforward for most politicians. This diverges at the point where certain issue areas are perceived by the electorate as "masculine" or "feminine". There has been a documented decrease in negative social attitudes, stereotypes, and biases regarding women running in campaigns and those in office (Dolan 2004), but some stereotypical perceptions remain. For instance, public opinion surveys find that women are still perceived as better suited to address education and health care while men seen as competent on defense and foreign affairs - termed as "issue competency" or a "domain stereotype" (Falk and Kenski 2006; Lawless 2004; Herrnson and Stokes 2003; Sanbonmatsu 2002; Kahn 1996; Huddy and Terkildsen 1993). As a result, "women's issues" can be a tricky area for congresswomen to navigate. While women are perceived by constituencies as having this "issue competency," there are partisan pressures that would impact Republican congresswomen from wanting to engage in women's issues, which are seen to have Democratic issue ownership (Evans 2005, Wolbrecht 2000).

Meeks (2015) found that Republicans tended to focus on Republican-owned issues with Democrats doing the same, though Democrats were more likely to trespass and talk about Republican categories than the reverse (Meeks 2016). This could be due to the perception of Republican-owned traits - tied to issues of national security - being more important to address (Hayes 2011; Smith et al., 2007). Republicans prize 
ideological purity (Grossman and Hopkins 2016), and since "women's issues" tend to fall under Democratic purview due to perceptions of issue ownership (Evans 2005, Wolbrecht 2000), with increased levels of partisanship in both chambers, Republican congresswomen may distance themselves from engaging with issue areas online, or instead bring up women's issues to emphasize how they align with their party's position. Dabelko and Herrnson (1997) find Republican congresswomen were more likely to advertise their positions on social issues and abortion than their male Republican counterparts. Lawless (2012) found lower levels of position taking for women, as well as lower levels of position taking for Republicans than Democrats, so the formal expectation is that Democratic congresswomen will position take at higher rates than men since they will be addressing women's issues and "masculine issues", with Republican congresswomen feeling the weight of their position taking and therefore cautiously tweeting at lower levels than Democratic women for this category of Mayhewian behavior.

H2: Democratic congresswomen will position take at higher rates than all other groups.

H3: Republican congresswomen will position take at lower rates than all other groups.

Gender, Party, and Credit Claiming

It is far easier to advertise or take a stance on a political issue than it is to take credit for legislation - there are only so many opportunities to get legislation passed. 
Therefore, a majority of the tweets posted by members of Congress tends to center around advertising (devoid of any policy), or position taking. When a congressmember can take credit for a piece of legislation, it is in their interest to publicize this fact particularly at the district level - for reelection purposes. Constituents indicate greater support when congressmembers are able to allocate money and projects for their district (Lazarus and Reiley 2010; Shepsle et al. 2009; Levitt and Snyder 1997; Bickers and Stein 1996). As part of their online presence, Evans and Hayden (2018) find members of Congress in challenging districts have made their congressional websites more accessible to constituent requests (regarding minor personal issues up to legislation requests) to be able to credit claim. It would therefore follow that congresswomen would tout their accomplishments through credit-claiming tweets.

In the second part of the chapter, I look at the specific instances where congresswomen and men take credit for passing legislation. For these credit-claiming tweets, previous political science research suggests that congresswomen counter voter stereotypes and take credit more often than congressmen (Dolan and Kropf 2004). This follows with the logic that congresswomen see the need to go above and beyond to prove to their constituencies that they are capable, based on gendered vulnerability (Lazarus and Steigerwalt 2018). In their study of credit claiming in newsletters, Dolan and Kropf $(2004,43)$ find that Democratic men share credit most often, followed by Republican men, Democratic women, and Republican women share credit least often. This may follow since women running for politics and within male-dominated professions are often pressured to adapt more masculine ways of interacting and speaking (Karpowitz and Mendelberg 2014; Dodson 2006; Bogoch 1997). However, 
the broader gender communications literature leads one to expect that women will use more credit sharing language when taking credit in a work setting (e.g. Haynes et al. 2013). Even though female legislators may choose a more collaborative leadership style (Rosenthal 1998), that does not stop them from giving credit to themselves to boost their electoral chances.

H4: Congresswomen will credit claim at higher rates than congressmen.

Looking at the text or language of these messages provides yet another layer to analyze. To date, there is no political science literature that delves into content analysis of the gendered language of tweets. My chapter will be informed by the three closest studies. The first is by Bei Yu (2013) who looking at Congressional speeches finds gendered differences have persisted from 1989-2008 based on coding language as feminine by "emotion words", and fewer articles, versus masculine with more nouns, long words, and fewer personal pronouns. Lenard (2016) also analyzed Congressional speeches for personal pronouns, this time for the $113^{\text {th }}$ Congress, also finding small but statistically significant gender differences in the qualitative component, and more pronounced gender differences in the qualitative analysis. The third study by Dolan and Kropf (2004) is the one I will most draw from. Dolan and Knopf use content analysis of 116 newsletters in the $107^{\text {th }}$ Congress, looking at the type of policy issues congresswomen and men take credit for, and whether they share that credit with others, or take sole credit. The authors find women counter negative stereotypes by not only taking credit more often than men, but also are less likely than men to share credit. 


\section{Data and Methods}

In this study, the Twitter feeds of all House congresswomen and men were hand-coded for the weeks of May 1-7, 2015 and May 1-7, 2016 to determine the types of Mayhewian activities they were emphasizing. Analyzing tweets from the $114^{\text {th }}$ Congress provides an important update to Lawless (2012) since Twitter has only become more and more central to the communication activities of members of Congress (Gainous and Wagner 2014) with nearly universal adoption (Golbeck, Grimes, and Rogers 2010). Furthermore, candidates must get out their message in a clear, simple message - all within 140 characters per tweet. Therefore, by analyzing Tweets, we see clear and concise campaign strategies, and can code for the appropriate Mayhewian behaviors.

During the week of May 1-7, 2015, according to the NY Times headlines, the top news of the week was: Congress passed a Cost-Cutting Budget plan, mulling the fate of the Iran nuclear agreement deal, whether the N.S.A. should be collecting data about Americans, dealing with allegations of police overreach. During May 1-7, 2016, Congress was preoccupied with: Flint Water Crisis, North Carolina's Law barring Trans individuals' bathroom usage, and another combat death in Iraq. During the week of May in 2016, Republicans and Democrats were in the midst of running potential presidential candidates, but the majority of MCs did not tweet either endorsing or denouncing a candidate. Most importantly, the week coincided with both Mental Health Awareness as well as Small Business week, allowing for a close view of how specific legislators broach the topic (if they do so at all) - both falling under the scope of gendered as well as party ownership of issue areas, and thus will allow for the testing 
of whether members of Congress take advantage of the issue activation to showcase their accomplishments, or engage in credit claiming.

The timeframe chosen for the analysis was the first week of May because it was an average week not near the House members' own election season. It also happened to coincide with a week that would activate both Democratic and Republican issue areas, which allows for a look at the phenomenon of gendered partisanship as it would activate for position taking and credit claiming purposes. The choice of the utilization of the entire House over a small timeframe allows for the chance to hand-code and pick up nuance that would otherwise missed through using automated methods of content analysis. Furthermore, the choice of using the House was to supplant the literature, as most studies looking at political communication either choose one chamber or another, or a small section of both.

The choice of the utilization of the entire House over a small timeframe allows for the chance to hand-code and pick up nuance that would otherwise would be missed through a program. The House has a small percentage of women compared to men and getting a look into what the entirety of Congress has to say for one week across two years during a part of the year not directly around election time allows for a look at what electorally motivated behaviors they display during a "regular" period. Of the total 431 MCs that use Twitter, 354 are men, and 77 are women. The average age of your Twitter using MC is 60 years old. Furthermore, on average, they are nearing their ninth year of serving in the House.

To choose how to go about coding the tweets, I first ran a pilot study where I took a small sample of 10 congresswomen and 10 congressmen and their tweets over 
the course of two weeks to establish a codebook and get a feel for the data I would be looking at. It became clear that some tweets were written in a manner that would not facilitate easy computer coding (e.g. no comment but a link to a picture in the district, one-word statements framed by an explanation of what it meant in surrounding tweets). Since the validity of automatically applied measures comes into question within computer-aided text analysis (CATA) as it does not account for human nuance (Neuendorf 2017, 39) and I wanted to be able to get rich qualitative data, I decided to use hand-coding for the entire House over a small timeframe. The House has a small percentage of congresswomen compared to congressmen and getting a slice of what all men and women in the House have to say for one week across two years allows for a look at what electorally motivated behaviors they display during a "regular" period. That said, the limitations for a smaller timeframe include not considering MCs who tweet less frequently - the number of tweets can range from a few per year all the way up to 20 a day.

To test intercoder reliability, a coder was trained by reviewing the codebook and independently applying it to a random sample of tweets $(n=500)$, meeting the minimum requirement based on Kaid and Wadsworth's (1989) suggestion of 5-7\% of the total sample size. A coding comparison query was run in NVIVO to determine the Kappa coefficient; if there is complete agreement then the Kappa coefficient $(K)=1$, while if there is no agreement among the raters (other than what would be expected by chance) then the Kappa coefficient $(K) \leq 0$. The Kappa values exceeded appropriate acceptance levels, as the overall weighted Kappa for the entire coded random sample 
was $0.79 .{ }^{25}$ The Kappa coefficient for the different nodes are as follows: 0.83 for advertising, 0.72 for position taking, and 0.91 for credit claiming, all meeting the standards of excellent agreement based on the guide to interpretation provided by NVIVO as delineated by Fleiss et al. (2003).

For the statistical analysis, I built several dependent variables that are a simple count of the number of tweets that each member of the House of Representatives had during the timeframe for each re-election minded behavior. Therefore, the dependent variables are: tweets targeted as advertising, position taking, and credit claiming as well as retweets of advertising, position taking, and credit claiming.

The main variables of interest are gender, party, and the interaction between gender and party. The statistical models account for a number of control variables that impact the level of tweets within the Mayhewian framework. A dichotomous variable of membership in a constituency or re-election minded committee ${ }^{26}$ was added as membership on such a committee may produce more benefits for legislators to be able to report and thus may increase rates of credit claiming. DW-Nominate scores ${ }^{27}$ were

\footnotetext{
${ }^{25} \mathrm{~A} \mathrm{~K}$ value of over 0.75 indicates excellent agreement, $0.40-0.75$ is fair to good agreement, and below 0.40 is poor agreement. See here: http://help-

nv11mac.qsrinternational.com/desktop/procedures/run_a_coding_comparison_query.htm\#Mi niTOCBookMark7

${ }^{26}$ Descriptive data for what committees the House members were in was gathered from Charles Stewart III and Jonathan Woon's Congressional Committees dataset in voteview.com, while the theoretical justifications for which committees qualified as a constituency committee came from a combination of Frisch and Kelly (2004) as well as Young and Heitschusen (2003)'s classifications of district motivated committees as opposed to informational committees. The re-election minded constituency committee was comprised of a bin of Agriculture, Armed Services, Natural Resources, Science, Small Business, Transportation, and Veterans Affairs committees.

${ }^{27}$ Voteview.com archive.
} 
added as tweets may be influenced by a liberal/conservative nature; for instance, many Democratic congresswomen tweeted their position in alignment with the party platform. Since the party leadership have a nationally visible stage, it may have an impact on Mayhewian behavior, thus a dichotomous party leader variable ${ }^{28}$ was added to the model. Finally, an MC's electoral margin percent ${ }^{29}$ may impact what they choose to focus on in tweets - they may focus on advertising behaviors rather than upset their district by position taking.

To identify tweets as either advertising, position taking, or credit claiming (as opposed to coding it for more than one category as Lawless (2012) did), my codebook strictly followed Mayhew's definitions of each category. Thus, this study follows the Mayhewian framework as Lawless did for coding tweets. Advertising is any effort to "disseminate one's name among constituents in such a fashion as to create a favorable image but in messages having little to no issue content" (Mayhew 1974, 49). Therefore, to be classified as an advertising tweet, the tweet had to be devoid of any position taking or credit claiming behaviors, only showcasing things such as a district appearance or a news link. For example, Rep. Matt Salmon's (R, AZ-5) tweet: “Don't miss my town hall tonight in Mesa. For more information or to RSVP, click here: https://t.co/zVI5xj3qtt." Credit claiming would consist of generating a belief that the MC was personally responsible for causing the "government, or some unit thereof, to do something that the actor (or actors) considers desirable" (Mayhew 1974, 53). Credit

\footnotetext{
${ }^{28}$ Leadership was counted from Speaker of the House to House Minority Whip.

${ }^{29}$ Daily Kos Elections dataset.
} 
claiming tweets showcased achievements for the district (such as getting funding for projects), legislative achievements that an MC spearheaded or co-sponsored in Congress, as well as claiming credit for voting against or for a bill. An example of a credit claiming tweet is as follows by Rep. Blake Farenthold (R, TX-27): "May the Fourth be with you today. Be sure to check out my YODA bill! https://t.co/adgiuwUKMb.” Position taking is an announcement of a stance, typically on governmental ends or means (Mayhew 1974, 61). To be coded as a position taking tweet, the tweet had to identify a stance on a bill, or a potential way of voting on an issue area. This category was coded exclusively from credit claiming so that this category would focus on potential positions on bills and issues, not actual voting measures. One example would be Rep. Brad Ashford's (D, NE-2) tweet: "I support tax credits that will grow \#Nebraska's economy. \#NE02 https://t.co/vKIRoUHZX0."

Credit Claiming tweets were looked at in greater depth in the second portion of the analysis, resulting in a nuanced understanding of credit sharing or individualistic credit claiming language. Mayhew defines credit claiming as generating a belief that the political actor is personally responsible for causing the government to do things beneficial for their district (though not excluding those outside the geographic boundaries), with an emphasis on their individual accomplishment (1973, 53). Following Dolan and Kropf (2004) study's framework for credit claiming as well as Lawless's (2012) identification of credit claiming behaviors, this chapter defines credit claiming tweets as any "bills sponsored, votes taken, initiatives requested, and any other sort of work that is undertaken and for which the member expresses his or her attempts to work on behalf of the district" (Dolan and Kropf 2004, 47). Sole credit was 
defined as a congressmember stating they personally did so (e.g. I, my, myself, me), while shared credit implies cosponsorship (e.g. we, our, with, consponsor, together). Neutral language was identified as using passive voice and formal language, ultimately referring to the $\mathrm{MC}$ in third person (e.g. "Congressman Al Green Introduces Resolution...”).

\section{Results}

Analyzing and coding tweets within a Mayhewian framework, the single most utilized tweet style is advertising. The majority of advertising tweets are about district visits, or an event: Small Business Week, Teacher Appreciation Week, Mental Health Awareness Month, or the National Day of Prayer. Table 1 shows little difference between congresswomen and men as far as these advertising behaviors - counting both tweets and retweets, congresswomen engage in $2 \%$ less advertising behaviors than their male counterparts (to $77 \%$ to $79 \%$ ), but position take $6 \%$ more than their male colleagues (19\% to $13 \%$ ). Men engage in more credit claiming behaviors by a three percent margin ( $8 \%$ to $5 \%)$. 


\section{Table 1}

Coded Mayhewian Tweets by Congressmember's Gender

\begin{tabular}{|c|c|c|c|c|}
\hline & \multicolumn{2}{|c|}{ Female MC } & \multicolumn{2}{|c|}{ Male MC } \\
\hline & $\begin{array}{c}\text { \# of } \\
\text { Tweets }\end{array}$ & $\begin{array}{l}\% \text { Total } \\
\text { Tweets }\end{array}$ & $\begin{array}{c}\text { \# of } \\
\text { Tweets }\end{array}$ & $\begin{array}{l}\% \text { Total } \\
\text { Tweets }\end{array}$ \\
\hline Advertising & 1291 & $60 \%$ & 4373 & $61 \%$ \\
\hline RT Advertising & 350 & $16 \%$ & 1327 & $18 \%$ \\
\hline Total Advertising Tweets & 1641 & $77 \%$ & 5700 & $79 \%$ \\
\hline Position Taking & 288 & $13 \%$ & 667 & $9 \%$ \\
\hline $\begin{array}{l}\text { RT Position Taking } \\
\text { Total Position Taking }\end{array}$ & 128 & $6 \%$ & 285 & $4 \%$ \\
\hline Tweets & 416 & $19 \%$ & 952 & $13 \%$ \\
\hline Credit Claiming & 89 & $4 \%$ & 410 & $6 \%$ \\
\hline $\begin{array}{l}\text { RT Credit Claiming } \\
\text { Total Credit Claiming }\end{array}$ & 10 & $0.5 \%$ & 156 & $2 \%$ \\
\hline Tweets & 99 & $5 \%$ & 566 & $8 \%$ \\
\hline Total Tweets & 1668 & $77 \%$ & 5450 & $76 \%$ \\
\hline Total ReTweets & 488 & $23 \%$ & 1768 & $24 \%$ \\
\hline & 2156 & $100 \%$ & 7218 & $100 \%$ \\
\hline
\end{tabular}

Source: Compiled by Author

Notes: DV is a count of tweets classified by their type of Mayhewian behavior.

Tweets or ReTweets may only be classified as one category. $\mathrm{N}=9374$. 
To identify the impact of party identification on tweets, Table 2 takes a closer look at the interaction of gender as well as partisanship as it impacts Mayhewian behavior. This is where we start to see differences emerge by party as well as gender. While we know that all members of Congress will have high rates of advertising behavior, based on Table 2, we see higher total levels of advertising behaviors for Republican congressmen and congresswomen (80-88\%) compared to Democratic congresswomen and congressmen (72-77\%). Republican congresswomen posted the most advertising tweets, with Democratic men retweeting advertising at the highest level $(21 \%)$. Democratic congresswomen were the highest position takers at $23 \%$, followed by Democratic congressmen at 16\%; Republican congressmen took positions on $11 \%$ of their total tweets and Republican congresswomen at $8 \%$. Finally, Republican congressmen have the highest level of credit claiming at $9 \%$, followed by Democratic congressmen at 6\%, Democratic congresswomen at 5\%, and Republican congresswomen at 3\% 
Table 2

Mayhewian Tweets by Congressmember's Gender and Party

\begin{tabular}{|c|c|c|c|c|c|c|c|c|}
\hline & \multicolumn{2}{|c|}{$\begin{array}{c}\text { Democratic } \\
\text { Women }\end{array}$} & \multicolumn{2}{|c|}{$\begin{array}{c}\text { Republican } \\
\text { Women }\end{array}$} & \multicolumn{2}{|c|}{$\begin{array}{c}\text { Democratic } \\
\text { Men } \\
\end{array}$} & \multicolumn{2}{|c|}{$\begin{array}{c}\text { Republican } \\
\text { Men }\end{array}$} \\
\hline & $\begin{array}{c}\text { \# of } \\
\text { Tweets }\end{array}$ & $\begin{array}{c}\% \text { of } \\
\text { Total } \\
\text { Tweets }\end{array}$ & $\begin{array}{c}\text { \# of } \\
\text { Tweets }\end{array}$ & $\begin{array}{c}\% \text { of } \\
\text { Total } \\
\text { Tweets }\end{array}$ & $\begin{array}{c}\text { \# of } \\
\text { Tweets }\end{array}$ & $\begin{array}{c}\% \text { of } \\
\text { Total } \\
\text { Tweets }\end{array}$ & $\begin{array}{c}\text { \# of } \\
\text { Tweets }\end{array}$ & $\begin{array}{c}\% \text { of } \\
\text { Total } \\
\text { Tweets }\end{array}$ \\
\hline Advertising & 894 & $55 \%$ & 397 & $74 \%$ & 1705 & $56 \%$ & 2668 & $64 \%$ \\
\hline RT Advertising & 270 & $17 \%$ & 80 & $15 \%$ & 644 & $21 \%$ & 683 & $16 \%$ \\
\hline Total Ad Tweets & 1164 & $72 \%$ & 477 & $88 \%$ & 2349 & $77 \%$ & 3351 & $80 \%$ \\
\hline Position Taking & 249 & $15 \%$ & 39 & $7 \%$ & 320 & $11 \%$ & 347 & $8 \%$ \\
\hline RT Position Taking & 122 & $8 \%$ & 6 & $1 \%$ & 177 & $6 \%$ & 108 & $3 \%$ \\
\hline Total Pos Tweets & 371 & $23 \%$ & 45 & $8 \%$ & 497 & $16 \%$ & 455 & $11 \%$ \\
\hline Credit Claiming & 73 & $5 \%$ & 16 & $3 \%$ & 148 & $5 \%$ & 262 & $6 \%$ \\
\hline RT Credit Claiming & 8 & $0.5 \%$ & 2 & $0.4 \%$ & 47 & $2 \%$ & 109 & $3 \%$ \\
\hline Total Cred Tweets & 81 & $5 \%$ & 18 & $3 \%$ & 195 & $6 \%$ & 371 & $9 \%$ \\
\hline Total Tweets & 1216 & $75 \%$ & 452 & $84 \%$ & 2173 & $71 \%$ & 3277 & $78 \%$ \\
\hline \multirow[t]{2}{*}{ Total ReTweets } & 400 & $25 \%$ & 88 & $16 \%$ & 868 & $29 \%$ & 900 & $22 \%$ \\
\hline & 1616 & $100 \%$ & 540 & $100 \%$ & 3041 & $100 \%$ & 4177 & $100 \%$ \\
\hline
\end{tabular}

Source: Author

Notes: DV is a count of tweets classified by their type of Mayhewian behavior. Tweets or ReTweets may only be classified as one category. $\mathrm{N}=9,374$. 
Do these differences hold up to statistical testing? In running a two-sample t-test, gender does have a statistically significant impact on advertising and position taking, but not for credit claiming. Considering the difficulty of pushing legislation forward, it is not that surprising to find low levels of credit-claiming behavior. The high incidence of advertising tweets is consistent with literature; most of what congressmembers do is engaging in opportunities to connect with the district in a way that puts them in a positive light. Indeed, many tweets in this category consisted of MCs tweeting about visiting their district where they would either have an opportunity to meet with constituents directly (e.g. Coffee with Congressman, or a Town Hall $-21 \%$ of all tweets for women; $27 \%$ for men) or their staff ("Need help with federal services?") to address any concerns they may have. These would either fall into the camp of general meeting with constituents (from visiting schools, to nursing homes), to explicitly referencing that they are explaining their DC activities.

Table 3, Table 4, and Table 5 present the statistical results for a series of negative binomial regressions. ${ }^{30}$ Each model uses a different dependent variable - a simple count of the number of tweets (or retweets) that each legislator sent for a particular Mayhewian behavior (advertising, credit claiming, or position taking) during the two-week period under study. The main independent variables of interest are gender, party, and the interaction between the two. The models also include a number of controls that the

\footnotetext{
${ }^{30}$ A negative binomial regression is more appropriate than a linear regression model as it can be used for over-dispersed count data (Long 1997). NBRM allows the conditional variance of the dependent variable to exceed the conditional mean, allowing me to model heterogeneity in the data.
} 
literature connects to the electoral behaviors of members of Congress (e.g., constituency committee membership, DW-nominate score, party leadership, and vote margin).

Within Table 3, the NBRM model indicates that congresswomen are more likely to advertise compared to congressmen, particularly within the second model for congresswomen which has the gender and party interaction. This supports hypothesis one - women will feel the need to advertise more, which is linked to the literature on gendered vulnerability. Since congresswomen feel the pressure to create a strong link to their constituencies, they advertise heavily: meeting with constituents, holding townhalls, sharing local news, and asking them for their input. There are no significant predictors for retweets. One possible explanation for the lack of results for the retweet models might be that it is difficult to consistently find tweets from others that portray members in a positive (and policy-free) light. Therefore, members have to do the bulk of advertising on their own. 
TABLE 3

The Impact of Gender and Party on the Number of Advertising Tweets and Retweets

\begin{tabular}{|c|c|c|c|c|c|c|c|c|}
\hline & \multicolumn{4}{|c|}{ Advertising Tweets } & \multicolumn{4}{|c|}{$\begin{array}{c}\text { Retweeted Advertising } \\
\text { Tweets }\end{array}$} \\
\hline & $\begin{array}{c}\text { Model } 1 \\
\text { Coef. } \\
\text { (S.E.) }\end{array}$ & & $\begin{array}{c}\text { Model } 2 \\
\text { Coef. } \\
\text { (S.E.) }\end{array}$ & & $\begin{array}{c}\text { Model } 1 \\
\text { Coef. } \\
\text { (S.E.) }\end{array}$ & & $\begin{array}{c}\text { Model } 2 \\
\text { Coef. } \\
\text { (S.E.) }\end{array}$ & \\
\hline $\begin{array}{l}\text { Main Independent } \\
\text { Variables }\end{array}$ & & & & & & & & \\
\hline Congresswoman & $\begin{array}{r}0.234 \\
(0.124)\end{array}$ & $\dagger$ & $\begin{array}{r}0.494 \\
(0.225)\end{array}$ & $*$ & $\begin{array}{r}-0.205 \\
(0.182)\end{array}$ & & $\begin{array}{r}0.167 \\
(0.337)\end{array}$ & \\
\hline Democrat & $\begin{array}{r}0.210 \\
(0.372)\end{array}$ & & $\begin{array}{r}0.303 \\
(0.316)\end{array}$ & & $\begin{array}{r}0.411 \\
(0.473)\end{array}$ & & $\begin{array}{r}0.494 \\
(0.529)\end{array}$ & \\
\hline $\begin{array}{l}\text { Congresswoman } \mathrm{x} \\
\text { Democrat }\end{array}$ & -- & & $\begin{array}{c}-0.389 \\
(0.269)\end{array}$ & & -- & & $\begin{array}{l}-0.270 \\
(0.401)\end{array}$ & \\
\hline Controls & & & & & & & & \\
\hline DW-Nominate (1st Dim) & $\begin{array}{r}0.164 \\
(0.350)\end{array}$ & & $\begin{array}{r}0.201 \\
(0.349)\end{array}$ & & $\begin{array}{r}-0.070 \\
(0.525)\end{array}$ & & $\begin{array}{r}-0.021 \\
(0.529)\end{array}$ & \\
\hline Two Party Margin & $\begin{array}{l}-0.252 \\
(0.150)\end{array}$ & & $\begin{array}{c}-0.239 \\
(0.150)\end{array}$ & & $\begin{array}{l}-0.067 \\
(0.227)\end{array}$ & & $\begin{array}{r}-0.065 \\
(0.226)\end{array}$ & \\
\hline Party Leader & $\begin{array}{r}0.509 \\
(0.542)\end{array}$ & & $\begin{array}{r}0.551 \\
(0.541)\end{array}$ & & $\begin{array}{r}1.220 \\
(0.773)\end{array}$ & & $\begin{array}{r}1.238 \\
(0.773)\end{array}$ & \\
\hline Constituency Committee & $\begin{array}{l}-0.119 \\
(0.094)\end{array}$ & & $\begin{array}{c}-0.111 \\
(0.094)\end{array}$ & & $\begin{array}{r}0.063 \\
(0.137)\end{array}$ & & $\begin{array}{r}0.066 \\
(0.137)\end{array}$ & \\
\hline Constant & $\begin{array}{r}2.570 \\
(0.198)\end{array}$ & $* *$ & $\begin{array}{r}2.526 \\
(0.199)\end{array}$ & $* *$ & $\begin{array}{r}1.150 \\
(0.299)\end{array}$ & $* *$ & $\begin{array}{r}1.109 \\
(0.304)\end{array}$ & $* *$ \\
\hline$N$ & 431 & & 431 & & 431 & & 431 & \\
\hline Log-likelihood & -1551.04 & & -1549.95 & & -1039.85 & & -1039.62 & \\
\hline Pseudo $R^{\wedge} 2$ & 0.003 & & 0.004 & & 0.007 & & 0.007 & \\
\hline
\end{tabular}

Source: Compiled by Author

Notes: $\dagger \mathrm{p}<.1 ;{ }^{*} \mathrm{p}<.05 ;{ }^{* *} \mathrm{p}<.01$. 
In Table 4, membership on a constituency committee statistically significant at $\mathrm{p}<0.05$ while gender is a weak indicator for position-taking tweets in Model 1 . The coefficient indicates that congresswomen are more likely to position take when compared to congressmen, but it is only significant at the $\mathrm{p}<0.1$ level. The effect disappears in Model 2 when the interaction between gender and party is considered. Members on constituencyoriented committees are significantly less likely to position take when compared to those with other kinds of committee assignments. This may be due to focusing less on position taking, and more on tweeting achievements due to their status on these committees. Therefore, the model does not provide evidence for hypothesis two, which states that Democratic congresswomen in particular will position take at higher rates than other groups. It also does not provide evidence for hypothesis three, which says Republican congresswomen will position take at lower rates than all other groups.

Also, in Table 4, members who are part of the party leadership are significantly more likely to retweet the position taking messages of others (although these effects are only significant at the $\mathrm{p}<0.1$ level). Since the party leadership play a large role in setting the party's agenda and developing their brand, it makes sense that they would be retweeting these kinds of position-taking messages. During this period, the Democrats had a consistent issue agenda that was widely retweeted. It included issues like healthcare, equal pay, resistance to the Republican budget. The Republican Party leadership also tried to amplify messages consistent with their issue agenda. In particular, they emphasized Small Business Week, efforts to balance the budget, and veterans' healthcare. 
TABLE 4

The Impact of Gender and Party on the Number of Position-Taking Tweets and Retweets

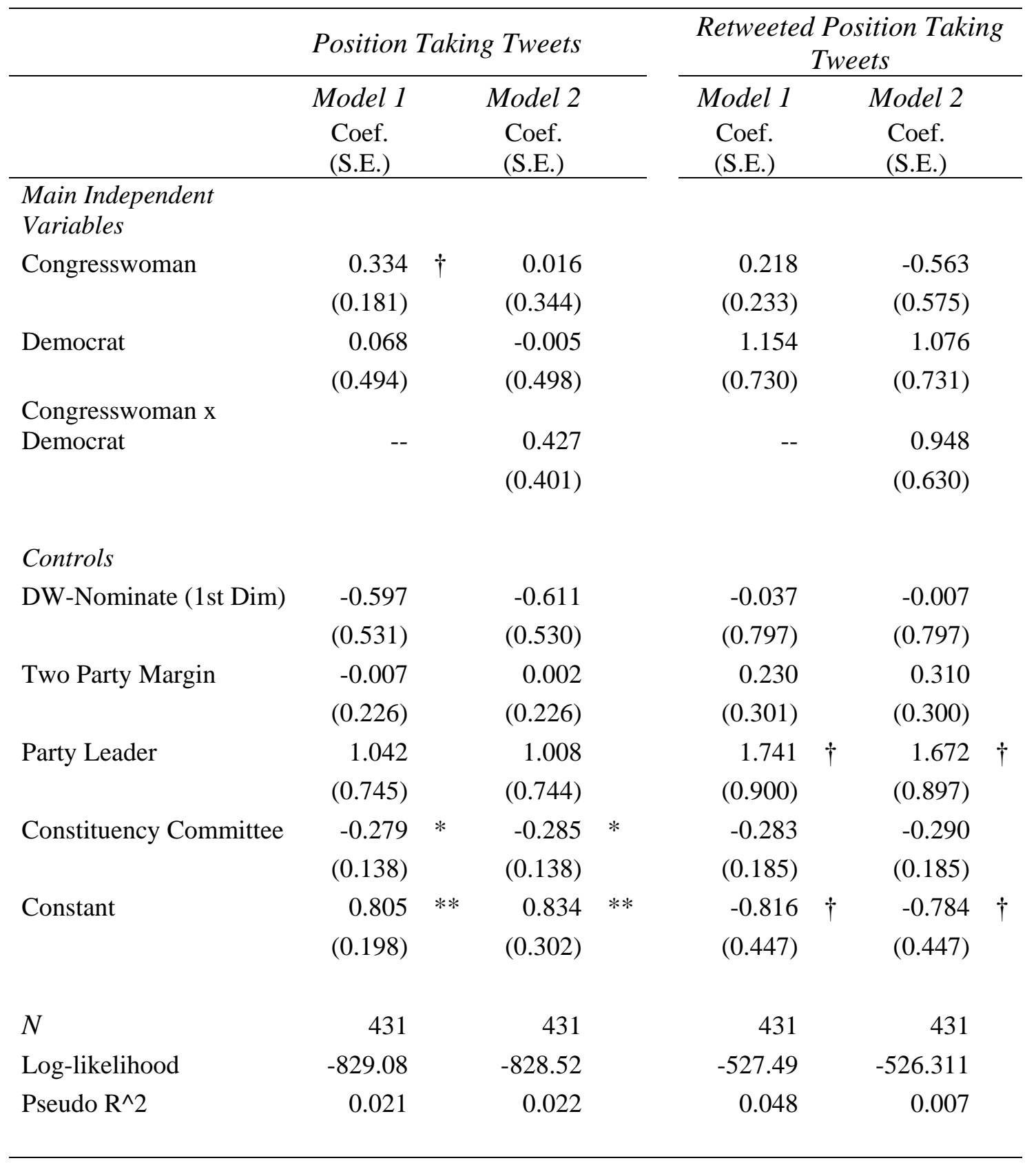

Source: Compiled by Author

Notes: $\dagger \mathrm{p}<0.1 ; * \mathrm{p}<.05 ; * * \mathrm{p}<.01$ 
Finally, Table 5 shows that the party leadership is significantly more likely to tweet credit claiming messages. The party leadership may have more notches in their belt to be able to post for their followers. Therefore, I find no support for $\mathrm{H} 4$, which states congresswomen will credit claim at higher rates than congressmen; the gender as well as gender and party indicator was not statistically significant in the model.

Additionally, for credit claiming retweets in Table 5, being a Democrat as well as having a liberal DW-nominate ideological score meant the MC was significantly less likely to credit claim. Republican congressmen were most likely to retweet others' credit claiming tweets for their benefit. Congresswomen were significantly less likely to retweet credit claiming tweets than congressmen; therefore I find that the opposite of hypothesis four, which claims women will do more credit claiming, even if they may share accomplishments. While Democratic congresswomen and congressmen tweeted credit claiming at the same percentage, the disparity between tweet totals for Democratic congresswomen was due to not retweeting credit claiming tweets. Congresswomen as a whole were not able to use as many tweets from other people to credit claim for various legislation. This gives us the understanding that congresswomen may tweet somewhat similarly as congressmen far as credit claiming, they are not able to rely on other sources to be able credit claim as congressmen do, be it special interest groups, or party leadership. 
TABLE 5

The Impact of Gender and Party on the Number of Credit Claiming Tweets and Retweets

\begin{tabular}{|c|c|c|c|c|c|c|c|c|}
\hline & \multicolumn{4}{|c|}{ Credit Claiming Tweets } & \multicolumn{4}{|c|}{$\begin{array}{c}\text { Retweeted Credit Claiming } \\
\text { Tweets }\end{array}$} \\
\hline & $\begin{array}{c}\text { Model } 1 \\
\text { Coef. } \\
\text { (S.E.) }\end{array}$ & & $\begin{array}{c}\text { Model } 2 \\
\text { Coef. } \\
\text { (S.E.) }\end{array}$ & & $\begin{array}{c}\text { Model } 1 \\
\text { Coef. } \\
\text { (S.E.) }\end{array}$ & & $\begin{array}{c}\text { Model } 2 \\
\text { Coef. } \\
\text { (S.E.) }\end{array}$ & \\
\hline $\begin{array}{l}\text { Main Independent } \\
\text { Variables }\end{array}$ & & & & & & & & \\
\hline Congresswoman & $\begin{array}{l}-0.187 \\
(0.202)\end{array}$ & & $\begin{array}{r}-0.348 \\
(0.383)\end{array}$ & & $\begin{array}{l}-1.228 \\
(0.409)\end{array}$ & $* *$ & $\begin{array}{l}-1.632 \\
(0.828)\end{array}$ & $*$ \\
\hline Democrat & $\begin{array}{r}0.057 \\
(0.464)\end{array}$ & & $\begin{array}{r}0.015 \\
(0.472)\end{array}$ & & $\begin{array}{l}-1.765 \\
(0.740)\end{array}$ & $*$ & $\begin{array}{l}-1.808 \\
(0.745)\end{array}$ & $*$ \\
\hline $\begin{array}{l}\text { Congresswoman } \mathrm{x} \\
\text { Democrat }\end{array}$ & -- & & $\begin{array}{r}0.222 \\
(0.447)\end{array}$ & & -- & & $\begin{array}{r}0.549 \\
(0.950)\end{array}$ & \\
\hline Controls & & & & & & & & \\
\hline DW-Nominate (1st Dim) & $\begin{array}{r}-0.100 \\
(0.527)\end{array}$ & & $\begin{array}{l}-0.115 \\
(0.528)\end{array}$ & & $\begin{array}{r}-1.873 \\
(0.835)\end{array}$ & $*$ & $\begin{array}{l}-1.874 \\
(0.836)\end{array}$ & $*$ \\
\hline Two Party Margin & $\begin{array}{l}-0.362 \\
(0.227)\end{array}$ & & $\begin{array}{l}-0.362 \\
(0.227)\end{array}$ & & $\begin{array}{r}-0.275 \\
(0.357)\end{array}$ & & $\begin{array}{l}-0.280 \\
(0.356)\end{array}$ & \\
\hline Party Leader & $\begin{array}{r}1.498 \\
(0.713)\end{array}$ & $*$ & $\begin{array}{r}1.486 \\
(0.713)\end{array}$ & $*$ & $\begin{array}{r}0.686 \\
(1.244)\end{array}$ & & $\begin{array}{r}0.659 \\
(1.241)\end{array}$ & \\
\hline Constituency Committee & $\begin{array}{l}-0.151 \\
(0.147)\end{array}$ & & $\begin{array}{c}-0.151 \\
(0.147)\end{array}$ & & $\begin{array}{r}0.089 \\
(0.246)\end{array}$ & & $\begin{array}{r}0.088 \\
(0.246)\end{array}$ & \\
\hline Constant & $\begin{array}{r}0.350 \\
(0.294)\end{array}$ & $* *$ & $\begin{array}{r}0.368 \\
(0.296)\end{array}$ & & $\begin{array}{r}0.162 \\
(0.417)\end{array}$ & & $\begin{array}{r}0.180 \\
(0.419)\end{array}$ & \\
\hline$N$ & 431 & & 431 & & 431 & & 431 & \\
\hline Log-likelihood & -634.34 & & -634.21 & & -328.95 & & -328.772 & \\
\hline Pseudo R^2 & 0.008 & & 0.008 & & 0.025 & & 0.026 & \\
\hline
\end{tabular}

Source: Compiled by Author

Notes: $\uparrow \mathrm{p}<.1 ;{ }^{*} \mathrm{p}<.05 ;{ }^{*} \mathrm{p}<.01$ 
The NBRM model gave some evidence for hypothesis 1, that congresswomen will advertise more than congressmen. Looking back at Table 2, this rings especially true for Republican congresswomen. For hypothesis 2 , the NBRM model only had weak evidence to indicate congresswomen will position take at higher rates than all other groups, and did not show Democratic congresswomen in particular to be the highest position takers. In Table 2 though, we see Democratic congresswomen have the highest percent of position taking tweets at $23 \%$ of their total while Republican congresswomen have $8 \%$, compared to Democratic congressmen at $16 \%$ and Republican congressmen at $11 \%$.

This high level of Democratic tweeting for position taking can be explained by two factors. Firstly, tweet blasts were occurring with Mental Health Week to destigmatize the issue, which falls under the issue area of healthcare and thus generally the Democratic agenda. Secondly, Democrats urged action (attempting to shame Speaker Ryan for not holding the vote) on the budget, Zika, opioid epidemic, as well as the Flint Water Crisis. This provides some evidence for hypothesis two, that Democratic congresswomen will hold the highest rates of position taking. The vast position taking efforts were within the Democratic party for their issue-owned content, and Republican congresswomen had the least percentage, lower than Republican congressmen.

For hypothesis three the NBRM did not find any significant predictors, but in Table 2 we see that Republican congresswomen in particular feel the constraints of position taking and thus have the least position taking tweet content. This may in part be due to Democratic congresswomen feeling more comfortable handling "masculine issues" in addition to "women's issues", while the reverse not being applicable due to party 
constraints (Swers 2013) and pressure from the district. Chapter Two delves more deeply into issue areas to explore this phenomenon.

For credit claiming, there is no support for hypothesis 4; congresswomen did not credit claim at higher rates than men. In fact, the data shows that both Democratic congresswomen and Republican congresswomen had the lowest rates of credit claiming. This finding may be a product of the small time frame, or may point to a low relative presence in the chamber for women which limits their effectiveness, particularly in promoting women's issue bills (MacDonald and O'Brien 2011). In comparison, during these two weeks, Republican congressmen took advantage of Small Business Week and touted their accomplishments frequently (whether they were recent or not).

How do these findings compare to Lawless's (2012) study? Firstly, her Twitter and Facebook results are disaggregated into separate categories, so we are not able to see the interaction of gender and party. In her study, Lawless finds Democrats are more likely than Republicans to include credit-claiming (13\% vs 5\%) and advertising (81\% to $71 \%$ ). Men were more likely to position take (a 15\% difference), with women $3 \%$ likely to advertise, and both women and men had the same percentage of credit-claiming tweets at $7 \%$ (Lawless 2012, 227).

The differences between this chapter's findings and Lawless's (2012) study follow in Table 7. In sum, where my analysis shows Republicans consistently having higher levels of advertising and credit claiming, Lawless (2012) finds Democrats have higher rates of advertising and credit claiming, probably due to being the party in power at the time of her study. What particularly stands out is the massive amount of position taking compared to my figures, but this can be explained by the fact that Lawless (2012) did not use mutually 
exclusive coding. The decision to keep the categories coded as mutually exclusive allowed for a clearer look at each Mayhewian category; what constitutes a position tweet versus a credit claiming tweet is being able to take specific credit for a measure, while advertising tweets were coded as such due to a lack of indication of any specific policy direction. While this may not allow for a perfect comparison between Lawless's (2012) study and my own, I ultimately chose to use a stricter coding scheme to get a more specific answer as to how MC's engage with different Mayhewian categories. Inherently, as you take credit for passing a legislative issue, you are taking a position on an issue; however, the position taking issue category should be reserved for those issues which members of Congress have not yet moved on - it is more of a signaling measure.

\section{Table 6}

Differences in Mayhewian Tweet Behavior Compared to Lawless (2012) Study

\begin{tabular}{|c|c|c|c|c|}
\hline \multirow[b]{3}{*}{ Advertising } & \multicolumn{2}{|c|}{ My Chapter Figures } & \multicolumn{2}{|c|}{ Lawless Figures } \\
\hline & Democrats & Republicans & Democrats & Republicans \\
\hline & $75 \%$ & $81 \%$ & $81 \%$ & $71 \%$ \\
\hline Position Taking & $19 \%$ & $11 \%$ & $41 \%$ & $53 \%$ \\
\hline \multirow[t]{2}{*}{ Credit Claiming } & $6 \%$ & $8 \%$ & $13 \%$ & $5 \%$ \\
\hline & Women & Men & Women & Men \\
\hline Advertising & $77 \%$ & $79 \%$ & $77 \%$ & $74 \%$ \\
\hline Position Taking & $13 \%$ & $13 \%$ & $37 \%$ & $52 \%$ \\
\hline Credit Claiming & $5 \%$ & $8 \%$ & $7 \%$ & $7 \%$ \\
\hline
\end{tabular}

Notes: Lawless's N=7,043 over 8 weeks in summer 2009; her percentages do not add to $100 \%$ as her coding was not mutually exclusive. My chapter's N=9,374. 
Another interesting element that Lawless (2012) analyzed was the way congressmembers disseminated information. In her chapter, she included the percentage of total MCs that included a link to another source (12.7\%), or included an audio or visual component (15.9\%) (Lawless 2012, 221). To gauge whether congressmembers have gotten a hang of social media since then, I added a few measures in my coding, including hashtag usage, linking to their official websites, adding a photo or video of themselves, adding an explanatory photo or visual to go along with their tweet, or a link to an official press statement from their campaign. Table 8 provides a summary of this data. Members regularly use hashtags to catch the attention of the constituents in the district. ${ }^{31}$ Links to news articles generally draw attention to the news of the day. These links included stories on a transgender bathroom bill, the death of a Navy Seal, local and state events, or for some lucky congressmembers, coverage of a legislative accomplishment.

\section{Table 7}

\section{Congressmembers Dissemination of Information on Twitter}

\begin{tabular}{|c|c|c|c|c|}
\hline & $\begin{array}{c}\text { Democratic } \\
\text { Women }\end{array}$ & $\begin{array}{c}\text { Democratic } \\
\text { Men }\end{array}$ & $\begin{array}{c}\text { Republican } \\
\text { Women }\end{array}$ & $\begin{array}{c}\text { Republican } \\
\text { Men }\end{array}$ \\
\hline Usage of Hashtags & $66 \%$ & $55 \%$ & $54 \%$ & $57 \%$ \\
\hline Link to News Article & $16 \%$ & $17 \%$ & $12 \%$ & $16 \%$ \\
\hline Link to Visual/Figure & $13 \%$ & $16 \%$ & $18 \%$ & $20 \%$ \\
\hline Link to Photo of MC & $26 \%$ & $28 \%$ & $38 \%$ & $26 \%$ \\
\hline Link to Video of MC & $2 \%$ & $2 \%$ & $3 \%$ & $4 \%$ \\
\hline Link to MC's website & $1 \%$ & $2 \%$ & $4 \%$ & $5 \%$ \\
\hline Link to Press Statement & $8 \%$ & $8 \%$ & $8 \%$ & $9 \%$ \\
\hline
\end{tabular}

Note: Percentage was calculated based on the total of tweets for each category (with a combined $\mathrm{N}=7118$ ), not the combined figure of tweets and retweets.

${ }^{31}$ See https://www.washingtonpost.com/blogs/govbeat/wp/2014/02/10/the-united-states-ofhashtags/?utm_term $=.54 \mathrm{c} 6 \mathrm{a} 31 \mathrm{ef} 8 \mathrm{cc}$ for a list of hashtags used for political chats within various states. 
To supplement their tweets, as a whole, women MCs linked photos of themselves to tweets $(28.7 \%)$, and men 1,448 times $(26.4 \%)$. These tended to coincide with district appearances. Radio appearances can be crucial at the local level, particularly when Congress wants to sell the concept of backing a piece of legislation they are cosponsoring. For instance, Rep. Mike Bishop (R, MI) posted this tweet: “This morning @Dakerly and I talked about the Water \& Energy Appropriations Bill's impact on \#FRIB, \#GreatLakes: http://t.co/FmaLJifNtd \#MI08" (May 4, 2015. 6:06 pm). Generating this democratic dialogue and accessibility between congressmember and constituent allows for a personalization of politics that paints them in a positive light.

Appearances matter, and drawing attention to where congressmembers spend their time - particularly at the district, as appearances are an important aspect of representation (Fenno 1987) - is illustrative of typical Mayhewian behavior. Table 6 covers the percentage of tweets drawing attention to visits to Congress or the district by gender and party. In Table 8, we see Republican congressmen and congresswomen having the highest rates of district appearances at $28 \%$. The week chosen for this study coincided with Small Business Week, and business is an issue area viewed by constituents as a strength for Republicans. Therefore, MC's took advantage of the week to come to the district and visit small businesses. The second highest district visits are by Democratic men (25\%), followed by Democratic women (21\%). Members of Congress tend not to tweet about their appearances in Congress unless they have the floor, which is why the rates are consistently low across both gender and party lines with Republican congresswomen holding the highest percentage at $2 \%$. Radio and TV appearances are also a small figure (from $0.3 \%$ to 
$2 \%$ ), but the figures would likely increase if the study considered a larger period of time. Ultimately, these figures should be taken with a grain of salt - many members of Congress simply tweeted multiple times about a single district visit or event, and so these numbers may be somewhat inflated due to a handful of members within both parties.

In total, congressmen mentioned or linked to 121 radio appearances, with women just doing a total of 13 . For the most part, link that congressmembers posted were to photos of themselves, followed by pictures to supplement the topic at hand (e.g. a picture of a nurse to advertise National Nurses Day; a diagram illustrating the main points of the bill they voted for). Links to news articles could have a partisan tie -and an opportunity to position take - which a few MC's did take the opportunity to do. That said, it was pretty notable to mention that most of the news stories actually did not come from highly partisan sources; the majority of posted news articles came from either local news, or fairly centrist news sources such as CBS or USA Today. More highly partisan members of Congress did use sources such as Breitbart, Fox News, New York Times, or The Guardian.

Explanation of Washington activities requires a detailed look at what MCs post. By "explaining", we mean to "include the description, the interpretation, and the justification of their behavior" (Fenno 1978, 136). Some explicitly state their intentions along with their photos of themselves: "Updated the Iowa State Assoc of Letter Carriers this AM on what we're working on in Congress. \#IA03 (@NALC_National) https://t.co/vb1Kz5gjwF" Rep. David Young (R, IA). (May 2, 2016. 3:54 pm. Tweet.) This was similar to Rep. Comstock's (R, VA) tweet, a picture of herself talking to a Rotary Club in her district to give a "legislative update," include a piece of legislation she had worked on passing. On occasion, representatives like Paul Tonko, or Elise Stefanik post links of interviews 
(whether videos, or radio appearances) regarding legislation they are sponsoring. For the most part, such activities tended to coincide with credit claiming behavior, which is the focus of the next section of the chapter. 
Table 8

Congressional Tweets about Appearances

\begin{tabular}{|c|c|c|c|c|c|c|c|c|}
\hline & \multicolumn{2}{|c|}{ Democratic Women } & \multicolumn{2}{|c|}{ Republican Women } & \multicolumn{2}{|c|}{ Democratic Men } & \multicolumn{2}{|c|}{ Republican Men } \\
\hline & $\begin{array}{c}\text { \# of } \\
\text { Tweets }\end{array}$ & $\begin{array}{c}\% \text { of Total } \\
\text { Advertising } \\
\text { Tweets }\end{array}$ & $\begin{array}{c}\text { \# of } \\
\text { Tweets }\end{array}$ & $\begin{array}{c}\% \text { of Total } \\
\text { Advertising } \\
\text { Tweets }\end{array}$ & $\begin{array}{c}\text { \# of } \\
\text { Tweets }\end{array}$ & $\begin{array}{c}\% \text { of Total } \\
\text { Advertising } \\
\text { Tweets }\end{array}$ & $\begin{array}{c}\# \text { of } \\
\text { Tweets }\end{array}$ & $\begin{array}{c}\% \text { of Total } \\
\text { Advertising } \\
\text { Tweets }\end{array}$ \\
\hline Congress Appearance & 8 & $0.7 \%$ & 9 & $2 \%$ & 8 & $0.3 \%$ & 46 & $1 \%$ \\
\hline District Appearance & 240 & $21 \%$ & 134 & $28 \%$ & 580 & $25 \%$ & 922 & $28 \%$ \\
\hline Radio Appearance & 2 & $0.2 \%$ & 11 & $2 \%$ & 24 & $1 \%$ & 97 & $3 \%$ \\
\hline TV Appearance & 3 & $0.3 \%$ & 3 & $0.6 \%$ & 39 & $2 \%$ & 54 & $2 \%$ \\
\hline
\end{tabular}

Notes: Percentages for each category were calculated based on total percentage of advertising tweets, ReTweets included. N=7,341. 


\section{A Deeper Examination of Credit-Claiming Tweets}

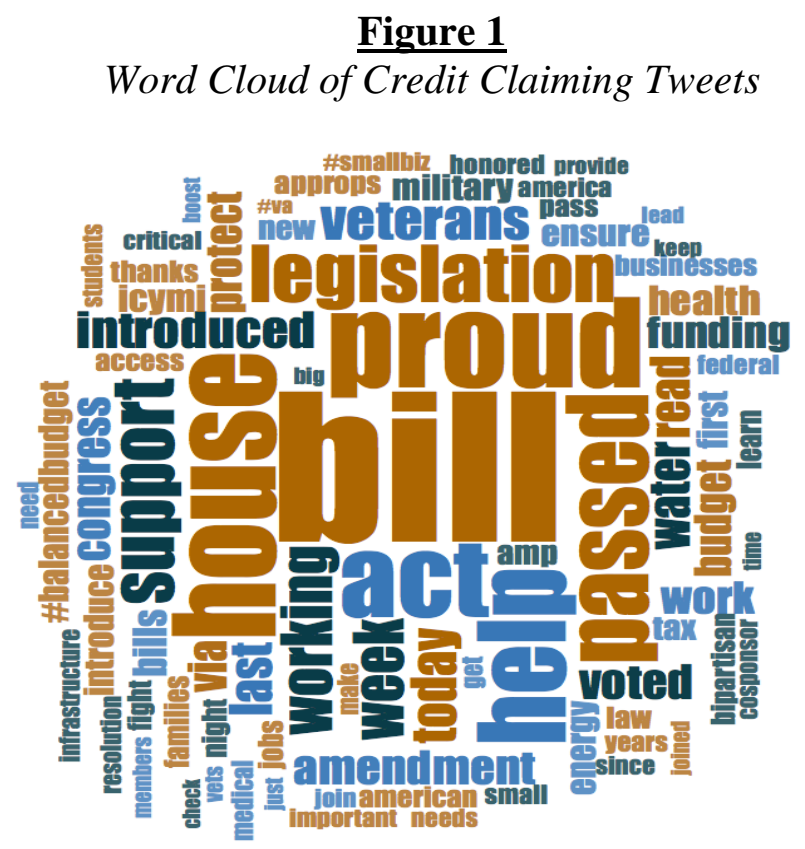

Figure 1 provides a broad look at which words were stressed within the credit claiming tweets. While computer assisted coding allows for some understanding, hand coding allows for nuance that would otherwise be missed by computer assisted coding. For instance, Ted Deutsch (D, PA) tweeted, "Even the Onion knows Super PACs aren't for you http://t.co/ggWrW48EfH. The Democracy4All Amendment is \#GetMoneyOut http://t.co/pxyZsh7HsY” (May 7, 2015 at 9:00:58PM). For computer coding, the temptation may be to code it for position taking or advertising, but when you follow the links, the first is to an Onion article, but the second is to a press release on Deutsch's official page claiming credit for reintroducing the "Democracy for All Amendment" on the fifth anniversary of Citizens United. In this second part of the chapter, I will be taking a close look at the credit-claiming behaviors being displayed and how they interact with gendered as well as partisan expectations. 
First, I will analyze the amount of credit claiming that legislators engage in. We observed in Table 3 that Republican congressmen engage in the highest level of posted $(6 \%)$ as well as retweeted (3\%) credit claiming behaviors to add to a total of $9 \%$ of their total tweets. In comparison to the Lawless (2012) study figures in Table 7, she found Democratic congressmen had the highest level of credit claiming tweets. To dig deeper into the content of the credit-claiming tweets I coded credit owning ("I"), credit sharing ("we"), and neutral language by gender and party in Table 9.

Table 9

Credit Claiming Gendered Language

Democrat Women

Democrat Men

Republican Women

Republican Men

\begin{tabular}{|c|c|c|}
\hline $\begin{array}{c}\text { "I" } \\
\text { passed } \\
\end{array}$ & $\begin{array}{l}\text { "We" } \\
\text { passed }\end{array}$ & $\begin{array}{c}\text { Neutral } \\
\text { language }\end{array}$ \\
\hline $44 \%$ & $42 \%$ & $14 \%$ \\
\hline $54 \%$ & $26 \%$ & $20 \%$ \\
\hline $50 \%$ & $19 \%$ & $31 \%$ \\
\hline $44 \%$ & $40 \%$ & $16 \%$ \\
\hline
\end{tabular}

Note: Tweets were coded as mutually exclusive for each category.

As Table 9 shows, the highest level for individual credit claiming falls to Democratic congressmen, who also happen to have the lowest levels of credit-sharing behavior. Democrat congresswomen use credit owning and sharing language nearly at the same level. The percentages do not add to $100 \%$, as some credit-claiming tweets used what I term "neutral language": either in formal press release language/as if a third party wrote it, or written in passive voice. Ken Calvert (R-CA), Al Green (D-TX), and Zoe Lofgren (D-CA) are examples of MC's who tended to use this approach; for instance: “Rep. Calvert 
Votes to Fulfill Our Obligations to Our Veterans http://t.co/SIDvgATVRb” (May 1, 2015 at 12:29:50AM).

Some credit-claiming tweets are written in a passive manner, where it is not immediately apparent that the $\mathrm{MC}$ is claiming credit for a measure until you follow the link they provide which generally takes you to a press release, such as Rep. Jim Cooper's (D$\mathrm{TN})$, “'Mad Men' may be ending soon, but medical research is still stuck in the '60s. http://t.co/qKLAUDCa6R http://t.co/maVhrPch70" (May 5, 2015 at 5:56:35PM). The press release states that Cooper is reintroducing bipartisan legislation to bring gender equality to medical research - something not immediate apparent in the tweet.

What issues were broached in these credit-claiming tweets? Democrats often claimed credit on the following topics: healthcare, veterans affairs, raising the minimum wage, education, the economy, and jobs. Republicans typically focused their credit claiming activities on the budget, energy, the military, taxes, jobs/businesses, medical leave for veterans, and infrastructure. Notable for Republican congresswomen was Rep Comstock's (R-VA10) tweet: "Gave the Clarke County Rotary Club a legislative update that focused on the human trafficking we passed. \#VA10 https://t.co/c7LrMKeZTf" - a women's issue that Democrats tend to hone in on, in conjunction with a notable display of home style. Both Democratic and Republican congressmen were those ones to reference if their measure was a bipartisan venture, while congresswomen typically did not. Committee participation can influence credit claiming as well, as it affords legislators input. For instance, Rep. Adams (D-NC) serves on the small business committee, and therefore she was able to claim credit for bills pertaining to the issue area, showing the district she is posed to bring tangible benefits in a traditionally "masculine" or Republican issue area. 
Very few credit-claiming tweets involved a member of Congress proudly declaring that they have voted against a bill. Generally, the negative aspect tends to be an introduction of one bill to kill another, such as Phil Roe's (R-TN) bill to repeal the Independent Payment Advisory Board (IPAB). One instance was Rosa DeLauro (D-CT) explaining in her tweet that she voted against the House GOP's “Work Harder for Less" budget because she didn't want to "leave the middle class out in the cold" (May 1, 2015 4:59:31PM). Another was Rick Nolan (D-MN) - "Yesterday, w the support of numerous \#veterans orgs, I joined bipartisan vote AGAINST the VA funding bill. READ MORE: http://t.co/9tbGS3pOaA" (May 1, 2015 at 6:54:23PM). Key here is that Nolan must explain why he would vote against a bill that would presumably help veterans, and as such he added the qualifier that it was a bipartisan group against this funding bill, as well as a detailed explanation on a Facebook post that read like a personalized press release. A new member of the legislation, Mimi Walters (R-CA) was proud to introduce a bill that would repeal Obamacare's cap on Flexible Spending Accounts (May 6, 2015 3:18:42PM).

The emphasis on bipartisan cooperation was made by congressmen. Republican congressmen had the highest rates of mentioning a bipartisan effort: at 8 tweets, they wanted to emphasize cooperation with the budget effort and miscellaneous bills such as FOIA Compliance, Lali's bill, or just an effort towards building a bipartisan consensus in Washington as Rep. Robert Dold (R-IL) tweeted: "Proud to be part of the group building bipartisan consensus in Washington. We need to put people ahead of politics: http://t.co/VbWDUnf5sK" (May 5, 2015 at 1:40:59PM). 3 Democratic congressmen tweeted about a bipartisan effort regarding finance reform, and against the VA funding bill. One Democratic congresswoman Zoe Lofgren (D, CA) tweeted about a bipartisan letter 
calling for human rights and a labor standard in the Trans-Pacific Partnership. No Republican congresswomen mentioned bipartisanship.

Some nontraditional legislation promoted through Twitter during this time was reduction of ceiling fan regulations (which then meant ridiculous congratulatory and excited tweets from legislators who cosponsored the initiative and were thrilled about, of all things, a cutback on ceiling fan regulations), Rep. Sam Farr (D-CA) pushing for removal of elephants from circus, and Rep. Jim McGovern (D-MA) standing with former Secretary of State John Kerry and others to push for truth in Honduras human rights murder. Lots of different types of legislation was spoken about, from veterans' healthcare, to environmental regulations, to the Cuban embargo.

\section{Republican Credit Claiming}

Republican congressmen were more likely to use Credit Claiming to bolster their party's success. For instance, Trent Franks (R, AZ) tweeted, "Last night I voted YES for the FY2016 Budget. Republicans are still committed to an \#opportunityeconomy" (May 1, 2015 at 8:32:38PM). The budget was a large part of the debate during this time, including on the Congressional Twitterverse, and with partisan cues, Republicans emphasized their vote for the bill. Some took it a step further to tie it to district efforts, as did Rep. Dave Joyce (R-OH) "which includes my language to protect our Great Lakes" or Rep. Mike Kelly's (R-PA) emphasis that the appropriations bill he voted on would directly support Erie and jobs. 
While Democrats tended to just retweet their leadership's positions on traditional Democratic issue areas, Republicans emphasized their cooperation as a party. Mario DiazBalart (R-FL) championed his work as part of the Republican party with a few tweets, including, "Did you know House Republicans have passed 4 bills in the 114th Congress that help to strengthen and empower American \#smallbiz? \#SBW2015" (May 6, 2015 at 8:18:19PM). Here we see Rep. Diaz-Balart take advantage of Small Business Week and the accompanying hashtag to highlight Republican achievements to underscore how he helped in those endeavors as part of the party.

Therefore, another good strategy congressmembers use is to take advantage of trending topics or themes to bring up their accomplishments. For Small Business Week, multiple Republicans emphasized their individual as well as party achievements, like Will Hurd (R-TX) using the hashtag to tout his vote to pass HR37, or Rep. Carolyn Maloney (D-NY) urging support for her small business act.

Directing followers to press releases on their websites is not uncommon, and some MCs give vague credit claiming tweets with the purpose of getting individuals to read their press releases or e-newsletters detailing achievements on their official website. For instance, Todd Rokita (R, IN) redirects his followers to his congressional website: "Rokita Report keeps Hoosiers informed. Latest edition discusses how 5 bills I cosponsored passed House last week. https://t.co/tl2bbUpuYn" (May 2, 2016 at 9:55:08PM). Similarly, Rep. Pete Sessions (R, TX) urges his followers to read his weekly newsletter to learn about his efforts to help startups, stop the USDOL's Fiduciary Rule, and more.

Some members of Congress like Rep. Phil Roe (R, TN) did not directly reference a specific piece of legislation, but urged readers to follow a link (most often to their official 
congressional website) to find out what they are doing to support a particular initiative, in this case supporting teachers and education - "Read more about Teacher Appreciation Week and what I'm doing to support teachers in this week's column: http://t.co/kGl3ot2wGRb (May 6, 2015 at 7:51:29PM). Rep. Roe was one of very few legislators who mentioned a bipartisan effort towards a piece of legislation - he mentioned being grateful to have Rep. Linda Sanchez as the "Democrat lead" on a bill that would repeal the Independent Payment Advisory Board (IPAB) - an effort to purportedly help seniors on Medicare. Roe's three credit claiming tweets focused on Democratic owned issue areas - his effort towards supporting teachers (as it was Teacher Appreciation Week), and two tweets about the effort to repeal IPAB, which had 220 cosponsors in Congress as well as the support from many health groups. The emphasis on health may be due to his background as a doctor.

The most effective instances of credit claiming are those displaying that the member of Congress is explaining their achievements in the districts, thus showcasing their effectiveness and the utility of ensuring they continue to get elected. One such instance is Rep. Barbara Comstock's (R-VA) tweet: "Gave the Clarke County Rotary Club a legislative update that focused on the human trafficking we passed. \#VA10 https://t.co/c7LrMKeZTf. (May 4, 2016 at 7:43:04PM). Just that tweet alone hits on not only her achievements in Congress, but showcases her presence in the district, grabs the attention of the district by using the district hashtag, and also links to a picture of her at the event. At the end of all her tweets, you might notice that Comstock uses the hashtag \#VA10 to catch the attention of her district. This is one way of directing her efforts at the district level. 
Rep. John Kline (R-MN) similarly used a district appearance to snap a picture to share and showcase how he responded to a Northfield resident asking about his Student Success Act, also with the use of his district's hashtag. These types of tweets may feel a bit staged, in an effort to show that some people in the MC's district are aware of the different initiatives that the legislator is pushing forth and fighting for. Some members of Congress even used tweets to link to press releases explaining their vote, using the hashtag of the district to catch their attention, such as Rep. Richard Hanna (R-NY):

- "Why I voted Yes on the CR to S.Con. Res 11, which establishes the budget for the U.S. Government for FY 2016. http://t.co/zbr1BWDU01 \#NY22"

- 'I voted No on H.J. Res. 43, regarding the D.C. Council's Reproductive Health Non-Discrimination Amendment Act. http://t.co/iuTG9V8uoY \#NY22”

In setting up his tweet to showcase his vote in a clear manner with a link of explanation, Rep. Hanna uses the short character limit of tweets effectively, making sure the district is aware of his work through the use of the district hashtag, while directing traffic to his official website for those who actually are interested in why he voted the way he did.

As more and more of what legislators do ventures into the online realm, we begin to observe the phenomenon of online or telephone hall meetings. For legislators, this is a great thing - they can pick and choose who to respond to, which is much more difficult in a face to face setting as a district town hall would be. During this time frame, Rep. John Kline (R, MN) conducted a telephone town hall meeting in 2015, tracking the tweets under the hashtag \#KlineTTH, engaging with his district through Twitter and on the phone. The issues that ultimately came up were the burden of Obamacare's cost, spending by the 
federal government, national security, federal government staying out of the state's business, and student loan interest rates. Engaging his followers on Twitter, Kline redirected them to take survey question on his official congressional website:

- \#KlineTTH survey question: What issue should be DC's top priority? Healthcare, gov't spending/debt, jobs, nat security or educ. Results soon" (May $5,2015$ at $11: 32: 20 \mathrm{PM})$

- “\#KlineTTH results: $42 \%$ say gov't spending \& debt should be Congress' top priority. Nat'l security - 19\%; Jobs 16\%, Healthcare 11\%, Educ. 9\%.” (May 5, 2015 at 11:39:55PM)

The bulk of credit claiming tweets for Republicans fell to Republican congressmen. Among the Republican congresswomen tweets for credit claiming, some topics included a bill preventing hackers from manipulating ticket prices (Rep. Marsha Blackburn), their efforts towards passing the balanced budget (Rep. Vicky Hartzler), halting a Medicare rule that would harm rural healthcare providers (Rep. Lynn Jenkins), introducing legislation to help local communities against terrorist attacks (Rep. Martha McSally), a bill asking Germany to help with survivors of the Holocaust (Rep. Ileana Ros-Lehtinen), and a bill to help protect against tax return fraud (Rep. Ann Wagner).

Of these Republican congresswomen's credit-claiming tweets, we do see a consciousness of showing the utility of these bills for the district - whether it is a Jenkin's opposition to legislation that would harm rural providers, which would be a concern for her rural district, or McSally's taking of a national issue with Republican domain (terrorism, or national security) and making it local. Since congresswomen have this concern of gendered vulnerability where they're feeling the pressures of delivering to their 
constituencies, it makes sense that they would not only emphasize Republican issue areas, but also these in conjunction with measures that would help their district, thus showing the utility of keeping them in office, providing some evidence to hypothesis 1 . Most of the mentions of women's issue areas occur in position taking tweets, where Republican congresswomen show their followers exactly where they stand and differentiate themselves from Democratic congresswomen.

\section{Democratic Credit Claiming}

With the incidence of Mental Health Week, many Democratic legislators brought up various health initiatives, as healthcare is seen to have Democratic issue ownership. For instance, during the tweet storm for Mental Health Awareness, Rep. Marcia Fudge (D-OH) brought up introducing the Breaking Addiction Act, as well as working towards ending the stigma around mental health, as did multiple Democrats. A bipartisan group of legislators advertised their position both for and against the veterans' healthcare bill. Some initiatives Democratic men took credit for were raising the minimum wage (Rep. Xavier Becerra), CA drought funding (Rep. Bera Ami), stopping metadata collection (Rep. Cicilline), and reforms preventing military equipment from getting into the hands of policy (Rep. Lacy Clay). There are also efforts to reintroduce legislation, as Jose Serrano (D-NY) and his Grand Act (expanding housing for 'grandfamilies'), or the Ted Deutsch (D-PA) tweet mentioned at the start of the credit claiming subsection.

Democratic women were taking credit for measures such as leading the call for childcare for families (Rep. Suzanne Bonamici), redistricting reform (Rep. Julia Brownley), a local bill for children to get access to quality early learning (Rep. Lois Capps), handgun 
trigger safety act (Rep. Carolyn Maloney), and a plan for veterans healthcare (Rep. Kyrsten Sinema).

Based on studies that find that it is not the amount but how often congressmembers advertise their achievements that produce a positive impact on constituents (Grimmer 2012), it is not surprising to see that some legislators do send more than one tweet to emphasize their legislation. For example, Peter Roskam tweets 4 times about his 'No Defense Contracts for Terror Profiteers Act' - first introducing it, then about the expectation for widespread support, a full statement announcing the Act, and advertising a co-sponsor's video appearance on OAN, the One America News network, adding a link to the interview on YouTube. Similarly, Kyrsten Sinema (D-AZ) dedicated several tweets to drawing attention to VA Accountability in between tweets aimed at the district, including, "We served residents..couldn't attend? Call us for help." Such a direct appeal to the district also increases the credit claiming capacity for the representative.

Rep. John Delaney (D, MD) in an effort to promote his legislation and continue to have it discussed on Twitter, gave credit by thanking individual MC's who joined in to support by tagging them (@) in these tweets - for instance: “Thank you to @ RepMcNerney - latest cosponsor of my universal pre-k bill https://t.co/P9AAZqiKWn \#prek \#earlyeducation \#MD6" (May 2, 2016 at 1:53:37PM). That was one reason why the number of credit-claiming tweets may be artificially inflated. For instance, Rep. Rick Larsen (D, WA) tweeted twice about his efforts to improve rail lines in the district, and three times about the Youth Access to American Jobs Act he is spearheading.

Credit claiming can end up sounding a bit awkward. Rep. Steve Cohen (D, TN) took advantage of Small Business Week to advertise, "It's Nat'1 \#SmallBiz Wk. \#Memphis 
Minority Business Development Center I helped launch can assist w/opening+growing your own \#DreamSmallBiz" (May 7, 2015 at 8:35:25PM). Members of Congress can feel pretty constrained with the amount of characters that they have to work with to try and concisely state their message. They can end up shortening words to try and cram as much information as possible as Cohen does. It is a common enough problem for users of Twitter to struggle to fit their message within the standard character limit that Twitter expanded its character count to 280 starting November 7, 2017.

When it was Holocaust Remembrance Day, Rep. Cohen took advantage of the occasion to remind his twitter followers, “ \#TBT to 1984 when I drafted \& passed a resolution as TN State Senator to create @TNHolCom. \#NeverForget. \#YomHashoa \#HolocaustRemembranceDay" (May 5, 2016). It might be a bit off-putting to some that he is taking advantage of a day to commemorate a horrific occurrence in history to tout his own achievements, even if it is directly related to the day.

The theme of awkward credit claiming continues with Star Wars. Since May $4^{\text {th }}$ occurred during this time, lots of legislators sent their followers a tweet similar to Rep. Elizabeth Esty's "May the fourth be with you! \#StarWarsDay." (May 4, 2016 at 2:46:53PM). Rep. Blake Farenthold (R, TX) took that a bit further by adding a gif of him whipping out a lightsaber against a fellow congressmember in 2016 and in 2015 telling his followers, "May the Fourth be with you today. Be sure to check out my YODA bill! https://t.co/adgiuwUKMb" (May 4, 2015 at 4:15:05PM). The YODA, or "You Own Devices Act" would allow a consumer to have more ownership over their products, including the ability to sell or give it away as some software licensing issues prevent consumers from doing so. The title of the act was very apt for the Star Wars minded tweet. 
For Democratic congresswomen, Rep. Tammy Duckworth (D-IL) was also a mega tweeter, really creating a connection to her district and drawing attention to her efforts and accomplishments. Duckworth sometimes shared the credit with her cosponsors while still maintaining that emphasis on her contribution to it - "I'm working w @ RepMikeQuigley, @janschakowsky \& @RepGutierrez to provide \#WhatMomsNeed: \#FairPay. https://t.co/elIdRqH8Ij \#MothersDay" (May 5, 2016 at 7:25:09PM). This follows with the finding that women will emphasize their individual contributions, though may share their accomplishments in an effort to get the bill pushed through, therefore emphasizing achieving the goal over sole ownership.

A prime example of a great credit claiming tweet was Rep. Barbara Lee being at signing ceremony: "Glad to see @HHSGov move forward w/ rules allowing \#HIV+-toHIV+ organ transplants. \#TBT to @WhiteHouse bill signing http://t.co/rMjBC7ww8V" (May 7, 2015 at 9:53:38PM). What better way to showcase your presence in Washington than to have a picture with the president at a signing ceremony? Rep. Lee can show her district that she was a pivotal player in this healthcare measure, a Republican issue area. Similarly, Rep. Krysten Sinema (D, AZ) emphasized a veterans healthcare bill in a few tweets, and notably made the tweet personal by tweeting, "We worked with @ TriWest to help \#AZ09 vet Stephen use the Veterans Choice Program to get his knee surgery. https://t.co/IYRNy5IMnr" (May 2, 2016 at 4:00:43PM). It is an intentional choice to emphasize this issue area, as her district produces missiles and hosts many military defense jobs, and therefore issue areas concerning national security or veterans will be a district priority. 
Just as Rep. Barbara Comstock illustrated effective use of Twitter to showcase elements of home style for Republicans, a great illustration of home style for Democrats is Rep. Elizabeth Esty (D-CT):

- "Proud to announce my office has returned nearly $\$ 5$ million this term to the residents of central and northwest Connecticut. (1/2)"

- "If you or anyone you know is having a problem dealing with a federal agency, you can contact my office for help: 860-223-8412. (2/2)" (May 5, 2016 at 7:59:29PM).

With Rep. Etsy's tweets, we clearly see the emphasis on utility to the district something expected in the third hypothesis, as gendered vulnerability causes women to disproportionately emphasize their service and accessibility to the district. Etsy was also able to secure funding for her district, another great marker of the usefulness of keeping her in office. Interesting to note is Etsy's credit claiming that emphasizes her office rather than her as an individual legislator claiming credit.

Another way some members used the district hashtag is to promote their legislation through what local news is saying - Rep. Joe Heck (D, WA) attached a link to his tweet, urging constituents to "Check out what media outlets" are saying about his bill. As mentioned earlier in the chapter, congressmembers tend to use local news media when they can, probably due to the perception that it is more trustworthy for their constituents and not colored by biases that come with national news outlets.

While not necessarily a standard credit-claiming tweet, Rep David Scott (D-GA) proclaimed he was, "Proud to be named on James Magazine 2015 Most Influential list." (May 7, 2015 at 6:54:05 PM). One of the goals of credit claiming is to show your district 
that you have influence, and there is no better way than receiving an award or distinction from an outside entity that proves it.

As a whole, credit-claiming tweets were a product of partisanship and gender, but we also see other aspects, such as ethnicity. There was a small link between ethnicity and tweet behavior. In their advertising, position taking, and credit claiming behaviors, black Democratic congressmembers drew attention to race as it intersected with a myriad of issues. For instance, while most Democrats made mention of Mental Health Awareness week, Al Green (D-TX) drew attention to his efforts to introduce legislation to "promote minority health awareness". Green brought the issue of race to the fore of a Democratic perceived issue area. It was not uncommon to see black MCs share a link to news articles covering police brutality, as it is an issue that disproportionately affects minorities.

Members of the Congressional Hispanic Caucus use a mix of English as well as Spanish tweets (though they are not only ones tweeting in Spanish; the GOP has a dedicated account to tweeting in Spanish in an effort to court the Latino voting bloc). For Hispanic legislators, immigration and the Cuban embargo were a topic of conversation on Twitter, particularly for members living in Florida and California. For legislators in Florida, regardless of how they felt about healthcare or government funding, Republicans and Democrats alike tweeted about the importance of receiving funding to combat the stem of Zika in the state. The story of these tweets is one where partisanship and gender plays a role, but at the end of the day, district considerations also play a major role. 


\section{$\underline{\text { Retweeted Credit Claiming }}$}

Retweeted credit claiming tweets were a small portion of overall tweets. Of this small slice of the picture, within Table 3, we see that congressmen had more retweeted credit claiming tweets than did congresswomen; Republican congressmen had the highest level followed by Democratic congressmen, Republican congresswomen, and Republican congresswomen having the least amount. This finding goes against the expectations of the literature that found congresswomen engage in more retweeting than their male counterparts (Evans 2016; Straus et al. 2014).

The majority of retweets consist of special interests (businesses, interest groups, etc.) thanking congressmembers for supporting legislation that would aid their group. For instance, Rep. Brad Ashford retweeted these incidences of credit claiming:

- “RT @HIMSS: Thank you @RepBradAshford for supporting CONNECT for Health Act, increasing high quality care access for seniors: https:/t.co/K..." (May 3, 2016 at 8:11:30PM).

- “RT @SeniorsSpeakOut: Thank you @ RepBradAshford for standing with \#seniors and protecting Medicare \#PartB from harmful changes" (May 3, 2016 at $5: 47: 37 \mathrm{PM})$.

All sorts of groups, from the ASPCA to the Brennan Center, got retweeted by congressmembers who want to claim credit outside sources. Even news outlets can get exposure from legislators, as did Rep. Randy Weber (R-TX) when the Texas Tribune tweeted that Randy was working on a bill to speed hurricane protection in Texas.

While MC's are no strangers to self-promotion, it holds more weight when another group is able to congratulate you for your work in Congress. This includes other legislators 
as well. When legislators give a shout out to one another for supporting bills (generally catching the attention of that MC by using @ to mention them specifically so they receive the notification), the tagged legislator will retweet this effort to claim credit for cooperation. This will especially occur when leadership of the party recognize the effort of legislators, as the HouseNewDems account did for Rep. Cheri Bustos - they promoted Bustos for fighting for export legislation to empower small businesses and grow the economy. Similarly, the Ways and Means GOP account on Twitter bemoaned America's broken tax code, and provided a link to Rep. Kevin Brady's plan to fix it, which Brady retweeted.

In comparison to the position taking or advertising section where I saw a handful of retweeting from constituent tweets, there were no credit claiming tweets that were not either from a special interest group, or from both political parties myriad accounts.

Overall, the findings from this chapter provide some evidence for the hypotheses; some weak evidence from the NBRM models, but mostly from the qualitative side and from tweet count percentages. However, hypothesis four was falsified on all accounts congresswomen did not credit claim the most, unlike the expectations given from the two studies (Evans 2016; Straus et al. 2014) which posit that congresswomen retweet more than congressmen.

\section{Discussion and Conclusion}

Overall, as expected, the majority of the content that a member of Congress promotes falls under the Mayhewian purview of advertising, even within the open dialogue format of Twitter. I find evidence for hypothesis one, which claims congresswomen will be advertising more, since they are particularly feeling the pressures of electoral insecurity 
in part due to gendered vulnerability. For position taking, there is very weak statistical evidence for hypothesis two for congresswomen as a group, but looking at the percentage tweet counts there is some evidence to show that Democratic congresswomen do position take at higher rates than all other groups. From these percentages, we see that Republican congresswomen in particular are very cautious - they have the highest rates of advertising behaviors, engage in less position taking behaviors, and instead rely on district visits and non-partisan events to showcase their helpfulness or cultivate their physical appearance in the district. From the tweet count percentages and the text of the tweets, we see some evidence for hypothesis three that states that they position take the least out of all the groups.

Lastly, while most members of Congress have the incentive to want to credit claim to show their district the utility of voting to keep them into office, the opportunity to get to do so in Congress does not come as often. When they can, congresswomen do not shy from taking credit for their accomplishments in Congress, be it helping to push forward a legislation, or killing a bill. However, the models and percentage counts both demonstrate that congressmen credit claim at higher rates, in particular conservative Republican congressmen. Looking at the figures for retweets by congresswomen, both Republican and Democrat, were not as high as their male counterparts. Since the bulk of these credit claiming retweets were from special interest groups or party leadership touting their achievements, one explanation could be that these groups simply do not give congresswomen the credit they are due. An alternate explanation could be that congresswomen, facing more sexism in the online environment, simply choose not to wade through the various tweets they are mentioned in (@) to decipher which of these are suitable for credit claiming, instead focusing on producing content instead. Either way, it 
is clear that there is much work to be done regarding congresswomen and their interactions in the social media realm.

Within the exploratory section, the general expectation guided by literature was that congresswomen would claim individual credit within tweets. The results show that once more, both party and gender play a role in how congresswomen and congressmen tweet. While Republican congresswomen did individually credit claim at high rates and very low within credit sharing, Democratic congresswomen claimed shared credit almost as much as they took individual credit. Therefore hypothesis four that stated congresswomen would individually take credit at higher rates than men was not affirmed, instead lending credence to earlier studies which found more credit sharing behavior, if only for Democratic congresswomen.

These findings, put in comparison to Lawless's (2012) study, show that a few considerations play out in the Twitterverse when it comes to congressional tweets. Which issues are currently part of the policy agenda, and are on the mind of constituents? Are those issues part of a political party's conceptualized issue ownership? Will engaging in these topics hurt my chances in the district, or should I instead focus on advertising, and areas that showcase my usefulness to the district (holding mobile office hours, town halls, focus groups, or visits to businesses and schools)? These considerations have a partisan and gendered component, as congresswomen have a particular concern to portray themselves as competent and likable, which may come easier to congressmen. 


\section{References}

Amman, Sky L. 2010. “A Political Campaign Message in 140 Characters or Less: The Use of Twitter by U.S. Senate Candidates in 2010. Available at SSRN: http://ssrn.com/abstract=1725477.

Twitter Style: An Analysis of How House Candidates Used Twitter in Their 2012 Campaigns (PDF Download Available). Available from: https://www.researchgate.net/publication/261913309_Twitter_Style_An_Analysis _of_How_House_Candidates_Used_Twitter_in_Their_2012_Campaigns [accessed Mar 16 2018].

Barnello, Michelle A., and Kathleen Bratton. 2007. "Bridging the Gap in Bill Sponsorship.” Legislative Studies Quarterly 32(3): 449-474.

Bickers, Kenneth N., and Robert M. Stein. 1996. "The Electoral Dynamics of the Federal Pork Barrel.” American Journal of Political Science 40 (4): 1300-26.

Bogoch, B. 1997. "Gendered lawyering: difference and dominance in lawyer-client interaction." Law and Society Review. 31(4): 677-712.

Burns, N., K. L. Schlozman and Sidney Verba. 2001. The private roots of public action. Cambridge, MA: Harvard University Press.

Burrell, B. 1992. "Women candidates in open-seat primaries for the U.S. House: 19681990." Legislative Studies Quarterly 17: 493-508.

Bystrom, Dianne, and L. L. Kaid. 2002. “Are Women Candidates Transforming Campaign Communication? A Comparison of Advertising Videostyles in the 1990s.” In Women Transforming Congress, ed. C. S. Rosenthal. Norman: University of Oklahoma Press,

Carroll, Susan J. 2001. "Representing Women: Women State Legislators as Agents of Policy Related Change." In The Impact of Women in Public Office, Ed. Susan Carroll. Bloomington: Indiana University Press.

Cormack, Lindsey. 2016. "Gender and vote revelation strategy in the United States Congress.” Journal of Gender Studies 25(6): 626-640.

Delli-Carpini, M.X. and S. Keeter. 1996. What Americans know about politics and why it matters. New Haven, CT: Yale University Press.

Dodson, Debra. 2006. The Impact of Women in Congress. New York: Oxford University Press. 
Dodson, Debra. 2001. “Acting For Women: Is What Legislators Say, What They Do?” In The Impact of Women in Public Office, Ed. Sue Carroll. Bloomington: Indiana University Press, 225-42.

Dodson, Debra L. 1995. Voices, views, votes: the impact of women in the 103rd Congress. New Brunswick, N.J.: Eagleton Institute of Politics, Rutgers, the State University of New Jersey.

Dolan, Julie and Jonathan S. Kropf. 2004. "Credit Claiming from the U.S. House: Gendered Communication Styles?” The International Journal of Press/Politics 9(1): 41-59.

Ditonto, Tessa M., Allison J. Hamilton, and David P. Redlawsk. 2013. "Gender Stereotypes, Information Search, and Voting Behavior in Political Campaigns." Political Behavior 36(2): 335-358.

Evans, Heather K., Joycelyn O’Valle and Stephen Green. 2015. “Rockin' robins: Do Congresswomen rule the roost in the Twittersphere?" Journal of the Association for Information Sience and Technology. 67)2: 268-275.

Evans, Heather K., Victoria Cordova, and Savannah Sipole. 2014. "Twitter Style: An Analysis of How House Candidates Used Twitter in Their 2012 Campaigns." Political Science and Politics 47(2): 454-461.

Evans, Jocelyn and Jessica M. Hayden. 2018. Congressional Communication in the Digital Age. Routledge.

Evans, Jocelyn, J. 2005. Women, Partisanship, and the Congress. New York: Palgrave MacMillan.

Fenno, Richard F. 1978. Home Style: House Members in Their Districts. Boston: Little, Brown and Company.

Fox, Richard Logan. 1997. Gender Dynamics in Congressional Elections. Thousand Oaks, CA: Sage.

Fleiss, J. L., B. Levin, M. C. Paik, 2003. "Statistical Models for Rates and Proportions.” In Wiley Series in Probability and Statistics, third eds. J. Wiley, Hoboken N.J.

Gainous, Jason, and Kevin M. Wagner. 2011. Rebooting American Politics: The Internet Revolution. Lanham, MD: Rowman and Littlefield.

Gainous, Jason, and Kevin M. Wagner. 2014. Tweeting to Power: The Social Media Revolution in American Politics. New York, NY: Oxford University Press. 
Gerrity, Jessica C., Tracy Osborn, and Jeanette Morehouse Mendez. 2007. "Women and Representation: A Different View of the District?" Politics and Gender 3(2):179200.

Gershon, Sarah Allen. 2008. "Communicating Female and Minority Interests Online: A Study of Web Site Issue Discussion among Female, Latino, and African American Members of Congress." Press/Politics. 13(2): 120-140.

Golbeck, Jennifer, Justin Grimes, Anthony Rogers. 2010. "Twitter Use by the U.S. Congress." Journal of the American Society for Science and Technology. 61(8): $612-21$.

Glassman, Matthew Eric, Jacob R. Straus, and Colleen J. Shogan. 2010. "Social Networking and Constituent Communications: Member Use of Twitter During a Two-Month Period in the 111th Congress." CRS Report for Congress.

Grimmer, Justin. 2013. Representational Style in Congress: What Legislators Say and Why It Matters. New York, NY: Cambridge University Press.

Grimmer, Justin, Solomon Messing, and Sean J. Westwood. 2012. "How Words and Money Cultivate a Personal Vote: The Effect of Legislator Credit Claiming on Constituent Credit Allocation.” American Political Science Review. 106(4): 703719.

Haber, Steven. 2011. "The 2010 U.S. Senate Elections in 140 Characters or Less: An Analysis of How Candidates Use Twitter as a Campaign Tool." Available at: http://aladinrc.wrlc.org/bitstream/handle/1961/10028/Haber,\%20Steven\%20-\%20 Spring $\% 20 \% 2711$.pdf? sequence $=1$.

Haynes, Michelle C., and Madeline E. Heilman. 2013. "It Had to Be You (Not Me!) Women's Attributional Rationalization of Their Contribution to Successful Joint Work Outcomes." Personality and Social Psychology Bulletin. 39(7): 959-969.

Jacobson, Gary C. 1987. "The Marginals Never Vanished: Incumbency and Competition in Elections to the U.S. House of Representatives, 1952-82." American Journal of Political science. 31(1): 126-141.

Kahn, Kim Fridkin. 1996. The Political Consequences of Being a Woman. New York: Columbia University Press.

Karpowitz, C. K. and T. Mendelberg. 2014. The Silent Sex: Gender, Deliberation, and Institutions. London: Princeton University Press.

King, Anthony. 1997. Running Scared: Why America's Politicians Campaign Too Much and Govern Too Little. New York: Martin Kessler Books. 
Lassen, David S., and Adam R. Brown. 2011. "Twitter: The Electoral Connection." Social Science Computer Review 29 (4): 419-36.

Lawless, Jennifer L. 2012. "Twitter and Facebook: New Ways to Send the Same Old Message?" In Richard L. Fox and Jennifer Ramos (eds.) iPolitics, New York: Cambridge University Press: pages 206-32.

Lazarus, Jeffrey, and Shauna Reiley. 2010. "The Electoral Benefits of Distributive Spending." Political Research Quarterly 63 (2): 343-55.

Levitt, Steven D., and James M. Snyder. 1997. "The Impact of Federal Spending on House Election Outcomes.” The Journal of Political Economy 105 (1): 30-53.

Lee, Jayeon. 2013. “'You know how tough I am?' Discourse analysis of US Midwestern Congresswomen's self-presentation.” Discourse \& Communication. 7(3): 299317.

Lenard, Dragana Bozic. 2016. "Gender differences in the personal pronouns usage on the corpus of congressional speeches." Journal of Research Design and Statistics in Linguistics and Communication Science 3(2): 161-188.

Lovenduski, Joni. 2005. Feminizing Politics. New York: Polity.

Maltz, D. and R. Borker. 1982. "A cultural approach to male-female miscommunication." In J. Gumberz (Ed.) Language and Social Identity. 196-216.

Mayhew, David R. 1974. Congress: The Electoral Connection. Yale University Press.

McElhinny, B. S. 1998. "I don't smile much anymore: Affect, gender and the discourse of Pittsburgh police officers." In J. Coates Ed. Language and Gender: A Reader, 309-327.

Meeks, Lindsey. 2012. "Is she 'man enough'? Women candidates, executive political offices, and news coverage.” Journal of Communication 62(1): 175-193.

Pearson, Kathryn and Logan Dancey. 2011. "Elevating Women's Voices in Congress Speech Participation in the House of Representatives." Political Research Quarterly. 64(4): 910-923.

Reingold, Beth. 2000. Representing Women: Sex, Gender, and Legislative Behavior in Arizona and California. Chapel Hill: University of North Carolina Press.

Rosenthal, Cindy Simon. 1998. When Women Lead: Integrative Leadership in State Legislatures. New York: Oxford University Press.

Shepsle, Kenneth A., et al. 2009. "The Senate Electoral Cycle and Bicameral Appropriations Politics." American Journal of Political Science 53 (2): 343-59. 
Tannen, D. 1990. You Just Don't Understand: Men and Women in Conversation. New York, NY: HarperCollins.

Tannen, D. 1986. Gender and Discourse. New York: Oxford University Press.

Thomas, Sue. 1994. How Women Legislate. New York: Oxford University Press.

Thomas, Sue, and Susan Welch. 2001. "The Impact of Women in State Legislatures: Numerical and Organizational Strength." In The Impact of Women in Public Office, ed. Susan J. Carroll. Bloomington: Indiana University Press.

Tolleson Rinehart, Sue. 2001. "Do Women Leaders Make a Difference? Substance, Style, and Perceptions." The Impact of Women in Public Office, ed. Susan J. Carroll. Bloomington: Indiana University Press.

Volden, Craig, Alan E Wiseman, and Dana E. Wittmer. 2013. "When are women more effective lawmakers than men?" American Journal of Political Science 57(2): 326-341.

Wagner, Kevin M., Jason Gainous and Maiya R. Holman. 2017. "I am Woman, Hear Me Tweet! Gender Differences in Twitter Use among Congressional Candidates." Journal of Women, Politics \& Policy. 1-26.

Welch, Susan. 1985. "Are Women More Liberal Than Men in the U.S. Congress?” Legislative Studies Quarterly 10: 125-34.

Yu, Bei. 2014. "Language and Gender in Congressional Speech." Literary and Linguistic Computing 29 (1): 118-32.

Webster, W. 1990. Not a Man to Match Her. London: Women's Press. 


\section{CHAPTER IV. GENDERED POLITICAL COMMUNICATION AND SURROGATE REPRESENTATION IN CONGRESSIONAL TWEETS}

In his classic book, Home Style, Richard Fenno (1978) identifies the ways that members of Congress view, and interact with, the various constituencies inside their districts. Later work by Susan Carroll (2000) shows that congresswomen feel a special obligation to the interests of women and see themselves as "surrogate representatives" beyond the geographic boundaries of their districts. Applying these findings to the basic logic of Home Style indicates that many congresswomen may have a fundamentally different representational style when compared to congressmen. In this chapter, I ask whether gender impacts the home style of members of Congress. I address this question by conducting a hand-coded content analysis of congressional tweets during two periods of the $114^{\text {th }}$ Congress. I use the data to uncover differences in how congresswomen and men target their political communications at the district and national level. The analysis reveals that it is not just congresswomen, but Democratic congresswomen in particular, who target national constituencies more often than their colleagues. Also, all congresswomen and congressmen tweet similarly at the district level. By bringing gender into Fenno's theoretical framework, this chapter pushes the literature toward a more nuanced understanding of political communication and representation.

Keywords social media, Congress, Twitter, gendered communication, Home Style

Given the importance of cultivating a positive image for electoral purposes, congressmembers take advantage of every opportunity and avenue to present themselves 
in a positive light to their constituents. Although Americans have a low approval rate for how Congress is doing their job (reaching a record low of $9 \%$ in 2014) ${ }^{32}$, the fact is that members of Congress enjoy a high incumbent reelection rate - in 2016, 97\% remained in the House of Representatives, $93 \%$ in the Senate. ${ }^{33}$ This high incumbent reelection rate occurs in other advanced democracies such as the UK and Ireland (Redmond and Regan 2015, Carey and Shugart 1995) ${ }^{34}$, where we see politicians nurture a personal relationship with their constituencies and deter potential candidates (Carson, Engstrom, and Roberts and Katz 1996). ${ }^{35}$ To build that relationship with constituents, politicians in parliamentary or presidential systems can use district casework, attempt to gain district funding, work on party maintenance, and strategically explain their vote choices (see Crisp et al. 2004, Buck and Cain 1990, Mayhew 1974, Fenno 1978). Since there is a low-cost threshold to maintaining an online presence and reaching voters - particularly those who may not otherwise read their newsletters - members of Congress (MCs) have adopted Facebook, Twitter, and other social media platforms to target these constituencies.

In his classic book Home Style, Richard Fenno (1978) identifies the ways that congressmen perceive and interact with their various constituencies. Their behavior

\footnotetext{
${ }^{32}$ Gallup poll. http://www.gallup.com/poll/1600/congress-public.aspx

${ }^{33}$ Data from https://www.opensecrets.org/overview/reelect.php

${ }^{34}$ In developing democracies, the incumbency effect may hurt reelection chances (Eggers et al. 2014, Opalo 2014).
}

${ }^{35}$ Scholars like Lenz (2012) challenge the assumption that voters are the ones guiding the reigns, positing that politicians steer voters to their position stances, therefore citizens choose their preferred candidates and adapt their positions to what the candidate or party says. 
consists of three "ingredients": presentation of self, allocation of resources, and explanation of Washington activities (Fenno 1978, 33). Later work by Susan Carroll (2000) shows that congresswomen feel a special obligation to the interests of women and see themselves as "surrogate representatives" beyond the geographic boundaries of their districts. Within his study, Fenno (1978) did not shadow any congresswomen; ${ }^{36}$ furthermore, the literature on home style does not analyze the impact of gender. Applying Carroll's (2000) findings to the basic logic in Fenno's (1978) work suggests that many congresswomen may have a fundamentally different representational style when compared to congressmen. In this context, the chapter aims to address the question of whether there is a gendered home style - do congresswomen and men target their tweets at different kinds of constituencies? Handcoded content analysis was undertaken for the Twitter feeds of all House congresswomen and men during May 1-7, 2015 and May 1-7, 2016 to see if the targeting and explanation for D.C. activity at the district, state, and national level had a gendered and/or partisan component.

While Republican women say they want to represent women broadly, they may have partisan pressures pulling them in a different direction. "Women's issues" tend to fall under Democratic purview due to perceptions of issue ownership (Evans 2005, Wolbrecht 2000); therefore, with increased levels of partisanship in both chambers and Republicans prizing ideological purity (Grossman and Hopkins 2016), Republican women may distance themselves from targeting women for primary concerns, as Republican voters and activists

\footnotetext{
${ }^{36}$ When Fenno formulated his conception of home style in 1978, there were a total of 20 women in the $95^{\text {th }}$ Congress, 18 of which were in the House. Of the Representatives that he shadowed, 0 were women.
} 
are more likely than their Democratic counterparts to prize "symbolic demonstrations of ideological purity and to pressure their party leaders to reject moderation and compromise" (Grossman and Hopkins 2016, 23).

Consistent with this line of argumentation, the analysis reveals that it is not just congresswomen, but Democratic congresswomen in particular, who target national constituencies more often than their colleagues. At the district and state level, however, gender and party do not seem to influence the number of targeted tweets. In the end, it appears that reelection-minded home-style tweets that reach out to national constituencies are linked to gendered partisanship. These findings provide a needed update to Fenno's (1978) classic work and should be interesting to scholars working on Congress, representation, gender, and political communication.

\section{Literature Review}

\section{The Re-election Motivation and Home Style}

The broadly accepted perspective that MCs are motivated by reelection undergirds much of the research on Congress. Mayhew's (1974) oft-cited text describes politicians in very simple terms: all their actions are explicable because everything they do is geared towards reelection. Claiming these MCs are "single-minded seekers of reelection" (1974, 5), Mayhew asserts that they look and act in ways to gain resources for their reelection. To achieve these goals congresswomen and men engage in three activities: advertising, credit claiming, and position taking (Mayhew 1974, 5). In the modern context, while each technological innovation provides new avenues for broadcasting, the type of information 
is similar; in addition to their formal campaign website, MCs use social media websites to reach out to and communicate with their constituents and potential voters.

Since the goal is to gain trust to give themselves latitude to act in Washington (Fenno 1978, 56), MCs' use of qualification, identification, and empathy both in person, and through tweets, is necessary. Legislators are conscious of their different audiences, taking pains to tailor their message accordingly. Jacobson (1987) bolsters Mayhew's claim that legislators and their campaigns have become more personalistic or candidate-centered and their drive due to risk and uncertainty leads them to take measures to gain power and influence in their electorate. This is done in particular to dissuade any strong competition. Thus, one should see legislators being proactive on Twitter, pandering to their electorate. To be visible to their targeted audience, MCs may use a district or state hashtag, post information and pictures of district events where they explicitly state they are explaining their DC activity, or appeal to a broader national or international audience through explicit policy stances.

The widespread use of Twitter enables MCs to get their message out in quick, easily decipherable bites. These messages are not sent in a vacuum; MCs are aware of the various constituencies they must target. Fenno's (1978) concentric circles encompass what House members see as their constituency - geographical (their district), the reelection constituency (their supporters), the primary constituency (strongest supporters) and the personal constituency (the "intimates"). Therefore, MCs may target these concentric circles explicitly, such as using a hashtag to draw the attention of their district, or indirectly by advertising their speech in Congress regarding a bill they are advocating for. 
Since congresswomen perceive women as a group that they are answerable to, this widens their concentric circles to women beyond their district, as opposed to congressmen, who would focus on the typical four. Therefore, congresswomen should more frequently target the national level because they are answerable to a broader constituency than just Fenno's (1978) concentric circles. Overall, the literature on home style does not have a focus on gender. The few studies that take into account gender in constituent interactions find that female policymakers interact with district constituents more (Epstein et al. 2005; Richardon and Freeman 1995), get more contact from constituents, are more likely to use constituent-derived information in making decisions, and attend more constituent meetings (Herrick 2012, 961).

The home-style literature primarly focuses on explaining casework practices (Grose et al. 2015; Cover and Serra 1992; Bond 1985; Johannes 1983) and how resource allocation matters for elections (Parker and Goodman 2013; Goodman and Parker 2010; Parker and Goodman 2009; Serra and Moon 1994). In responding to requests from their constituents, Butler et al. (2012) find that MCs prioritize service over policy in their home style. For marginal representatives, senators whose policy positions do not align with the median district member will focus on appropriations and avoid position taking, leaving aligned senators more likely to participate in policy debates, perpetuating extremes from both parties dominating policy debates (Grimmer 2013, 639). ${ }^{37}$ MCs' voting behavior is evaluated on its sophistication (Denzau et al. 1985), and political decisions must be

\footnotetext{
${ }^{37}$ It is not surprising candidates might try to adapt a more extreme personality: politicians with extreme ideologies tend to benefit more from their social media adoptions, including financially (Hong 2013).
} 
justified (McGraw et al. 1993). Hill and Hurley (2002) found senators used speeches for home style representational concerns, which would be interesting to contextualize with findings that congresswomen use speeches more often (Pearson and Dancey 2011), and are especially concerned about their perception in the district (Lazarus and Steigerwalt 2018).

MCs increasingly use digital tools to aid their home style. For example, there is work on how MCs use their official websites (Esterling et al. 2013; Adler et al. 1998) and how state legislators use e-mail for targeted advertising and to showcase accomplishments (Richardson Jr. and Cooper 2006). Meinke (2009) finds variance in partisan presentation of official websites based on MCs' constituencies, career stages, and majority party status. Yiannakis's (1982) study on House Members' communication style within newsletters and press releases found that those newly elected MCs as well as those in richer and more homogeneous districts took more positions on national issues, while senior members focused more on claims to particularized benefits. Overall, there is reason to believe there may be variance in the which constituencies MCs focus their efforts on signaling to.

\section{Surrogate Representation}

Although the proportion of women serving in Congress has increased over the years, a gender gap exists in the composition of Congress. From 1917 to 2018, a total of 296 women have served in the House and Senate. As of 2018, the current number of women serving in Congress is 106 out of 535 seats, or 19.8\%; 23 in the Senate (17 Democrats, 6 Republicans) and 83 in the House (61 Democrats, 22 Republicans). ${ }^{38}$ These

\footnotetext{
${ }^{38}$ Additionally, of the 106 women serving in the 115th U.S. Congress, 38 (or 35.8\%) are women of color; in addition, a Black woman, a Latina, an Asian Pacific Islander, and a Caribbean
} 
congresswomen have generally been Democrats. Democratic women running for office have outnumbered Republican women by more than a two to one margin (Pearson 2013, 21). In comparison, the national population of women is $50.8 \%$. Due to this phenomenon of a continued gap in substantive presence in the legislature, congresswomen continue to say they feel the pressure to represent women and their interests. As a result, research shows that the addition of women and minority MCs has expanded the legislative agenda to better address the interests of women and racial minorities in U.S. domestic policy (Wallace 2014; Tate 2003; Swers 2002; Wolbrecht 2002).

Congresswomen feel a special obligation for the interests of women, irrespective of party, and see themselves as a surrogate representative beyond the geographic boundaries of their districts (Carroll 2000, 2). Because these women differ ideologically, their actions may not always appear to be representing women's interests more broadly. These perspectives differ due to their gender role socialization (Mansbridge 2005). Congresswomen can be perceived as pursuing a women's issue agenda by introducing more women's issue bills than congressmen (Bratton and Haynie 1999; Thomas 1994).

Since they focus on women's issues, women also elect to sit on committees that focus on policy areas that tend to be attributed to women (Dolan and Ford 1997; Thomas 1994). Research shows the mere presence of women affects patterns of legislation, and not in a way that is favorable. For example, Kathlene $(1994,569)$ finds a pattern of male domination in committee meetings where bills are initially debated. Other research reveals

\footnotetext{
American woman serve as Delegates to the House from Washington, DC, Puerto Rico, American Samoa, and the Virgin Islands, respectively. Women of color constitute 7.1\% of the total 535 members of Congress. (CAWP 2018)
} 
that bills sponsored by women receive more scrutiny and hostile treatment than bills sponsored by men (Kathlene et al. 1991; Hawkesworth 2003). On the other hand, Rosenthal (1998) shows found that women in committees were more likely to be inclusive and cooperative as the number of women in leadership positions increased, but men were less likely to be inclusive and cooperative as women rose in leadership power. In addition, congresswomen are viewed as being more competent on women's issues (Kahn 1996; Huddy and Terkildsen 1993). As a result, it may be in congresswomen's best interest to emphasize their productivity or perspectives on these issues in order to appeal to their various constituencies, especially women voters and supporters. However, congresswomen balance these gender issues with their other obligations and influences as legislators (Tamerius 1995), which includes the impact of partisanship.

\section{Gendered Political Communication}

Congress has come a long way in adapting various mediums of communication in the internet age. From 7 MCs doing a pilot e-mailing project in the $103^{\text {rd }}$ House in 1993 (Browning 1994), to the current 49 MCs using Snapchat as of 2018 to give followers an intimate, immediate glimpse of their day-to-day activities through pictures and videos, Congress has seized the opportunity to connect with their constituents. Regarding the MCs' use of internet to aid their home style, there is work on how MCs use their official website (Esterling et al. 2013; Adler et al. 1998) and use of targeted e-mail in the state legislature (Richardson Jr. and Cooper 2006), but what they find is that it has not fostered the dialogue that was hypothesized to occur in this type of environment. Instead, we still the same reelection motivated one-way advertising behaviors, just in different spaces. 
The usage of a gendered communication style is one covered in the gender and communication literatures very broadly (Meeks 2016). This style tends to be described in terms of acts or tendencies evoking a "feminine" or "masculine" style - e.g. self-disclosure viewed as feminine (Davisson 2009) while being impersonal and analytical viewed as masculine (Campbell 1989). Public speech has traditionally been viewed as 'masculine' (Brody 1993), and even following the greater participation of women in that realm, still continues to be viewed as such (Cameron 2006). The usage of the language of war and sports is prevalent in campaign coverage, and aggressiveness by candidates is framed positively - qualities more associated with masculinity (Carroll and Fox 2014). GoodyearGrant's $(2013,186)$ analysis of the gendered mediation approach shows that while the media may cover women at the same rate as men, the quality of the coverage reflects traditional gender stereotypes but exaggerate their "attack-style behaviors." Lee (2013) finds Midwestern congresswomen emphasizing masculine terminology and personal traits in comparison to congressmen. Unfortunately, low-information voters in particular have been shown to rely on stereotypes to determine their vote choice (Sanbonmatsu 2004, 2002; Kahn 1992). Male candidates who "gender-bend" by persuading and priming voters contrary to gendered expectations (e.g. being family-centric, "women's issues") are more successful than their women counterparts (Schneider 2014).

While there is a great deal of literature outlining the gender difference in policy agendas, roll-call votes, and behavior in office, there is less on gendered behavior regarding constituent communications. To get at the question of whether gender and partisanship play a role in traditional Mayhewian behavior, Lawless (2009) samples the entirety of Congress's tweets and Facebook messages during an eight-week period (June 24-August 
18, 2009), while Fridkin and Kenney (2014) sample 32 congressmen and women's social media use and media portrayal during the 2006 election year to determine whether congresswomen shape their messages in a different manner on various platforms, online and offline. Each work finds there are differences in the manner in which these men and women use social media, some of which is a product of partisanship. Fridkin and Kenney (2014) find representational communications would vary by gender and find evidence for their strategic stereotype theory, positing that senators' representational messages are more influential when reinforcing stereotypical gender strengths; the media will likely mirror these messages, and citizens are more likely to absorb these messages, compared to counter-stereotypical messages. Considering further research provided evidence that internet news tends uphold gender stereotypes (Ruggerio 2014; Anderson 2011; Lawrence and Rose 2010), congresswomen can choose to engage or use social media to foster a different image.

To that point, some congresswomen cultivate a persona online that may not necessarily reflect their views.

Social media gives you a parallel identity, and not just for women. It gives you a chance to create an avatar of you, independent of the "you" you, that's more manipulable. Politics is one of the realms where you can do it in artful ways. Palin became very conscious of social media. Hillary backed into it unwittingly. (Gelber 2011, 12)

It is not surprising candidates might try to adapt a more extreme personality: politicians with extreme ideologies tend to benefit more from their social media adoptions, including financially (Hong 2013). Social media can aid in the perception one is a strong candidate, but in the end it will not mean much if the "friends," likes, and retweets do not translate into votes. At the end of the day, partisanship and gender both can play a role in 
tweeting behavior as Wagner et al. (2017) find: congresswomen who use Twitter more than congressmen tend to do better electorally. Looking deeper, however, the difference is conditioned by party -- female Republican candidates who tweeted more increased their vote share, but the opposite is true for Democratic congresswomen.

\section{Social Media}

Following the success of President Barack Obama and his efforts on social media in 2008, other politicians rapidly began utilizing Twitter. Some had more than one Twitter account - one for campaign advocacy and another for congressional activity information (Parmelee and Bichard 2012). MCs with urban constituencies were found to be more likely to use Twitter than those with rural ones (Straus et al., 2013). Belonging to the minority party was an important determinant of Twitter use among MCs (Lassen and Brown 2011). After a Democratic majority was established in Congress, Republicans used Twitter far more than Democrats (Ammah-Tagoe 2009). Generally, social networking favors outsiders and political newcomers, so it could be an asset for women candidates (Gelber 2011). Those who follow only elected political leaders are "less likely to be driven by social, expressive, or entertainment motivations"; these followers regularly look up information on politics, and political leaders are able to motivate these followers to action (Parmelee and Bichard 2012, 65). It is clear to see why nearly all MCs would have a Twitter account to target these constituencies, whether these individuals live in their geographic district or not.

Political communications and the media have also been characterized in terms of marketing - the media provides politicians contact with citizens and each party stands to 
gain (Davis 2010). Politicians are not just selling policies, but engaging in show business; this has led to the emergence of the 'celebrity' politician (Street 2003) such as President Donald Trump. Challengers and candidates in open-seat races tend to attract larger audiences online as do candidates who are more visible on political blogs (Vaccari and Nielson). When considering "mentions" of politicians on traditional media outlets, with every $10 \%$ increase in the number of media mentions for that politician, there is a $4-6 \%$ increase in number of mentions for that politician on Twitter (Hong and Nadler 2012). These celebrity politicians in turn perform for the public but rarely receive critical attention (Martin 2014).

Digital communication has allowed discourse to "democratize," meaning access to narratives beyond the mainstream have a platform, but this also means citizens must take the step forward to search for them. Politicians want to take advantage of the opportunity to reach out to more constituents and put forth their unedited comments to be heard and viewed without distortion by what they perceive as the liberal/conservatively-biased media. Since MCs are marketing themselves and are concerned with reelection prospects, they have the incentive to target their online constituencies, going so far as to add hashtags of their district or state, and engaging in the national level of hashtags of the moment, in an effort to be seen and heard. For congresswomen, because they feel that they are surrogate representatives for women, their online activity could be geared towards a national audience.

My work thus complements and builds upon these important works by bridging them in new ways. By applying concepts like surrogate representation and gendered political communication to the home style framework, this project will look at both 
partisanship and gender as they impact how MCs target their various constituencies. From the gender literature and statements made by congresswomen themselves, I expect to see congresswomen targeting communications to women within and outside of their districts. Yet, I also expect that those communications will be subject to various pressures related to party, as Republican congresswomen have partisan considerations to consider. I now turn to developing these points more systematically.

\section{Theory}

The extant literature analyzing gender has been important in understanding how women reach office, as well as their impact while in office. The question still remains regarding congresswomen serving as surrogate representatives, particularly as it relates to Fenno's (1978) conception of their constituencies. Figure 1 is a representation of the theoretical framework for this chapter. Both congresswomen and men target Fenno's (1978) concentric circles in their bid for reelection. The addition to this theoretical frame comes from congresswomen's indicated surrogacy for women outside of these four concentric circles. Congresswomen have an extra "constituency" to target because of the pressure they feel to represent women generally (see Carroll 2000), whereas congressmen do not face similar pressure and maintain their focus on the women within the classic constituencies outlined by Fenno (1978).

However, while Republican congresswomen feel the weight of this surrogacy, they often do not follow through to target women beyond Fenno's (1978) constituency at the national level as they feel the reelection pressures of their party, who prize ideological purity (Grossman and Hopkins 2016). Since "women's issues" tend to fall under 
Democratic purview due to perceptions of issue ownership (Evans 2005, Wolbrecht 2000), the link of surrogate representation is disrupted for Republican congresswomen at the national level. Electoral pressures therefore will stop Republican congresswomen from targeting at the national level, particularly because Republican congresswomen tend to be elected from more marginal districts (Evans 2005). This synthesis of the literature on home style, surrogate representation, and party politics, leads to the following expectation:

Hypothesis 1: Democratic congresswomen should be significantly more likely to target a national constituency in their tweets when compared to other groups. 
FIGURE 1: GENDERED HOME STYLE WITH ADDED SURROGATE REPRESENTATION FOR CONGRESSWOMEN

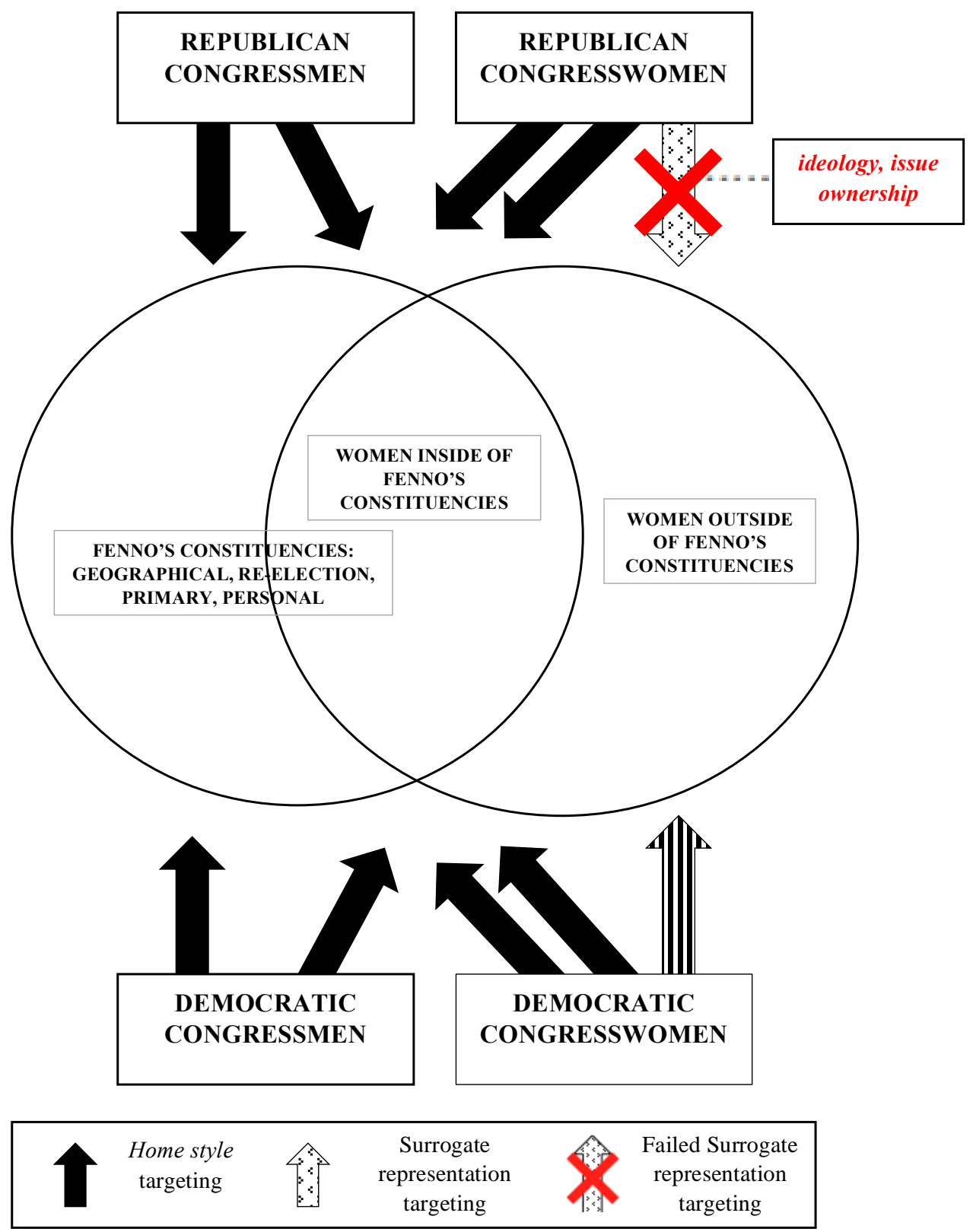


Using black arrows, Figure 1 shows that all MCs will need to target Fenno's (1978) constituencies. Both congresswomen and men should target Fenno's (1978) constituencies at similar levels at the district and state level. Since women comprise a portion of these constituencies, they fall in the semicircle portion of total women in the national population. Congresswomen feel surrogate responsibility towards women within and outside of their constituencies (Carroll 2000), but the arrow for Republican congresswomen targeting outside of Fenno's constituencies is broken due to ideology and issue ownership (Evans 2005, Wolbrecht 2000). Furthermore, congresswomen should tweet more than men (Evans, Cordova, and Sipole 2014) because they have this additional constituency to target. Since everyone needs to target Fenno's (1978) classic constituencies, there should be no significant difference in the way that they tweet at the district level.

Hypothesis 2: Congresswomen will target the district more.

\section{Data and Methods}

Since citizens regularly assert that they prefer simple policy statements or planned legislative direction as opposed to detailed plans for candidates (Kahn and Kenney 2002), Twitter is the perfect medium for such message transmission due to its enforced character limit. Twitter makes campaign activities efficient, inexpensive, and immediate (Gainous and Wagner 2014), and as such was widely adopted by both chambers of Congress. Choosing Twitter for this study was due to the widespread use of it as a means of congressional self-promotion and constituent communication (Golbeck, Grimes, and Rogers 2010), but also as a means for targeted advertising outside of the district. Therefore, in this study, the Twitter feeds of all House congresswomen and men were hand-coded for 
the weeks of May 1-7, 2015 and May 1-7, 2016 to see if message targeting and explanations of D.C. activity at the district, state, and national level differed based on gender and partisanship.

When faced with the choice of a small $n$ and larger time frame or a large $n$ but a smaller time window, for the purpose of this study the latter was chosen. Since the percentage of women in Congress is small compared to the total male population, it is more useful to get the tweets of all members of the House for a smaller period of time but allowing for in-depth content analysis of the text of their tweets, rather than a smaller $\mathrm{n}$ (a sample of member in the House) and a longer timeframe. Getting a slice of what the entirety of a chamber has to say for two weeks that are not directly around election time allows for a look at what electorally-motivated behaviors they display during a "regular" period.

The validity of automatically applied measures comes into question within computer-aided text analysis (CATA) as it does not allow for human nuance (Neuendorf 2017, 39). For this study, it would be difficult for CATA to code tweets for different constituencies, particularly when multiple tweets link to text in picture format. Therefore, given resource constraints and issues associated with CATA, it made sense to hand-code tweets from the entire House from a small timeframe. I used NVIVO (a software package that includes built-in tools for importing the text of tweets from Twitter's API) to store and hand-code every single tweet on a wide-range of important characteristics.

To test intercoder reliability, a coder was trained by reviewing the codebook and independently applying it to a random sample of tweets $(n=500)$, meeting the minimum requirement based on Kaid and Wadsworth (1989) suggestion of 5-7\% of the total sample size. A coding comparison query was run in NVIVO to determine the Kappa coefficient; 
if there is complete agreement then the Kappa coefficient $(\mathrm{K})=1$, while if there is no agreement among the raters (other than what would be expected by chance) then the Kappa coefficient $(\mathrm{K}) \leq 0$. The Kappa values exceeded appropriate acceptance levels, as the overall weighted Kappa for the entire coded random sample was $0.79 .{ }^{39}$ The Kappa coefficient for nodes are as follows: 0.77 for the district level, and 0.70 for the national level, meeting the standards of good to excellent agreement based on the guide to interpretation provided by NVIVO as delineated by Fleiss et al. (2003). ${ }^{40}$

That said, the limitations of a small timeframe should be acknowledged. For example, some MCs tweet infrequently and others are very active. This creates the possibility that some MCs may not be well-represented in the data. However, this potential limitation did not appear to be an issue for the timeframe being considered. The data are well-balanced. Neither week is close to Election Day and both coincided with issues of importance to Democrats and Republicans - namely, Mental Health Week and Small Business Week. As such, both parties took advantage of national dialogue around these issues to target their constituencies (particularly through the use of hashtags for the district or state).

The dependent variables in this chapter are a simple count of the number of tweets that each MC targeted at the district or national level. The tweets were coded by either

\footnotetext{
${ }^{39}$ A K value of over 0.75 indicates excellent agreement, $0.40-0.75$ is fair to good agreement, and below 0.40 is poor agreement. See here: http://helpnv11mac.qsrinternational.com/desktop/procedures/run_a_coding_comparison_query.htm\#MiniT OCBookMark7

${ }^{40}$ While the national level had a lower kappa level, the percent agreement was still high at $80.24 \%$.
} 
explicit or implicit mention of the three levels. For example, an explicit mention might include direct references to the district and/or the use of hashtags related to the district or state - "Great time speaking with @AllegionUS employees this morning at their employee town hall. \#IN05 http://t.co/nViRp5Fh6Y" - Rep. Susan Brooks (R, IN-5). Some examples of implicit mentions include indirect references related to national news stories, a statelevel conference, or a picture of themselves at a sports event in their district. For the district, the easiest marker was the MC using their district hashtag, but it also included any mention of district visits, pictures of the MC in the district, having staff present there, as well as any local news or event occurring within the district. At the national level, national news stories, issue areas that are handled at the national level, and national events or holidays (like Small Business Week) were the bulk of tweets. For example, a national level tweet would look like: "As a former professor, I know how challenging yet rewarding it is to be an educator. \#TeacherAppreciationWeek" - Rep. Alma Adams (D, NC-12).

The main independent variables of interest are gender (dichotomous, $1=$ congresswoman), party (dichotomous, $1=$ Democrat), and the interaction between gender and party. These variables will be crucial for getting leverage on Hypothesis 1 and Hypothesis 2 - whether congresswomen target the national level more so than their male colleagues, or if party additionally impacts Republican or Democratic congresswomen from targeting additionally at the national level.

The statistical models also account for a number of control variables that potentially impact the level of tweets within the home style framework. Given that a MC's committee assignment can guide policy activity (Norton 2002; Hall 1996) and influence the volume of their political communication directed at certain constituencies (district or national), I 
include a dichotomous variable for membership in a constituency or re-election minded committee $^{41}$ (as opposed to informational committees, as defined by Young and Heitschusen 2003, and Frisch and Kelly 2004). Membership on these kinds of committees should give more material for MCs to tweet at the district. Another measure that is common in models related to home style and electoral behavior more generally is ideology. As a result, I also incorporate a MC's DW-Nominate score ${ }^{42}$ as a control. The party leadership is a more nationally visible role than an average legislator and there is reason to believe they might be more nationally-minded; therefore, I include a dichotomous party leader variable. ${ }^{43}$ Additionally, I integrate the most recent two-party electoral margin (percent) in each MC's district. The representational style and communications strategies of those running on tight margins may look different from those running in relatively safe districts. This serves as an important control because Republican women tend to be elected from more marginal districts (Evans 2005). ${ }^{44}$

Before diving into the data, it is worth setting the scene to develop a better understand of the political context during the weeks under examination. According to

${ }^{41}$ Descriptive data for what committees the House members were in was gathered from Charles Stewart III and Jonathan Woon's Congressional Committees dataset in voteview.com, while the theoretical justifications for which committees qualified as a constituency committee came from a combination of Frisch and Kelly (2004) as well as Young and Heitschusen (2003)'s classifications of district motivated committees as opposed to informational committees. The reelection minded constituency committee was comprised of a bin of Agriculture, Armed Services, Natural Resources, Science, Small Business, Transportation, and Veterans Affairs committees.

${ }^{42}$ Voteview.com archive.

${ }^{43}$ Leadership was counted from Speaker of the House to House Minority Whip.

${ }^{44}$ Daily Kos Elections dataset. 
headlines in the New York Times, the top stories during May 1-7, 2015 were: Congress passing a cost-cutting budget plan, mulling the fate of the Iran nuclear deal, whether the N.S.A. should be collecting data about Americans, and dealing with allegations of police overreach. To take in a broader range of data, tweets were also scraped for the same week in 2016. During May 1-7, 2016, Congress was preoccupied with: the Flint water crisis, North Carolina's controversial transgender bathroom law, and another combat death in Iraq. During this week of May in 2016, Republicans and Democrats were already deep into the presidential primaries, but nearly all MCs did not tweet about it.

Table 1 shows the sample characteristics of all MCs using Twitter in the $114^{\text {th }}$ House. The dataset includes $431 \mathrm{MCs}, 354$ are congressmen, and 77 are congresswomen. The average age is 60 . Furthermore, the average length of service is approximately 9 years.

\section{TABLE 1}

Sample Characteristics of Twitter Using Representatives $-114^{\text {th }}$ Congress

\begin{tabular}{lc}
\hline & Whole sample \\
\hline Sample size (N) & 431 \\
Male & 354 \\
Female & 77 \\
Age (Year of birth) - Mean & 1957 \\
Average Length of Service & 8.8 years (4.4 terms) \\
\hline
\end{tabular}

Notes: Average Length of Service data from "Membership of the 114th Congress: A Profile" compiled by the Congressional Research Service. Other data is from author.

To begin exploring the data, it is useful to see some general features related to the total number of tweets sent by MCs in the House. Figure 2 presents a histogram of the total number of tweets. Most MCs sent somewhere between 0 and 25 tweets during these two 
weeks. Few MCs sent more than 75 tweets. The average is 21 tweets with a standard deviation around 20. Rep. Brian Higgins (D, NY-26) was an outlier during these two weeks - he sent 160 tweets.

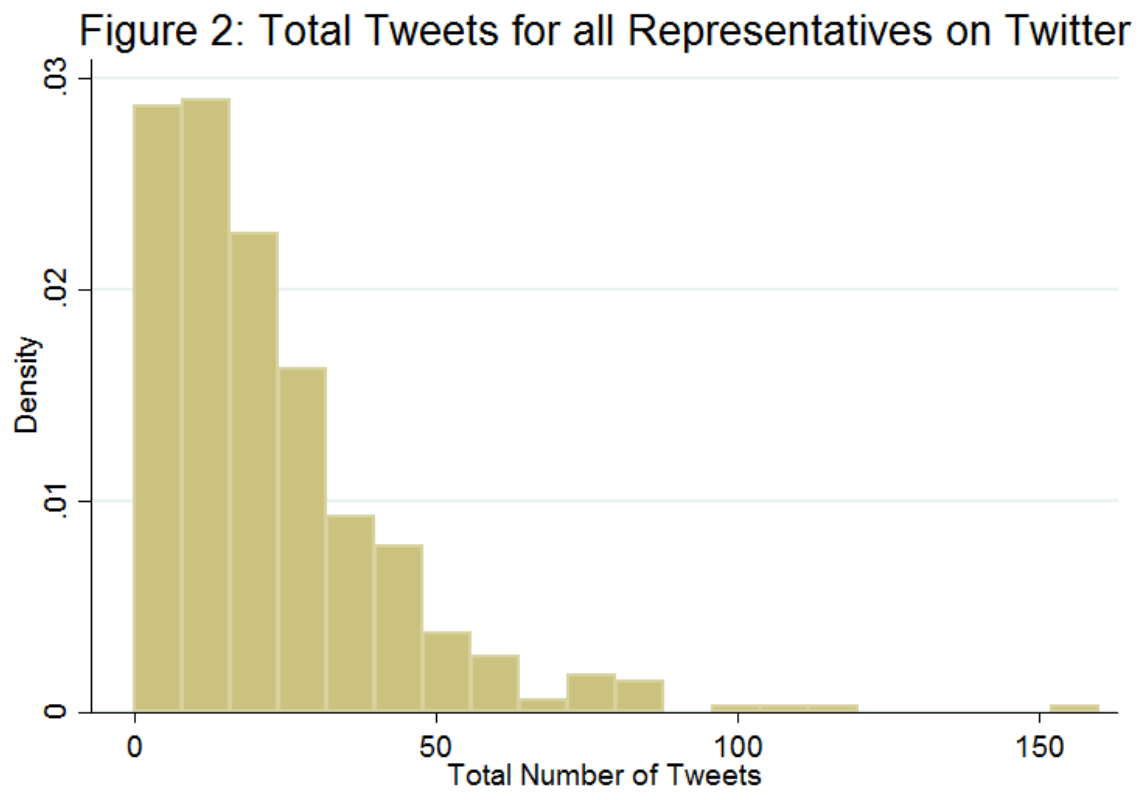

Figure 3 shows the total tweet count by gender. Overall, congresswomen as a group tweet more than men, with the mean for men at 20 tweets with a standard deviation of 19.91 versus women at 26 with a standard deviation of 19.1. A simple difference of means test shows that these differences are statistically significant, which supports literature that congresswomen tweet more than congressmen (Wagner et al. 2017). The bulk of congressmen's tweets fall between $0-25$, while congresswomen tend to tweet between 1040 times. The congresswoman who tweeted the most during this period was Rep. Dina Titus (D, NV-01) at 101 tweets. 
Figure 3: Total Tweets by Gender of Representatives

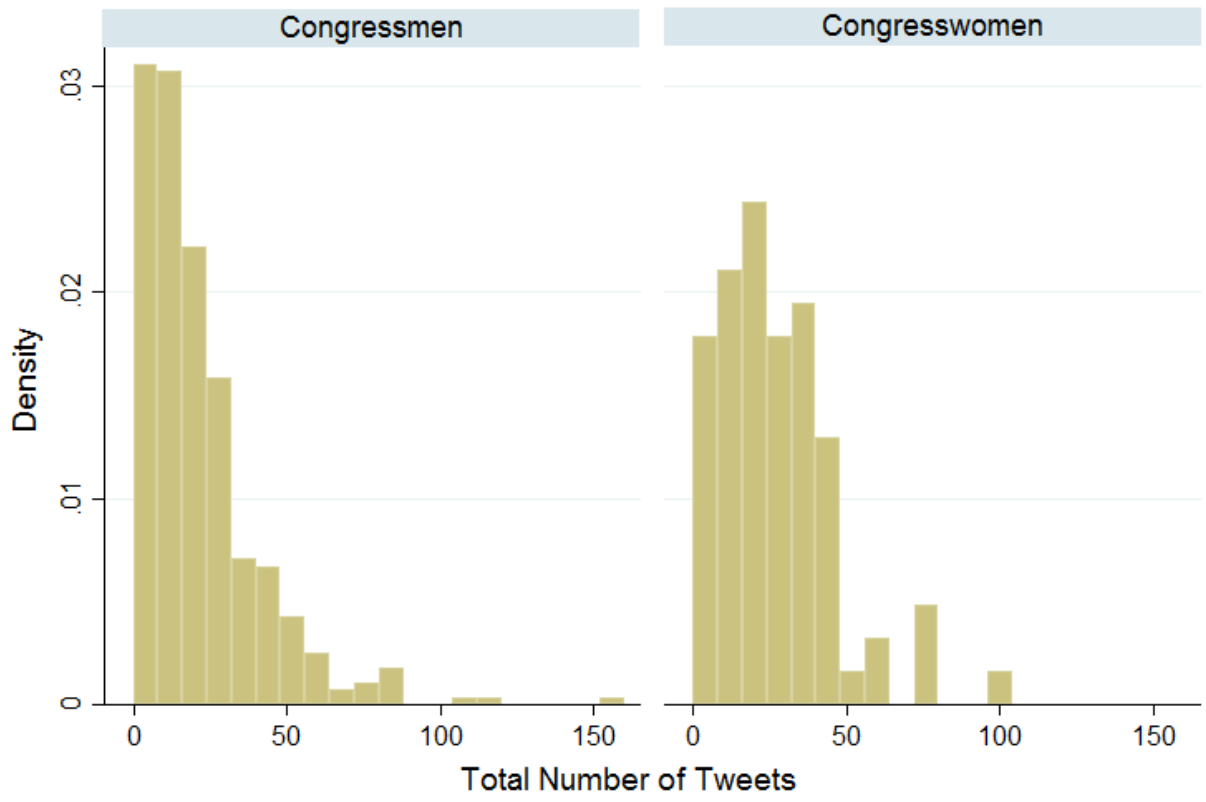

Figure 4 illustrates differences in the distribution of tweet totals by gender and party. Democratic congressmen tweet more often than Republican congressmen, and Democratic congresswomen tweet a little bit more than Republican congresswomen. Over the two weeks under consideration, the average Republican congressman tweeted 19 times with a standard deviation of 16.98, with Rep. Paul Ryan (R, WI-01) tweeting most often at 86 times. The average Democratic congressman sent 24 tweets, with a standard deviation of 24.01. Republican congresswomen on average sent 26.1 tweets with a standard deviation of 18.77; the max at 72 tweets is Rep. Ileana Ros-Lehtinen (R, FL-27). Democratic congresswomen send on average 26.6 tweets with a standard deviation of 19.39. 


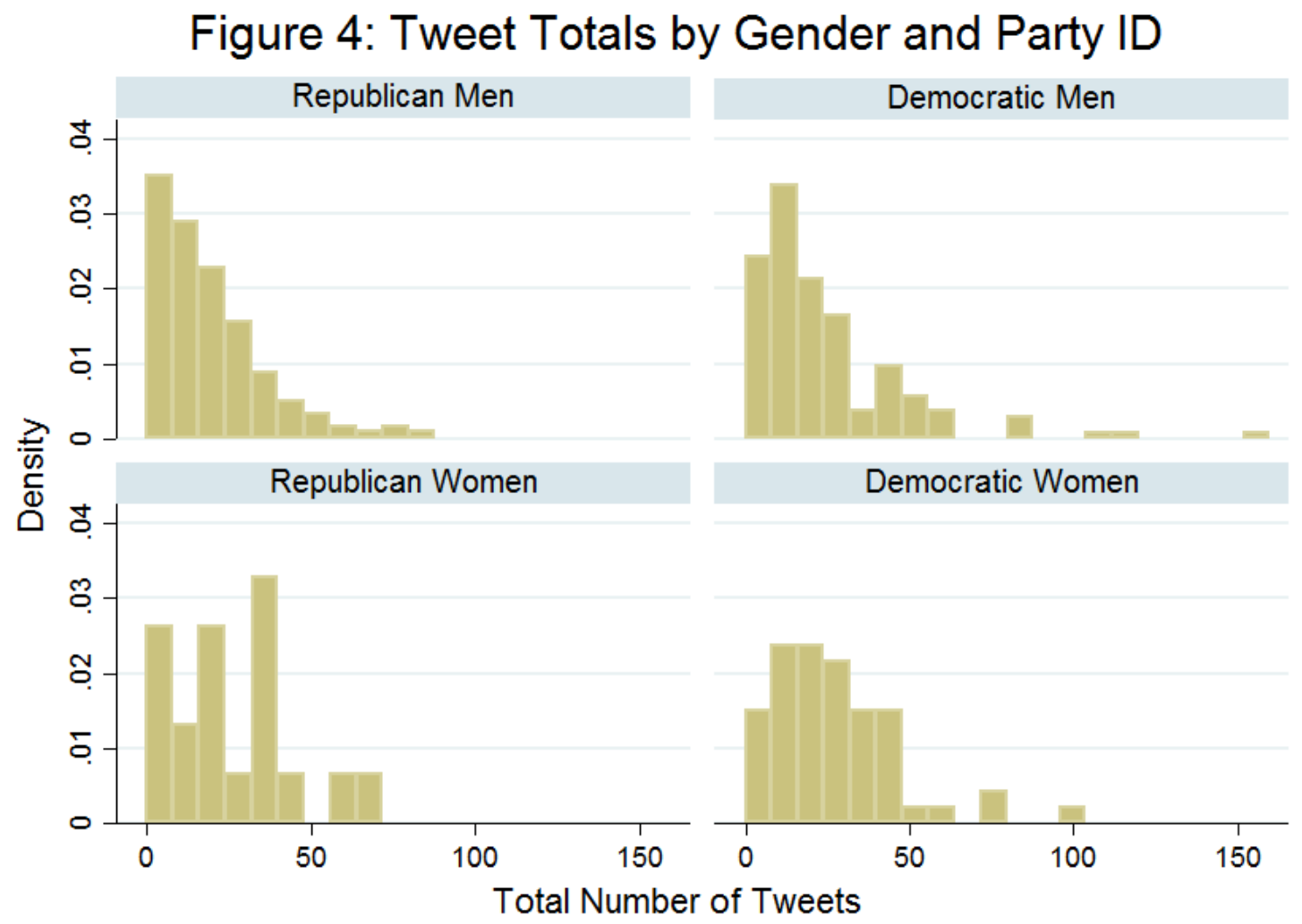

To start visualizing data related to Hypothesis 1, Figure 5 looks at the variance in MC's targeting at the national level by gender and party. Democratic congressmen tweet more than Republican congressmen, and Democratic congresswomen significantly outtweet Republican congresswomen at the national level. In sum, Republican congressmen averaged 5 national-level tweets at a standard deviation of 9.5, with the highest count being Rep. Paul Ryan (R, WI-01) at 84. Democratic congressmen averaged 6 national-level tweets at a standard deviation of 8.98, with Rep. Paul Tonko (D, NY-20) tweeting a max of 65. Republican congresswomen averaged 2 tweets with a standard deviation of 5.03, and the highest count belonged to Rep. Marsha Blackburn (R, TN-07) at 22 tweets. Democratic congresswomen averaged 7 tweets, with a standard deviation of 9.5. Rep. Frederica Wilson (D, FL-24) had the highest count at 31 tweets. 


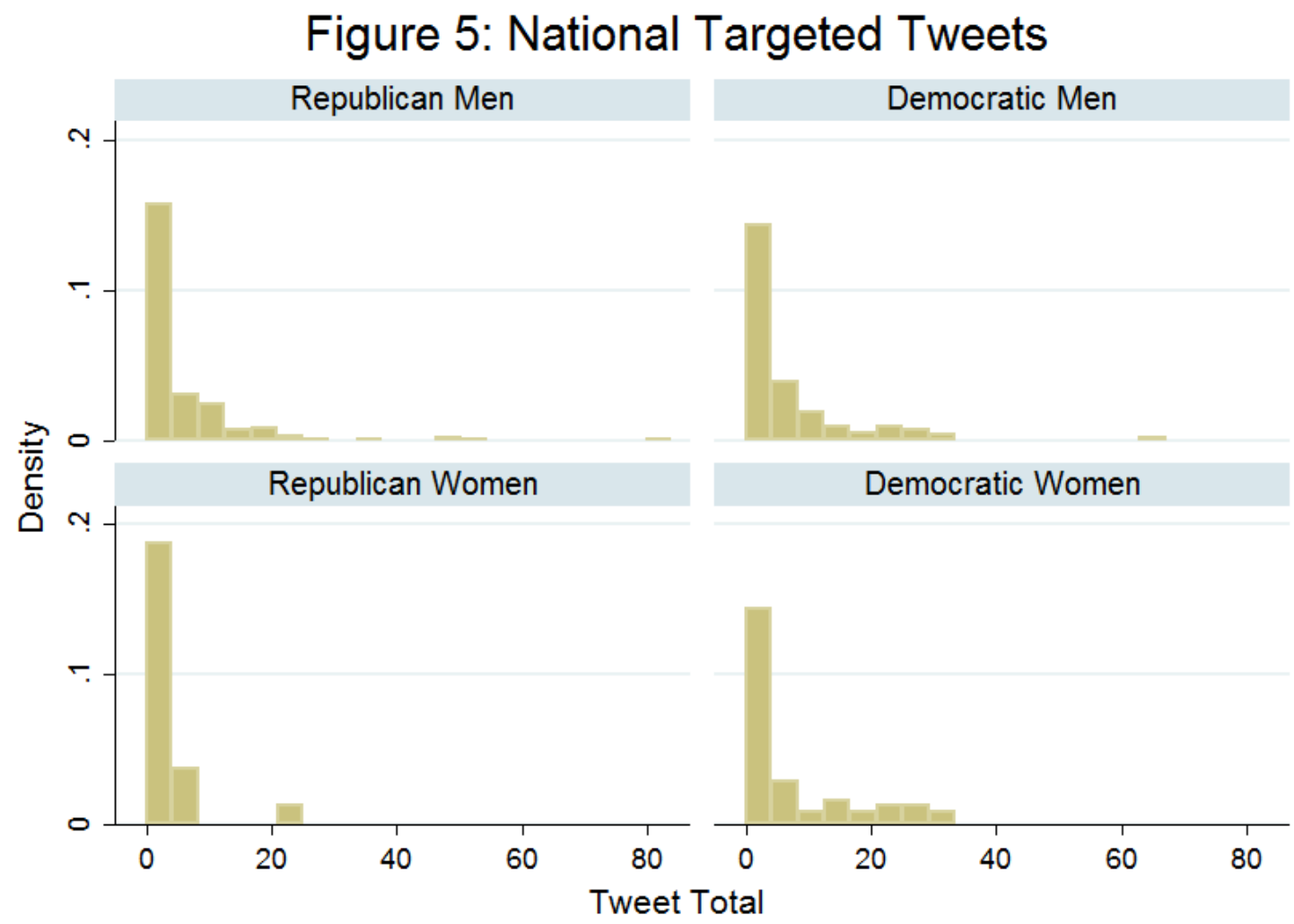

From the simple descriptive patterns in Figures 2 through 5, we start to see some relationships emerge - while congresswomen tweet more than congressmen, there is variance based on party and gender, with Democratic congressmen tweeting more often than Republican congressmen, and Democratic congresswomen more than Republican congresswomen at the national level. This provides some preliminary support for Hypothesis 1, which states that Democratic congresswomen should be significantly more likely to target a national constituency than other groups. Additionally, Hypothesis 2 tests whether their congressmembers' targeted tweets are similar at the district and state level. To analyze both hypotheses while also controlling for other confounding factors, a negative binomial regression was run. Since the dependent variables are a simple count of the 
number of tweets for each $\mathrm{MC}$, a count model is more appropriate than a linear regression model (Long 1997).

\section{Results}

Table 2 presents the results of a negative binomial regression to test whether congresswomen and men's targeting at the district level differs by gender and party. Model 1 does not include a gender and party interaction variable, while Model 2 does. Neither model reveals significant gender or party differences at the district level. This provides some support for Hypothesis 2. It appears that congresswomen and men behave similarly when targeting communications to their districts through Twitter - at least in terms of volume. The only significant predictor of tweeting at the district level is the variable for two-party electoral margin. If an MC's electoral margin is slim, they target the district with more tweets in an effort to connect more to their home constituency. 
TABLE 2

Influence of Gender on the Number of District-Target Tweets

\begin{tabular}{|c|c|c|c|c|}
\hline & $\begin{array}{c}\text { Model } 1 \\
\text { Coef. } \\
\text { (S.E.) }\end{array}$ & & $\begin{array}{c}\text { Model } 2 \\
\text { Coef. } \\
\text { (S.E.) }\end{array}$ & \\
\hline \multicolumn{5}{|l|}{ Main Independent Variables } \\
\hline Congresswoman & $\begin{array}{c}0.085 \\
(0.150)\end{array}$ & & $\begin{array}{c}0.432 \\
(0.272)\end{array}$ & \\
\hline Democrat & $\begin{array}{l}-0.098 \\
(0.372)\end{array}$ & & $\begin{array}{c}0.028 \\
(0.377)\end{array}$ & \\
\hline Congresswoman x Democrat & --- & & $\begin{array}{l}-0.527 \\
(0.326)\end{array}$ & \\
\hline \multicolumn{5}{|l|}{ Controls } \\
\hline Constituency Committee & $\begin{array}{c}0.015 \\
(0.113)\end{array}$ & & $\begin{array}{c}0.022 \\
(0.113)\end{array}$ & \\
\hline DW-Nominate (1st Dimension) & $\begin{array}{c}-0.188 \\
(0.424)\end{array}$ & & $\begin{array}{l}-0.139 \\
(0.421)\end{array}$ & \\
\hline Party Leader & $\begin{array}{l}-0.786 \\
(0.709)\end{array}$ & & $\begin{array}{l}-0.746 \\
(0.707)\end{array}$ & \\
\hline Two-Party Margin & $\begin{array}{c}-0.494 \\
(-0.182)\end{array}$ & $* *$ & $\begin{array}{c}-0.492 \\
(-0.181)\end{array}$ & $* *$ \\
\hline Constant & $\begin{array}{c}2.445 \\
(0.237)\end{array}$ & $* *$ & $\begin{array}{c}2.385 \\
(0.237)\end{array}$ & \\
\hline$N$ & 431 & & 431 & \\
\hline Log-likelihood & -1396.354 & & -1394.99 & \\
\hline Pseudo $\mathrm{R}^{2}$ & 0.003 & & 0.004 & \\
\hline
\end{tabular}

Source: Compiled by Author

Notes: The dependent variable is a count of the number of districttargeted tweets for each member of Congress.

$\dagger \mathrm{p}<.1 ; * \mathrm{p}<.05 ; * * \mathrm{p}<.01$. 
Table 3 analyzes gendered targeting at the national level. Democratic congresswomen are the ones most likely to target at the national level, consistent with Hypothesis 1. Party leadership is also a significant predictor of targeting at the national level - party leaders have the incentive to target the national level given their visibility, responsibilities with regard to messaging, and concerns about building and sustaining majorities. In Model 6, there is weak evidence for MCs with marginal seats target the national level more. Furthermore, membership in a constituency committee is a weak predictor of targeting less at the national level. This follows, as membership on those committees would be for the benefit of the district, and there is less incentive to target this type of information to the national level.

All in all, I find evidence to support only hypothesis 1, not hypothesis 2 . For Hypothesis 1, Figure 4 and Table 4 reveal that Democratic congresswomen are significantly more likely to target a national constituency when compared to other groups. For Hypothesis 2, Table 1 and shows that both congresswomen and congressmen, regardless of partisanship, target their constituencies similarly (in terms of the volume of tweets) at the district and state level. Therefore, we reject the hypothesis. The extra tweeting that Democratic congresswomen do in comparison to Republican congresswomen seems to be directed at the national level, but they behave similarly at the district level. 
TABLE 4

Influence of Gender on the Number of National-Target Tweets

\begin{tabular}{|c|c|c|c|c|}
\hline & $\begin{array}{c}\text { Model } 5 \\
\text { Coef. (S.E.) }\end{array}$ & & $\begin{array}{c}\text { Model } 6 \\
\text { Coef. (S.E.) }\end{array}$ & \\
\hline Congresswoman & $\begin{array}{l}-0.061 \\
(0.224)\end{array}$ & & $\begin{array}{l}-0.783 \\
(0.398)\end{array}$ & $*$ \\
\hline Democrat & $\begin{array}{l}0.598 \\
(.565)\end{array}$ & & $\begin{array}{l}0.587 \\
(.561)\end{array}$ & \\
\hline Congresswoman x Democrat & & & $\begin{array}{c}0.958 \\
(.4761762)\end{array}$ & $*$ \\
\hline Controls & & & & \\
\hline Constituency Committee & $\begin{array}{l}-0.271 \\
(.161)\end{array}$ & $\dagger$ & $\begin{array}{l}-0.300 \\
(.161)\end{array}$ & $\dagger$ \\
\hline DW-Nominate (1st Dimension) & $\begin{array}{l}0.228 \\
(.611)\end{array}$ & & $\begin{array}{l}0.340 \\
(.611)\end{array}$ & \\
\hline Party Leader & $\begin{array}{c}1.86 \\
(.901)\end{array}$ & $*$ & $\begin{array}{r}1.810 \\
(.897)\end{array}$ & $*$ \\
\hline Two-Party Margin & $\begin{array}{l}0.078 \\
(.273)\end{array}$ & & $\begin{array}{l}0.046 \\
(.272)\end{array}$ & $\dagger$ \\
\hline Constant & $\begin{array}{l}1.482 \\
(.355)\end{array}$ & $* *$ & $\begin{array}{l}1.492 \\
(.354)\end{array}$ & $* *$ \\
\hline$N$ & 431 & & 431 & \\
\hline Log-likelihood & -1134.478 & & -1132.643 & \\
\hline Pseudo $R^{\wedge} 2$ & 0.006 & & 0.008 & \\
\hline
\end{tabular}

Source: Compiled by Author

Notes: The dependent variable is a count of the number of national-targeted tweets for each member of Congress.

$\dagger \mathrm{p}<.1 ; * \mathrm{p}<.05 ; * * \mathrm{p}<.01$. 


\section{Discussion and Conclusion}

Ultimately, the results indicate that while congresswomen generally tweet more than congressmen, Democratic congresswomen target a national constituency significantly more than other groups. Why is this the case, when the commitment to representing women was widely shared by congresswomen of "different parties, ideologies, races and ethnicities, tenures in office, and institutional position" (Carroll 2000, 4)? Looking at the content of the tweets, the national level tweets tended to center around topics such as education and healthcare. These issues relate to the "women's issues" agenda, which also coincides with the Democratic platform (Evans 2005). For example, the following tweets were coded at the national level, and were widely retweeted by many Democratic colleagues:

- "As communities across US face heartbreak of opioid addiction every day, the time is now for comprehensive mental health reform \#MHM2016." (Rep. Diana DeGette (D, CO) May 2, 2016 at 6:23:57 PM. Tweet.)

- “@HouseDemocrats' \#WomenSucceed Agenda promotes policies that ensure working parents have access to affordable \& high-quality \#ChildCareNow!" (Rep. Marcy Kaptur (D, OH-9), May 5, 2016, 6:03:43 PM. Tweet.)

Furthermore, there was an effort on the part of Democrats to get out a consolidated message. This included health care, equal pay, the opioid crisis, Zika funding, and issues pertaining to social programs. For example:

- "Unacceptable House recessed w/o \#budget vote, action on \#Zika, opioid epidemic, OR \#FlintWaterCrisis. Time to work together for American ppl" (Rep. Debbie Dingell, (D, M-12), May 2, 2016, 12:35:57 PM. Tweet.)

- RT@HouseDemocrats: It's simple: every American in need should have access to quality, affordable mental health care \#MHM2016" (Rep. Don Beyer (D, VA) May 2, 2016 at 6:27:51 PM. Tweet.)

It is no surprise, then, that Democratic congresswomen were signficiantly more likely to target their constituencies at the national level when compared to other groups. 
Because of their party's electoral pressure (Grossman and Hopkins 2016), Republican congresswomen seem to have put most of their effort into targeting their reelection constituencies. Therefore, the finding of the statistically significant importance of a party and gender interaction in the model coincides with the theoretical expectations presented in this chapter. Figures 2 through 5 find congresswomen tweeting more than their male counterparts, while Table 2 shows that they behave similarly at the district level (Hypothesis 2), with Democrat congresswomen displaying significantly more activity at the national level, which can be best understood through the lens of surrogate representation (Hypothesis 1).

When Fenno (1978) formulated his conception of home style, there were a total of 20 women in the $95^{\text {th }}$ Congress, 18 of which were in the House. Of the Representatives that he shadowed, none were women. Perhaps Fenno would have incorporated broader constituencies outside of the district into his theory of representational style had he observed these congresswomen. Today, since the resource of the internet has reduced political communication costs for MCs as well as the "cost" of researchers to analyze said data, one can analyze the targeted behavior of MCs in a platform that allows for targeting at any level, from district to international. Since this research points to a gendered interaction in the targeting behavior of MCs, one might ask whether female Democratic senators similarly target a national constituency out of a feeling of surrogate representation that their Republican colleagues cannot follow through with.

Since politicians are motivated to shape public perceptions, documenting a gendered difference in the way congresswomen and men use Twitter to influence their constituencies has ramifications beyond American politics. In an age of internet politics 
where tweets have a real-world ramification in public perception of candidates, it is a worthy endeavor to capture how legislators perceive their duties in comparison with how they act on these beliefs, as we saw with the phenomenon of surrogate representation. In future research, a test to see whether ethnic minority groups also feel the pressure of surrogate representation and thus also have this broader constituencies outside their districts to consider would also provide a better understanding of representation. To further the findings of this chapter, further research can take a closer look at the behavior of specific MCs, or simply extend this framework to a larger time frame. On a larger scale, seeing how the different constraints of presidential versus parliamentary systems affects the home style that politicians exhibit online as well as in person would also be a worthy endeavor. Ultimately, the interaction of party in addition to gender creates a more nuanced understanding of congressional political communication than just gender.

\section{References}

Alexander, Deborah and Kristi Anderson. 1993. "Gender as a Factor in the Attributions of Leadership Traits.” Political Research Quarterly. 46: 527-545.

Althaus, S. L. 2003. Collective preferences in democratic politics: Opinion surveys and the will of the people. New York: Cambridge University Press.

Ammah-Tagoe, A. 2009. "Who’s winning the Twitter wars?” Newsweek. September 8.

Anderson, Karin V. 2011. “'Rhymes with Blunt': Pornification and U.S. Political Culture." Rhetoric and Public Affairs. 14(2): 327-368.

Anzia, Sarah and Christopher Berry. 2011. "The Jackie (and Jill) Robinson Effect: Why Do Congresswomen Outperform Congressmen?". American Journal of Political Science. 55(3): 478-493.

Bartels, Larry M. 2003. "Democracy with attitudes.” In M. MacKuen \& G. Rabinowitz (Eds.), Electoral democracy. Ann Arbor: University of Michigan Press, 48-82. 
Bartels, Larry M. 1996. "Uninformed Votes: Information Effects in Presidential Elections." American Journal of Political Science 40(1): 194-230.

Becker, Jeffrey A. 2014. Ambition in America: Political power and the collapse of citizenship. Lexington: University Press of Kentucky.

Blight, Michelle C, Michèle M. Schlehofer; Bettina J. Casad; Amber M. Gaffney. 2011. "Competent Enough, But Would You Vote for Her? Gender Stereotypes and Media Influences on Perceptions of Women Politicians."

Bond, Jon R. 1985. "Dimensions of District Attention over Time." American Journal of Political Science. 29(2): 330-347.

Bratton, Kathleen, and Kerry Haynie. 1999. “Agenda Setting and Legislative Success in State Legislatures: The Effects of Gender and Race.' Journal of Politics 61(3): 658-79.

Brody, M. 1993. Manly Writing: Gender, Rhetoric, and the Rise of Composition. Carbondale and Edwardsville: Southern Illinois Press.

Brooks, Deborah Jordan. 2013. He runs, she runs: Why Gender Stereotypes do not Harm Women Candidates. Princeton: Princeton University Press.

Brown, Nadia E. 2014. "Political Participation of Women of Color: An Intersectional Analysis." Journal of Women, Politics \& Policy. 35:315-348.

Browning, Graeme. 1994. “Don’t Call Me, Call My E-Mail.” National Journal. 26(20): 1146.

Bryce, James. 1893. The American Commonwealth. New York: Macmillan.

Cameron, D. 2006. "Theorising the Female Voice in Public Contexts.” In J. Baxter (ed.), Speaking Out: The Female Voice in Public Contexts. Basingstoke: Palgrave Macmillan, 3-20.

Cameron, D. 2005. "Language, gender and sexuality: Current issues and new directions." Applied Linguistics. 26(4): 482-502.

Campbell, A., Converse, P., Miller, W. E., and Stokes, D. 1960. The American Voter. New York: Wiley.

Charles Stewart III and Jonathan Woon. Congressional Committee Assignments, 103rd to 114th Congresses, 1993--2017: House of Representatives, February 7, 2017.

Carroll, Susan J, and Richard L. Fox. 2014. Gender and Elections: Shaping the Future of American politics. New York: Cambridge University Press. 
Carroll, Susan J. 2000. “Representing Women: Congresswomen's Perceptions of Their Representation." Presentation at "Women Transforming Congress: Gender Analyses of Institutional Life," Carl Albert Congressional Research and Studies Center, University of Oklahoma, April 13-15.

CAWP. 2018. "Women in the U.S. Congress 2018." http://www.cawp.rutgers.edu/womenus-congress-2018

CAWP. 2018. "Women of Color in Elective Office 2018." http://www.cawp.rutgers.edu/women-color-elective-office-2018

Chang, Chingching \& Jacqueline Hitchon. 1997. "Mass Media Impact on Voter Response to Women Candidates: Theoretical Development." Communication Theory. 7(1): 29-52.

Cover, Albert and George Serra. 1992. "The Electoral Consequences of Perquisite Use: The Casework Case.” Legislative Studies Quarterly. 17(2): 233-246.

Dahl, Robert A. 1989. Democracy and Its Critics. New Haven: Yale University Press.

Converse, P.E.. 1964. "The Nature of Belief Systems in Mass Publics." In D. E. Apter (Ed.), Ideology and Discontent (pp. 206-261). New York: Free Press.

Davis, A. 2010. Political Communications and Social Theory. London: Routledge.

Denzau, Arthur, William Riker, and Kenneth Shepsle. 1985. "Farquharson and Fenno: Sophisticated Voting and Home Style." 79(4): 1117-1134.

Dodson, Debra L. 2006. The Impact of Women in Congress. New York: Oxford University Press.

Dolan, Kathleen A. 2013. "Gender Stereotypes, Candidate Evaluations, and Voting for Women Candidates: What Really Matters?" Political Research Quarterly. 1-12.

Dolan, Kathleen A., Sanbonmatsu, K. 2009. "Gender stereotypes and attitudes toward gender balance in government." American Politics Research. 37(3): 409-428.

Dolan, Kathleen A. 2003. Voting for women: How the Public Evaluates Women Candidates. Boulder: Westview Press.

Dolan, Kathleen, and Lynne Ford. 1997. "Change and Continuity among Women State Legislators: Evidence From Three Decades.” Political Research Quarterly 50(1): $137-51$.

Ditonto, Tessa M.; Allison J. Hamilton; David P. Redlawsk. 2014. "Gender Stereotypes, Information Search, and Voting Behavior in Political Campaigns." Political Behavior. 36: 335-358. 
Eagly, Alice H. and Steven J. Karau. 2002. "Role Congruity Theory of Prejudice Toward Female Leaders.” Psychological Review. 109: 573-598.

Edwards, Janis L. 2009. Gender and political communication in America: Rhetoric, Representation, and Display. Lanham: Lexington Books.

Entman, Robert M. 1993. "Framing: Towards Clarification of a Fractured Paradigm." Journal of Communication 43(4): 51-58.

Esterling, Kevin M., David M. J. Lazer, and Michael A. Neblo. 2013. "Connecting to Constituents: The Diffusion of Repersentation Practices among Congressional Websites." Political Research Quarterly. 66(1): 102-114.

Evans, H.K., Cordova, V., \& Sipole, S. 2014. "Twitter style: An analysis of how house candidates used Twitter in their 2012 campaigns." Political Science and Politics, 47(2): 454-462.

Evans, Jocelyn Jones. 2005. Women, Partisanship, and the Congress. New York: Palgrave Macmillan.

Fenno, Richard F. 1978. Home Style: House Members in Their Districts. Boston: Little, Brown and Company.

Fishman, P. 1978. "Interaction: The work women do.” Social Problems. 25: 397-406.

Fox, Richard L. and Jennifer M. Ramos. 2012. iPolitics: Citizens, elections, and governing in the new media era. New york: Cambridge University Press.

Fox, Richard L. and Eric R. A. N. Smith. 1998. "The Role of Candidate Sex in Voter Decision-Making.” Political Psychology. 19: 405-419.

Fleiss, J. L., B. Levin, M. C. Paik, 2003. “Statistical Models for Rates and Proportions.” In Wiley Series in Probability and Statistics, third eds. J. Wiley, Hoboken N.J.

Fridkin, Kim L. and Patrick J. Kenney. 2014. The Changing Face of Representation: The Gender of U.S. Senators and Constituent Communciations. Ann Arbor: University of Michigan Press.

Frisch, Scott A. and Sean Q. Kelly. 2004. "Self-Selection Reconsidered: House Committee Assignment Requests and Constituency Characteristics." Political Research Quarterly. 57(2): 325-336.

Fulton, Sarah A. 2014. "When Gender Matters: Macro-dynamics and Micro-mechanisms." Political Behavior. 36: 605-630.

Fulton, Sarah A. 2012. "Running Backwards and in high heels: The gendered equality gap and incumbent electoral success." Political Research Quality. 65(2): 303-314. 
Gainous, Jason and Kevin M. Wagner. 2014. Tweeting to Power: The Social Media Revolution in American Politics. New York: Oxford University Press.

Gelber, Alexis. 2011. "Digital Divas: Women, Politics and the Social Network." Joan Shorenstein Center on the Press, Politics and Public Policy Discussion Paper Series. Harvard University John F. Kennedy School of Government.

Gershon, Sarah. 2012. "When Race, Gender, and the Media Intersect: Campaign News Coverage of Minority Congresswomen." Journal of Women, Politics and Policy. 33(2): 105-125.

Gertzog, Irwin N. 2004. Women and Power on Capitol Hill: Reconstructing the Congressional Women's Caucus. Boulder: Lynne Rienner Publishers.

Gertzog, Irwin N. 1995. Congressional women: their recruitment, integration, and behavior. Westpor: Praeger.

Golbeck, Jennifer, Justin M. Grimes, Anthony Rogers. 2010. "Twitter use by the U.S. Congress." Journal of the Association for Information Science and Technology. 61(8): 1612-1621.

Goodyear-Grant, Elizabeth. 2013. Gendered news: Media coverage and electoral politics in Canada. Vancouver: UBC Press.

Grose, Christian R., Neil Malhotra, and Robert Parks Van Houweling. 2015. "Explaining Explanations: How Legislators Explain their Policy Positions and How Citizens React." American Journal of Political Science. 59(3): 724-743.

Hall, Richard. 1996. Participation in Congress. New Haven, CT: Yale University Press.

Hawkesworth, Mary. 2003. "Congressional Enactments of Race-Gender: Toward a Theory of Raced-Gendered Institutions." The American Political Science Review. 97(4): 529-550.

Hill, Kim Quaile and Patricia A. Hurley. "Symbolic Speeches in the U. S. Senate and Their Representational Implications." The Journal of Politics. 64(1): 219-231.

Hong, Sounman. 2013. "Who benefits from Twitter? Social media and political competition in the U.S. House of Representatives." Government Information Quarterly. 30: 464-472.

Hong, Sounman and Daniel Nadler. 2012. "Which candidates do the public discuss online in an election campaign?: The use of social media by 2012 presidential candidates and its impact on candidate salience." Government Information Quarterly 29: 455461.

Huddy, Leonie and Nadya Terkildsen. 1993. "The Consequences of Gender Stereotypes 
for Women Candidates at Different Levels and Types of Office." Political Research Quarterly. 46: 503-525.

Huddy, Leonie and Nayda Terkildsen. 1993. "Gender Stereotypes and the Perception of Male and Female Candidates.” American Journal of Political Science. 37: 119-147.

Inglehart, Ronald, and Pippa Norris. 2003. Rising Tide: Gender Equality and Cultural Change Around the World. New York: Cambridge University Press.

Jeffares, Stephen. 2014. Interpreting hashtag politics: Policy ideas in an era of social media. New York: Palgrave Macmillan.

Johannes, John R. 1983. "Explaining Congressional Casework Styles.” American Journal of Political Science, 27(3): 530-547.

Johnson-Cartee, Karen S. \& Gary A. Copeland. 2004. Strategic Political Communication: Rethinking Social Influence, Persuasion, and Propaganda. Rowman \& Littlefield Publishers, Inc. New York.

Kaid, Lynda Lee. 2004. Handbook of political communication research. Mahwah: Lawrence Eribaum Associates.

Kahn, Kim Fridkin, and Patrick J. Kenney. 2002. "The Slant of the News." American Political Science Review 96 (2): 381-94.

Kahn, Kim F. 1992. "Does Being Male Help? An Investigation of the Effects of Candidate Gender and Campaign Coverage on Evaluations of US Senate Candidates." Journal of Politics 54(2): 497-517.

Kam, C. D. 2007. "Implicit attitudes, explicit choices: When subliminal priming predicts candidate preference." Political Behavior. 29: 343-367.

Kaplan, A. M. and Haenlein, M. 2010. "Users of the world, unite! The challenges and opportunities of social media." Business Horizons. 53(1): 59-68.

Karpf, David. 2012. The MoveOn Effect: The unexpected transformation of American political advocacy. New York: Oxford University Press.

Kathlene, L. 1994. "Power and ingluence in state legislative policymaking: the interaction of gender and position in committee hearing debates." American Political Science Review 88(3): 560-76.

Kathlene L., Clarke S.E., Fox B.A. 1991. "Ways Women Politicians are Making a Difference." In Gender and Policymaking Studies of Women in Office, ed. DL Dodson, pp. 31-38. New Brunswick, NJ: Cent. Am. Woman Politics.

Katz, James E., Michael Barris, and Anshul Jain. 2013. The social media president: Barack 
Obama and the politics of digital engagement. New York: Palgrave Macmillan.

Kidd, Quentin. 2011. Civic participation in America. New York: Palgrave Macmillan.

Kies, Raphaël. 2010. Promises and limits of Web-deliberation. New York: Palgrave Macmillan.

Kindler, Donald R., and Thomas R. Palfrey. 1993. "On Behalf of an Experimental Political Science.” In Experimental Foundations of Political Science, ed. Kinder and Palfrey, Experimental Foundations of Political Science, Ann Arbor: University of Michigan Press.

Lakoff, Robin. 1975. “Language and Woman's Place.” Language and Society, 2(1): 45-80.

Lassen, D. S. \& Brown, A. R. 2011. "Twitter: the electoral connection?" Social Science Computer Review. 29(4): 419-436.

Lawrence, Regina G. and Melody Rose. 2009. Hillary Clinton's Run for the White House: Media, Gender Strtegy, and Campaign Politics. Boulder: Lynne Rienner.

Lee, Jayeon. 2013. "'You Know how tough I am?;' Discourse analysis of US Midwestern congresswomen's self-presentation." Discourse \& Communication. 7(3): 1-19.

Lippmann, Walter. 1922. Public Opinion. New York: Macmillan.

Lockhart, Michele and Kathleen Mollick. 2013. Political women: language and leadership. Lanham: Lexington Books.

Long, J.S. 1997. "Regression models for categorical and limited dependent variables." Advanced Quantitative Techniques in the Social Sciences, Vol 7. Sage: Thousand Oaks, CA.

Mayhew, David R. 1974. Congress: The Electoral Connection. Yale University Press.

McGraw, Kathleen M., Richard Timpone, and Gabor Bruck. 1993. "Justifying Controversial Political Decisions: Home Style in the Laboratory." Political Behavior. 15(3): 289-308.

Neuendorf, Kimberly A. 2017. The Content Analysis Guidebook. London: SAGE Publications, Inc.

Norton, Noelle H. 2002. "Transforming Congress from the Inside: Women in Commit- tee." In Women Transforming Congress, ed. Cindy Simon Rosenthal. Norman: University of Oklahoma Press.

Parker, David C.W. and Craig Goodman. 2013. "Our State's Never Had Better Friends: Resource Allocation, Home Styles, and Dual Representation in the Senate." 
Political Research Quarterly. 66(2): 370-384.

Parker, David C. W. and Craig Goodman. 2009. "Making a Good Impression: Resource Allocation, Home Styles, and Washington Work." Legislative Studies Quarterly. 34(4): 493-524.

Parmelee, John H. and Shannon L. Bichard. 2012. Politics and the Twitter revolution: How tweets influence the relationship between political leaders and the public. Lanham: Lexington Books.

Passini, F. T., \& Norman, W. T. 1976. "A universal conception of personality structure." Journal of Personality and Social Psychology. 4:44-49.

Paxton, Pamela 1997. Women in national legislatures: a cross-national analysis. Social Science Research $26: 442-64$.

Paxton, Pamela, and Melanie M. 2007. Women, Politics, and Power: A Global Perspective. Thousand Oaks, CA: Pine Forge.

Paxton, Pamela, Kunovich, Sheri, and Melanie M. Hughes. 2007. "Gender in Politics." Annual Review of Sociology 33: 263-270.

Pearson, Kathryn and Logan Dancey. 2011. "Elevating Women's Voice in Congress: Speech Participation in the House of Representatives." Political Research Quarterly. 64: 910-923.

Rhode, Deborah L. 2014. What Women Want: An Agenda for the Women's Movement. New York: Oxford University Press.

Richardson, Jr., Lilliard E. and Christopher A. Cooper. 2006. "E-mail Communication and the Policy Process in the State Legislature." The Policy Studies Journal. 34(1): 113129.

Richardson Jr., Lilliard E. and Patricia K. Freeman. 1995. "Gender Differences in Constituency Service Among State Legislators." Political Research Quarterly. 48(1): 169-79.

Romero, David W. 2006. "What They Do Does Matter: Incumbent Resource Allocations and the Individual House Vote." Political Behavior. 28(3): 241-258.

Rosenthal, C.S. 1998. When Women Lead: Integrative Leadership in State Legislatures. New York: Oxford Univ. Press.

Ross, Karen and Tobias Bürger. 2014. "Face to face(book): Social media, political campaigning and the unbearable lightness of being there." Political Science. 66(1): 46-62. 
Ruggerio, Alena A. Media Depictions of Brides, Wives, and Mothers. Maryland: Lexington Books.

Sanbonmatsu, Kira. 2004. "Political Knowledge and Gender Stereotypes." American Politics Research. 31(6): 575-594.

Sanbonmatsu, Kira. 2002. "Gender Stereotypes and Vote Choice." American Journal of Political Science. 46(1): 20-34.

Schneider, Monica C. 2014. "The Effects of Gender-Bending on Candidate Evaluations." Journal of Women, Politics \& Policy. 35: 55-77.

Serra, George and David Moon. "Casework, Issue Positions, and Voting in Congressional Elections: A District Analysis.” The Journal of Politics. 56(1): 200-213.

Shockels, Theodore F., Nichola D. Gutgold, and Diana B. Carlin. 2012. Gender and the American presidency: Nine presidential women and the barriers they faced.

Straus, J. R., Glassman, M. E., Shogan, C. J., \& Navarro Smelcer, S. (2013). "Communicating in 140 characters or less: Congressional adoption of Twitter in the 111th Congress." PS: Political Science \& Politics, 46(1), 60-66.

Streb, Matthew J., Barbara Burrell, Brian Frederick, and Michael A. Genovese. 2008. "Social Desirability Effects and Support for a Female American President." Public Opinion Quarterly, 72: 76-89.

Swers, Michele L. 2002. The Difference Women Make: The Policy Impact of Women in Congress. Chicago: The University of Chicago Press.

Tamerius, Karin. 1995. "Sex, Gender and Leadership in the Representation of Women." In Gender Power, Leadership and Governance, eds. Georgia Duerst-Lahti and Rita Mae Kelly. Ann Arbor: University of Michigan Press, 93-112.

Thomas, Sue and Clyde Wilcox. Women and elective office: Past, present, and future. New York: Oxford University Press.

Thomas, Sue. 1994. How Women Legislate. New York: Oxford University Press.

Wittmer, Dana E. and Vanessa Bouché. 2013. "The Limits of Gendered Leadership: Policy Implications of Female Leadership on 'Women's Issues". Politics \& Gender, 9: $245-275$

Wolbrecht, Christina. 2000. The Politics of Women's Rights: Parties, Positions, and Change. Princeton, NJ: Princeton University Press. 
Young, Garry and Valerie Heitschusen. 2003. "Party and the Dynamics of Congressional Committee Composition in the US House, 1947-96." British Journal of Political Science. 33(4): 659-679. 


\section{CHAPTER V: CONCLUSION}

In studying congresswomen both as a group but also as members of increasingly partisan political parties, we emerge with a better picture of how their perceived "surrogate representation" affects their political communication on Twitter. In Chapter 2, liberals are more likely to discuss women's issues. There is no relationship between gender and the propensity to discuss women's issues, and the only effect of party is in the wrong direction (probably due to collinearity between ideology and party). There is no interactive effect of party and gender. When it comes to men's issues, neither ideology, party, gender, or the interaction between party and gender predicts tweeting. In Chapter 3, women are more likely to advertise and position-take, but there is no relationship between gender and credit claiming, and there are no relationships between party and any of the three behaviors, nor does party condition the relationship between gender and any of the three behaviors. In Chapter 4, Democratic women are more likely to tweet on matters with a national focus, while there are no statistically significant differences among Democratic men, Republican men, and Republican women. There are also no effects of party, gender, or the interaction between the two when it comes to district-focused tweets.

In this final chapter, we will explore the contribution of this dissertation to the political communication, gender, as well as congressional literatures.

\section{Political Communication}

The literature on gender's explanatory value on behavior and language has evolved. From characterizing men's language as standard and women's as other and lesser (Lakoff 1975) to a constructivist interpretation (Shotter and Gergen 1994), classifying what exactly 
counts as feminine versus masculine and a value judgment on each has shifted. Rooted in traditional notions of gendered communication, the expectation is that women will use more credit sharing language when taking credit in a work setting (Haynes et al. 2013) stemming from their gender role socialization (Mansbridge 2005), however women running for politics and within male-dominated professions are often pressured to adapt more masculine ways of interacting and speaking (Karpowitz and Mendelberg 2014; Dodson 2006; Bogoch 1997). More recent work finds women MCs counter voter stereotypes and take credit more often than men MCs (Dolan and Kropf 2004). Even though female legislators may choose a more collaborative leadership style (Rosenthal 1998), that does not stop them from giving credit to themselves to boost their electoral chances. From this expectation, I tested in chapter three whether congresswomen would use credit sharing or individualistic language more in claiming credit for legislative activity - an important endeavor for MCs.

While Republican congresswomen did individually credit claim at high rates and shared credit at a very low percent, Democratic congresswomen claimed shared credit almost as much as they took individual credit. Therefore, partisanship impacts credit sharing behavior for congresswomen. Democratic congresswomen felt they could share credit more than Republican congresswomen could, while Republican men also shared credit nearly as much as they took individual credit. Democratic men used even more individualistic language than Republican women, but also used more credit sharing language than Republican women too. This tells us that building an expectation on sharing credit based solely on gender characteristics is not enough; partisanship must also be a factor. 
According to Mayhew's (1974) classic work on the subject, the reelection impulse leads all members to advertise, credit claim, and position take. The literature on women in politics however finds that women political candidates tweet more often, attack their opponents more often, engage in different types of tweeting than their male counterparts, as well as differ in tweets before and after the election (Evans, Ovalle and Green 2015; Evans, Cordova and Sipole 2014). Congresswomen and men also focus on different themes while campaigning and once they get into office (Fox 1997; Kahn 1996; Dodson 1995; Thomas 1994). This stems to politics traditionally being viewed as a masculine venture (Meeks 2012; Burns, Schlozman \& Verba 2001; Delli-Carpini \& Keeter 1996), and thus female candidates face additional pressures in their pursuit to office - they must possess stereotypical masculine traits, but not straying too far from stereotypes of female traits (e.g. toughness, competence, and confidence versus empathy, compassion, and modesty); therefore, congresswomen stress their qualifications and competence at higher levels than their male challengers in an attempt to fight and counteract these gender stereotypes (Lee 2013; Fox 1997; Burrell 1992). Since congresswomen feel electoral insecurity combined with extant gender stereotypes, they are more likely to signal their electoral activities (Cormack 2016; Dolan and Kropf 2004).

Constituents indicate greater support when MCs are able to allocate money and projects for their district (Lazarus and Reiley 2010; Shepsle et al. 2009; Levitt and Snyder 1997; Bickers and Stein 1996). Evans and Hayden (2018) find MCs in challenging districts have made their congressional websites more accessible to constituent requests (regarding minor personal issues up to legislation requests) to be able to credit claim. Congresswomen, especially Republican congresswomen, tend to be elected in marginal districts and thus the 
expectation is that they would cater to their district so that they are perceived to be effective, and thus worthy to stay in office. The literature does show some confirmation for this congresswomen interact with district constituents more (Richardson and Freeman 1995), get more contact from constituents, are more likely to use constituent-derived information in making decisions, and attend more constituent meetings (Herrick 2012, 961). Lawless (2012) found lower levels of position taking for women, as well as lower levels of position taking for Republicans than Democrats, so the formal expectation was that Democratic congresswomen will position take at higher rates than men since they will be addressing women's issues and "masculine issues", with Republican congresswomen feeling the weight of their position taking and therefore cautiously tweeting at lower levels than Democratic women for this category of Mayhewian behavior.

Therefore, I wanted to test whether congresswomen had different rates of Mayhewian advertising position taking, and credit claiming behaviors compared to congressmen. The findings in chapter three show that congresswomen, in particular Republican congresswomen, do advertise more. Republican congresswomen in particular are very cautious - they have the highest rates of advertising behaviors, engage in less position taking behaviors, and instead rely on district visits and non-partisan events that showcase their helpfulness or cultivate their physical appearance in the district. Ultimately however, the models did not show a relationship between gender and credit claiming, and there are no relationships between party and any of the three behaviors, nor does party condition the relationship between gender and any of the three behaviors.

While claiming credit happens in fairly similar percentages across party and gender, the figures for retweets by congresswomen, both Republican and Democrat, were not as 
high as their male counterparts. Since the bulk of these credit claiming retweets were from special interest groups or party leadership touting their achievements, one explanation could be that these groups simply do not give congresswomen the credit they are due. Another could be that congresswomen choose not to sift through these mentions and retweets and instead prefer to craft their own messages.

\section{Gender}

The argument for a greater physical presence of women in Congress has been due to the perception that it will increase substantive representation (Swers 2002; Pitkin 1967). Scholars find that female representatives "are more likely to care about, sponsor, and/or vote for 'women's issue' bills" (e.g. Swers 2005; Frederick 2011; Thomas and Welch 2001). Initial work found congresswomen would discuss "women's issues" more than congressmen (Fridkin and Woodall 2005; Dolan and Kropf 2004; Gulati 2004; Witt et al. 1994), or that congresswomen spent more time addressing women's issues while congressmen spent more time addressing men's issues (Fox 1997; Kahn 1993). Looking at social media communication, we see congresswomen tweeting more about women's issues than congressmen, but not in lieu of "male issues" (Evans 2016; Evans and Clark 2015; Gershon 2008).

While there has been a documented decrease in negative social attitudes regarding women in office and the masculine versus feminine stereotypes playing out in regards to the perception of women candidates (Dolan 2004), public opinion surveys find that women are still perceived as better suited to address education and health care while men seen as competent on defense and foreign affairs - termed as "issue competency" or a "domain 
stereotype" (Falk and Kenski 2006; Lawless 2004; Herrnson and Stokes 2003; Sanbonmatsu 2002; Kahn 1996; Huddy and Terkildsen 1993). Therefore, engaging in "women's issues" can be a tricky endeavor for congresswomen. Meeks (2016) finds Democratic women propose a wider array of masculine and feminine issues, while her earlier work (2015) found that Republicans tended to focus on Republican-owned issues with Democrats doing the same, though analyzing the tweets of Democrats and Republicans who lost tended to stress owned content compared to unowned content, with winning Democrats seen as more likely to trespass. This could be due to the perception of Republican-owned traits - tied to issues of national security - being more important to address (Hayes 2011).

As the field increasingly moves towards using both gender and party to analyze differences between congresswomen and men, we start to see that differences start to be more a factor of party than of gender (Bystrom 2006; Dolan 2005; Niven and Zilber 2001; Williams 1998). As I found in chapter two, the NBRM model shows liberals are more likely to discuss women's issues; there is no relationship between gender and the propensity to discuss women's issues, and the only effect of party is in the wrong direction (probably due to collinearity between ideology and party). There is no interactive effect of party and gender. When it comes to men's issues, neither ideology, party, gender, or the interaction between party and gender predicts tweeting behavior. Looking at just the percentage counts however, there is a small amount of evidence that both Republicans and Democrats emphasize their partisan ties when it comes to issues that coincide with what constituencies deem feminine or masculine issues, but Democratic congresswomen and Republican congressmen do address women's and men's issues areas more, respectively. 
Furthermore, while Republican congresswomen tweet a little more than their male counterparts about "women's issues" (again, not at statistically significant levels within the NBRM model), they mainly do so to emphasize their partisan loyalty (as found in Dabelko and Herrnson 1997). Republicans prize ideological purity (Grossman and Hopkins 2016), and since "women's issues" tend to fall under Democratic purview due to perceptions of issue ownership (Evans 2005, Wolbrecht 2000), they have to be careful about addressing women's issues. Therefore, Republican congresswomen tied these Democrat-owned issue areas to Republican strengths, such as veterans, or emphasized their partisan ties on the subject, such as being against planned parenthood. Democratic congresswomen tied women's issues to the larger Democratic agenda. For men's issues, while the percentage count of tweets indicated Republican congressmen tweeted the most about them, the findings were not found to be statistically significant in the model. Congressmen and women alike needed to engage in these issues, but Republican congressmen tended to tie it to their achievements.

\section{Congress}

In studying Congress, we use Mayhew (1974) and Fenno (1978) to complete a picture of a rational, electoral-minded Congress. As the online realm takes on greater political significance, scholars have studied how MCs engage on the platform to speak to their constituents. While congresswomen and men are similar in their general campaigning style, women tweet more often (Bystrom and Kaid 2002). This may be tied to perceived electoral insecurity, as members in unsafe or challenged districts tend to tweet more often (Haber 2011; Amman 2010). This, in conjunction with congresswomen's own perceived 
electoral gendered vulnerability (Lazarus and Steigerwalt 2018) means women MCs will likely devote more of their time than their male colleagues to courting and winning their constituents' favor, since they feel the pressure of persistent gender bias throughout society. Therefore, the results in chapter three show congresswomen, (with the percent tweet count indicating Republican women having the highest amount, though it was not significant in the NBRM model) use advertising tweets more than their male counterparts, in an effort to reach their constituencies. Congresswomen are also more likely to position-take, but there is no relationship between gender and credit claiming. Furthermore, party does not condition the relationship between gender and any of the three behaviors.

Applying Carroll's (2001) findings that congresswomen feel a special obligation to the interests of women and see themselves as "surrogate representatives" beyond the geographic boundaries of their districts to the basic logic of Home Style (Fenno 1978), may indicate that many congresswomen may have a fundamentally different representational style when compared to congressmen. In chapter four, I provide some evidence that Democratic congresswomen are more likely to target their tweets at the national level, while gender and party do not seem to influence the number of tweets targeted at the district level. Therefore, reelection minded home style tweets beyond the district are a product of gendered partisanship - an interesting update to Fenno's classic work.

These findings impact our understanding of congressional behavior - it provides a partisan and gendered dimension to how much MCs engage in these re-election minded behaviors. Congressional scholars should be aware of the considerations and insecurity that congresswomen have in regard to their electoral behavior, and how it influences their political communication. 


\section{Future directions}

While this was an exciting start to an analysis of gender and partisanship on Twitter, future work will involve a broader timeframe to be able to distinguish electoral factors as they impact how and what MCs tweet about. The limitations on resources meant I could not undertake a longer timeframe without having to drop House members, and utilizing computer assisted coding would miss the nuance of the various targeting behaviors MCs engage in. Also, considering a time frame directly around an $\mathrm{MC}$ 's election and comparing it to an average week would allow for a clearer picture regarding which types of tweets MCs deem worthy of emphasizing right before election day, compared to a regular period. How would additional electoral vulnerability play out for congresswomen? Would it lead to further emphasizing advertising behaviors, or would we see a stress on position taking

or credit claiming? Would the emphasis on the district continue? Which issue areas would they emphasize? There are many directions to take this research project.

In addition, these different angles of study MCs could be analyzed in the Senate as well. The men and women of the Senate also must contend with electoral forces, but these do not play as constant a role as it does for the MCs in the House, since MCs in the House must go up for election every two years. It would be interesting to note how Mayhewian tweeting behavior is affected for senators, and whether types of credit-claiming behaviors would vary by chamber as well as gender and partisanship. Since there is evidence that Democratic congresswomen and Republican congressmen go above and beyond to address feminine and masculine issue areas respectively, noting how senators tweet about various issue areas would draw attention to which of these they think are important to address for their constituencies. 


\section{References}

Amman, Sky L. 2010. “A Political Campaign Message in 140 Characters or Less: The Use of Twitter by U.S. Senate Candidates in 2010. Available at SSRN: http://ssrn.com/abstract=1725477.

Bogoch, B. 1997. "Gendered lawyering: difference and dominance in lawyer-client interaction." Law and Society Review. 31(4): 677-712.

Bickers, Kenneth N., and Robert M. Stein. 1996. "The Electoral Dynamics of the Federal Pork Barrel.” American Journal of Political Science 40 (4): 1300-26.

Burns, N., K. L. Schlozman and Sidney Verba. 2001. The private roots of public action. Cambridge, MA: Harvard University Press.

Bystrom, Dianne G. 2006. "Advertising, Web Sites, and Media Coverage: Gender and Communication along the Campaign Trail." In Gender and Elections, eds. Carroll, Susan J. and Fox, Richard L. New York: Cambridge University Press, 239-62.

Bystrom, Dianne, and L. L. Kaid. 2002. “Are Women Candidates Transforming Campaign Communication? A Comparison of Advertising Videostyles in the 1990s.” In Women Transforming Congress, ed. C. S. Rosenthal. Norman: University of Oklahoma Press,

Carroll, Susan J. 2000. "Representing Women: Congresswomen's Perceptions of Their Representation." Presentation at "Women Transforming Congress: Gender Analyses of Institutional Life," Carl Albert Congressional Research and Studies Center, University of Oklahoma, April 13-15.

Dabelko, Kirsten la Cour and Paul S. Herrnson. 1997. “Women's and Men's Campaigns for the U.S. House of Representatives, ” Political Research Quarterly 50: 121135.

Delli-Carpini, M.X. and S. Keeter. 1996. What Americans know about politics and why it matters. New Haven, CT: Yale University Press.

Dodson, Debra. 2006. The Impact of Women in Congress. New York: Oxford University Press.

Dodson, Debra L. 1995. Voices, views, votes: the impact of women in the 103rd Congress. New Brunswick, N.J.: Eagleton Institute of Politics, Rutgers, the State University of New Jersey.

Dolan, Kathleen. 2005. "Do Women Candidates Play to Gender Stereotypes? Do Men Candidates Play to Women? Candidate Sex and Issues Priorities on Campaign Websites." Political Research Quarterly, 58(1): 31-44. 
Dolan, Katherine and J.S. Kropf. 2004. "Credit claiming from the U.S. House: gendered communication styles?” The Internatinoal Journal of Press/Politics. 9(1): 41-59.

Evans, Jocelyn and Jessica M. Hayden. 2018. Congressional Communication in the Digital Age. Routledge.

Evans, Heather K., Joycelyn O’Valle and Stephen Green. 2015. 'Rockin' robins: Do Congresswomen rule the roost in the Twittersphere?" Journal of the Association for Information Sience and Technology. 67)2: 268-275.

Evans, Heather K., Victoria Cordova, and Savannah Sipole. 2014. "Twitter Style: An Analysis of How House Candidates Used Twitter in Their 2012 Campaigns." Political Science and Politics 47(2): 454-461.

Evans, Jocelyn, J. 2005. Women, Partisanship, and the Congress. New York: Palgrave MacMillan.

Falk, Erika and Kate Kenski. 2006. "Issue Saliency and Gender Stereotypes: Support for Women as Presidents in Times of War and Terrorism," Social Science Quarterly. 87(1): 1-18.

Fenno, Richard F. 1978. Home Style: House Members in Their Districts. Boston: Little, Brown and Company.

Fox, Richard. 1997. Gender Dynamics in Congressional Elections. Thousand Oaks: Sage.

Frederick, Brian. 2011. "Gender Turnover and Roll Call Voting in the US Senate." Jounnal of Women, Politics, \& Policy 32 (3): 193-210.

Fridkin, K. and G. Woodall. 2005. "Different portraits, different leaders? Gender differences in US Senators' presentation of self", in Thomas, S. and Wilcox, C. (Eds) Women and Elective Office: Past, Present, and Future, $2^{\text {nd }}$ ed., Oxford University Press, New York, NY pp. 126-144.

Gershon, Sarah Allen. 2008. "Communicating Female and Minority Interests Online: A Study of Web Site Issue Discussion among Female, Latino, and African American Members of Congress." Press/Politics. 13(2): 120-140.

Grossman, Matt and David Hopkins. 2016. Asymmetric Politics: Ideological Republicans and Group Interest Democrats. New York: Oxford University Press

Gulati, G. 2004. "Members of Congress and presentation of self on the World Wide Web." International Journal of Press/Politics. 9(1): 22-40.

Haber, Steven. 2011. "The 2010 U.S. Senate Elections in 140 Characters or Less: An Analysis of How Candidates Use Twitter as a Campaign Tool." Available at: 
http://aladinrc.wrlc.org/bitstream/handle/1961/10028/Haber,\%20Steven\%20-\%20 Spring $\% 20 \% 2711$.pdf? sequence $=1$.

Hayes, Danny. 2011. "When Gender and Party Collide: Stereotyping in Candidate Trait Attribution." Politics \& Gender 7(2): 133-165.

Haynes, Michelle C., and Madeline E. Heilman. 2013. "It Had to Be You (Not Me!) Women's Attributional Rationalization of Their Contribution to Successful Joint Work Outcomes." Personality and Social Psychology Bulletin. 39(7): 959-969.

Herrick, Rebekah. 2012. "Listening and Representation." State Politics and Policy (13)1: 88-106.

Herrnson, P., Lay, J., Stokes, A. 2003. Women running "as women": Candidate gender, campaign issues, and voter-targeting strategies. The Journal of Politics, 65, 244255.

Huddy, Leonie and Nayda Terkildsen. 1993. "Gender Stereotypes and the Perception of Male and Female Candidates.” American Journal of Political Science 37: 119-47.

Karpowitz, C. K. and T. Mendelberg. 2014. The Silent Sex: Gender, Deliberation, and Institutions. London: Princeton University Press.

Kahn, Kim Fridkin. 1996. The Political Consequences of Being a Woman: How Stereotypes Influence the Conduct and Consequences of Political Campaigns. New York: Columbia University Press.

Kahn, Kim Fridkin. 1993. "Gender differences in campaign messages: the political advertisements of men and women candidates for U.S. Senate." Political Research Quarterly. 46(3): 481-502.

Lakoff, Robin. 1975. “Language and Woman's Place.” Language and Society, 2(1): 45-80.

Lawless, Jennifer L. 2012. "Twitter and Facebook: New Ways to Send the Same Old Message?” In Richard L. Fox and Jennifer Ramos (eds.) iPolitics, New York: Cambridge University Press: pages 206-32.

Lawless, Jennifer L. 2004. "Women, War, and Winning Elections: Gender Stereotyping in the Post-September 11th Era." Political Research Quarterly 57(3):479-490.

Lazarus, Jeffrey and Amy Steigerwalt. 2018. "Gendered Vulnerability: How Women Work Harder to Stay in Office.” Ann Arbor: University of Michigan Press.

Lazarus, Jeffrey, and Shauna Reiley. 2010. "The Electoral Benefits of Distributive Spending." Political Research Quarterly 63 (2): 343-55. 
Levitt, Steven D., and James M. Snyder. 1997. "The Impact of Federal Spending on House Election Outcomes.” The Journal of Political Economy 105 (1): 30-53.

Mansbridge, Jane, and Katherine Flaster. 2005. "'Male Chauvinist,' 'Feminist,' 'Sexist,' and 'Sexual Harassment': Different Trajectories in Feminist Linguistic Innovation.” American Speech 80: 256-279.

Mayhew, David R. 1974. Congress: The Electoral Connection. Yale University Press.

Meeks, Lindsey. 2016. "Examining Partisan Men and Women's Issue Emphases from Campaigns to Legislation." In Why Congress Needs Women: Bringing Sanity to the House and Senate. By Michele A. Paludi. Praeger:

Meeks, Lindsey. 2016. “Aligning and trespassing: Candidates' Party-based issue and Trait ownership on Twitter." Journalism \& Mass Communication Quarterly. 93(4): 1050-1072.

Meeks, Lindsey. 2012. “Is she 'man enough'? Women candidates, executive political offices, and news coverage." Journal of Communication 62(1): 175-193.

Niven, David, and Jeremy Zilber. 2001a. "Do Women and Men in Congress Cultivate Different Images? Evidence from Congressional Web Sites." Political Communication 18: 395-405.

Pitkin, Hanna Fenichel. 1967. The Concept of Representation. Berkeley: University of California Press.

Richardson Jr., Lilliard E. and Patricia K. Freeman. 1995. "Gender Differences in Constituency Service Among State Legislators.” Political Research Quarterly. 48(1): 169-79.

Rosenthal, Cindy Simon. 1998. When Women Lead: Integrative Leadership in State Legislatures. New York: Oxford University Press.

Sanbonmatsu, Kira. 2002. "Gender Stereotypes and Vote Choice." American Journal of Political Science. 46(1): 20-34.

Shepsle, Kenneth A., et al. 2009. "The Senate Electoral Cycle and Bicameral Appropriations Politics.” American Journal of Political Science 53 (2): 343-59.

Shotter and Gergen. 1994. "Social construction: Knowledge, self, others, and continuing the conversation." Annals of the International Communication Association. 17(1): 3-33.

Swers, Michele L. 2005. "Connecting Descriptive and Substantive Representation: An Analysis of Cosponsorship Activity.” Legislative Studies Quarterly 30 (3): 407-33. 
Swers, Michele L. 2002. The Difference Women Make: The Policy Impact of Women in Congress. Chicago: The University of Chicago Press.

Thomas, Sue, and Susan Welch. 2001. "The Impact of Women in States Legislatures: Numerical and Organizational Strength." In The Impact of Women in Public Office, ed. Susan Carroll. Bloomington: Indiana University Press.

Thomas, Sue. 1994. How Women Legislate. New York: Oxford University Press.

Witt, Linda, Glenna Matthews, and Karen M. Paget. 1994. "Running as a Woman: Gender and Power in American Politics." The Free Press: New York.

Williams, Leonard. 1998. "Gender, Political Advertising, and the "Air Wars." In Sue Thomas and Clyde Wilcox, eds., Women and Elective Office: Past, Present, and Future. New York: Oxford.

Wolbrecht, Christina. 2000. The Politics of Women's Rights. Princeton, NJ: Princeton University. 
VITA

MARIA I. GABRYSZEWSKA

2010
A.S., Liberal Studies
Union County College
Cranford, New Jersey

2012

B.S., Political Science

Kean University

Union, New Jersey

2015

M.A., Political Science

Florida International University Miami, Florida

2012-2018

Doctoral Candidate

Florida International University

Miami, Florida

2018

Assistant Professor

Lone Star College

Houston, Texas 